João Guilherme Muniz Alvarez

\title{
Desenvolvimento de uma ferramenta computacional para dimensionamento de vigas em concreto protendido.
}

Trabalho apresentado como requisito parcial à conclusão do curso de Engenharia Civil na Pontifícia Universidade Católica do Rio de Janeiro, Rio de Janeiro, Brasil.

Orientador: Glauco José de Oliveira Rodrigues.

Rio de Janeiro 


\title{
Resumo
}

\author{
ALVAREZ, João Guilherme. Desenvolvimento de uma ferramenta computacional \\ para dimensionamento de vigas em concreto protendido. 2021. 89f. Projeto de \\ Graduação (Graduação em Engenharia Civil) - Faculdade de Engenharia, Pontifícia \\ Universidade Católica do Rio de Janeiro, Rio de Janeiro, 2021.
}

Concreto protendido é uma técnica construtiva que progrediu fortemente ao longo do século XX e XXI e, portanto, o desenvolvimento de técnicas computacionais para a sua verificação é de extrema relevância. O concreto protendido é um material de muito importante na atualidade permitindo a superação de grandes vão e um maior controle da fissuração do elemento estrutural. Apesar de sua relevância, existe um déficit em questão de softwares de fácil acesso sendo seu cálculo executado utilizando planilhas feitas por engenheiros e empresas para seu próprio uso ou por programas que apresentam um elevado custo monetário por trás de sua obtenção. Assim, neste projeto de graduação em engenharia civil, procurará ser elaborada uma ferramenta computacional com o objetivo de realizar o dimensionamento de elementos estruturais em concreto protendido. O projeto atual será focado no dimensionamento de vigas biapoiadas isostáticas.

Palavras-chave: Concreto protendido; Cálculo automatizado; Dimensionamento de vigas. 


\section{Abstract}

Prestressed concrete is a constructive technique that has been strongly growing throughout the 20th and $21 \mathrm{st}$ centuries and, therefore, the development of computational techniques for its verification is extremely relevant. Prestressed concrete is a very important material, allowing the overcoming of large spans and greater control of cracking in the structural element. Despite its relevance, there is a deficit in the matter of easily accessible software, with its calculation being performed using spreadsheets made by engineers and companies for their own use or by programs with a high monetary cost access. Thus, in this civil engineering graduation project, a computational tool will be designed with the aim of performing the design of structural elements in prestressed concrete. The current project will be focused on the dimensioning of isostatic bi-supported beams.

Keywords: Prestressed concrete; Structural calculation; Beam calculation. 


\section{SUMÁRIO}

\section{INTRODUÇÃO} 1

1.1 Objetivo. .2

2 FUNDAMENTAÇÃO TEÓRICA .3

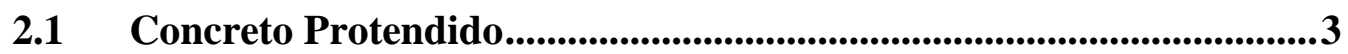

2.1.1 Vantagens e desvantagens ....................................................

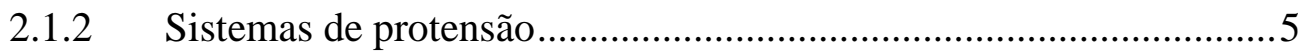

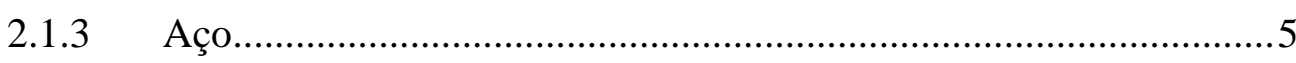

2.2 Dados das seções da viga ..............................................................................6

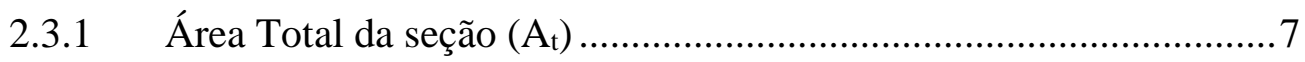

2.3.2 Altura do centroide da seção $(\mathrm{y})$.............................................. 8

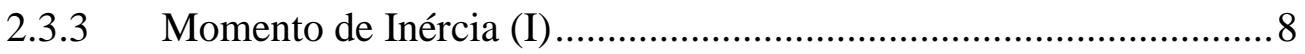

2.3.4 Módulo resistente elástico (W) ................................................

2.3 Ações atuantes ................................................................................... 10

2.4.1 Carga de Peso Próprio ................................................................... 10

2.4.2 Carga variável Móvel ................................................................ 11

2.4 Diagramas .................................................................................... 13

2.5.1 Peso Próprio, Permanente e Acidental ......................................... 13

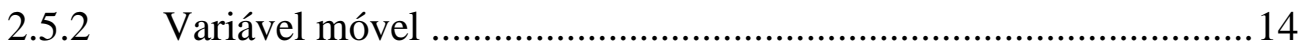

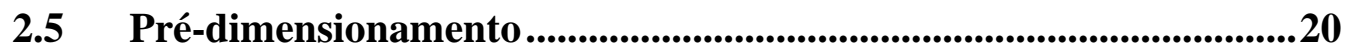

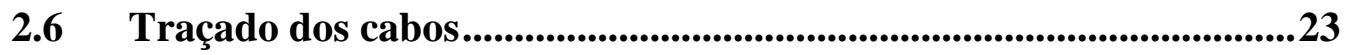

2.7 Força na armadura de protensão ............................................................26

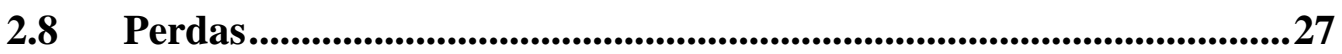


2.8.1 Perdas por atrito ................................................................. 28

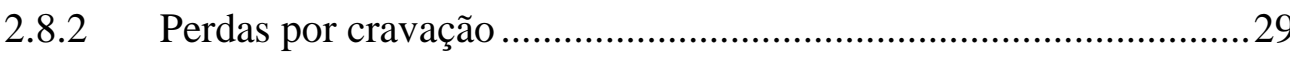

2.8.3 Perdas por deformação imediata.................................................... 31

2.8.4 Perdas por deformação lenta.......................................................... 32

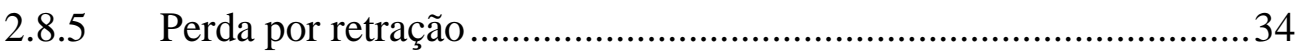

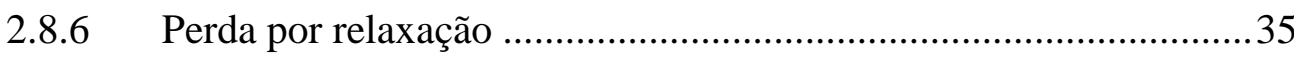

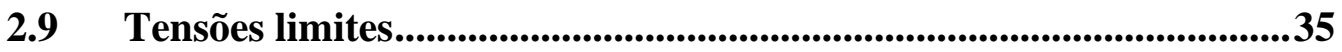

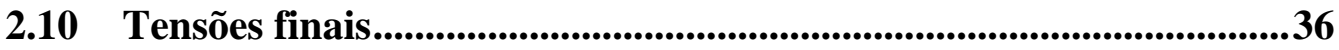

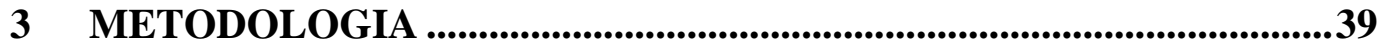

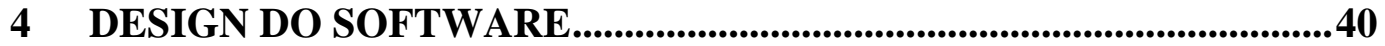

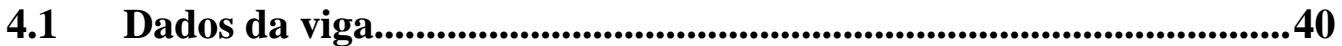

4.2 Pré-Dimensionamento ….....................................................................41

4.3 Diagramas ............................................................................................................442

4.4 Traçado dos cabos.............................................................................................43

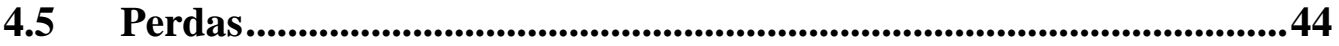

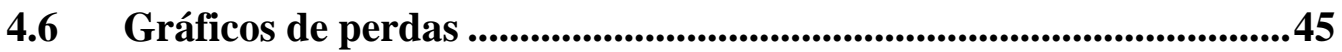

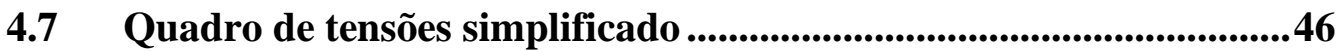

4.8 Quadro de tensões completo ...........................................................................47

4.9 Editar parâmetros.....................................................................................48

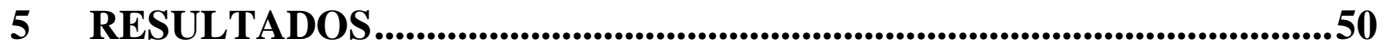

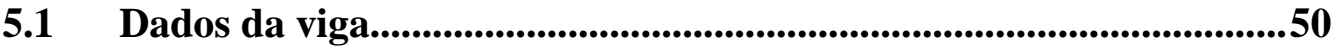

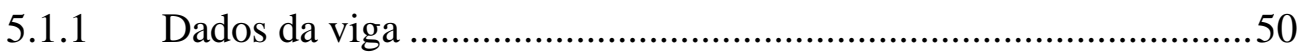

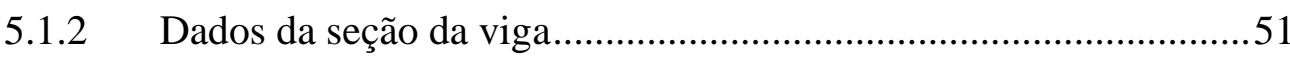


5.2 Tensões máximas .52

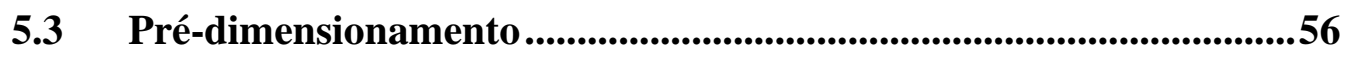

5.4 Traçado dos cabos.........................................................................5

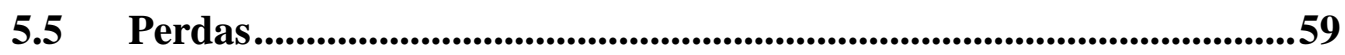

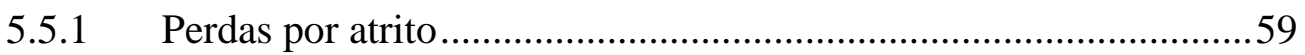

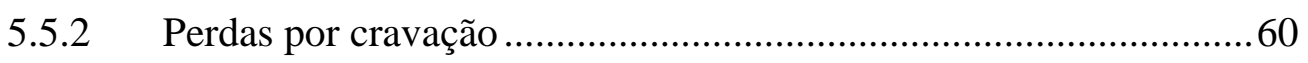

5.5.3 Perdas por deformação imediata................................................. 61

5.5.4 Perdas por deformação lenta.....................................................62

5.5.5 Perdas por retração do concreto...................................................63

5.5.6 Perdas por relaxação do aço .......................................................64

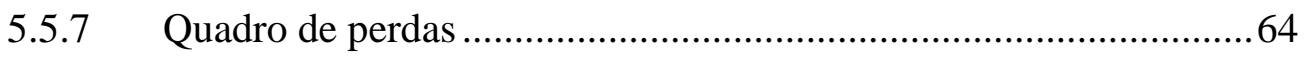

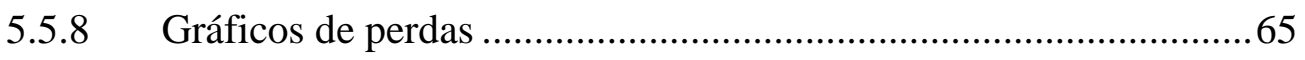

5.6 Quadro de tensões finais.......................................................................66

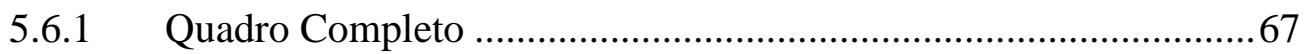

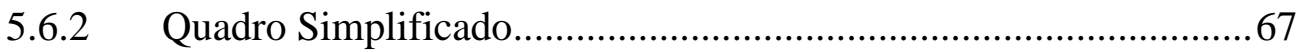

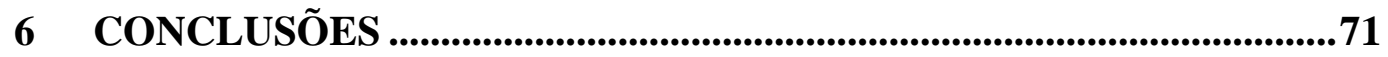

REFERÊNCIAS BIBLIOGRÁFICAS...............................................................72

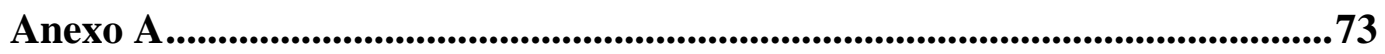

\section{ÍNDICE DE FIGURAS}

Figura 2.1 - Esquema de viga de concreto armado tradicional. 3

Figura 2.2 - Esquema de viga de concreto protendido. 4

Figura 2.3 - Esquema das diferentes regiões da viga. $\quad 6$ 
Figura 2.4 - Esquema de seção da viga na região do apoio.

Figura 2.5 - Esquema da viga na região intermediária.

Figura 2.6 - Cargas atuantes sobre uma viga.

Figura 2.7 - Esquema de um trem tipo e seu carregamento.

Figura 2.8 - Divisões e seções da viga numerados.

Figura 2.9 - Esquema de viga isostática com seção S.

Figura 2.10 - Esquema da LI na seção S para cortante.

Figura 2.11 - Esquema da LI na seção S para momento fletor.

Figura 2.12 - Esquema do carregamento móvel sobre uma viga.

Figura 2.13 - Esquema do carregamento para o cálculo do cortante máximo na seção S.

Figura 2.14 - Esquema do carregamento para o cálculo do cortante mínimo na seção S.

Figura 2.15 - Envoltórias de cortante.

Figura 2.16 - Esquema do carregamento para o cálculo do momento fletor máximo na seção $\mathrm{S}$.

Figura 2.17 - Envoltórias de momento fletor.

Figura 2.18 - Esquema dos trechos do traçado dos cabos.

Figura 4.1 - Aba "Dados da viga" do programa desenvolvido.

Figura 4.2 - Aba "Pré-Dimensionamento" do programa desenvolvido.

Figura 4.3 - Aba "Diagramas" do programa desenvolvido.

Figura 4.4 - Aba "Traçado dos cabos" do programa desenvolvido.

Figura 4.5 - Aba "Perdas" do programa desenvolvido.

Figura 4.6 - Divisões e seções da viga numerados.

Figura 4.7 - Aba "Gráficos de perdas" do programa desenvolvido.

Figura 4.8 - Aba "Quadro de tensões simplificado" do programa desenvolvido. 46

Figura 4.9 - Aba "Quadro de tensões completo" do programa desenvolvido. 
Figura 4.10 - Aba "Editar Parâmetros" do programa desenvolvido.

Figura 5.1 - Aba "Dados da viga" do programa preenchida.

Figura 5.2 - $\mathrm{f}_{\mathrm{ck}}$ e comprimento do vão da viga exemplo.

Figura 5.3 - Dados da seção na região do apoio da viga exemplo.

Figura 5.4 - Dados da seção na região intermediária da viga exemplo.

Figura 5.5 - Carregamentos atuantes sob a viga exemplo.

Figura 5.6 - Coeficientes de ponderação das cargas.

Figura 5.7 - Diagrama de momento fletor desenhado pelo programa.

Figura 5.8 - Diagrama de cortante desenhado pelo programa.

Figura 5.9 - Carregamento linear atuante sobre a viga no FTool.

Figura 5.10- Carregamento móvel atuante sobre a viga no FTool.

Figura 5.11 - Diagrama de momento fletor desenhado pelo programa FTool. 55

Figura 5.12 - Diagrama de cortante desenhado pelo programa FTool.

Figura 5.13 - Quadro de carregamentos completo da viga exemplo.

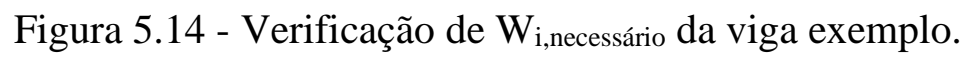

Figura 5.15 - Força de protensão da viga exemplo.

Figura 5.16 - Quadro completo do Pré-dimensionamento da viga exemplo.

Figura 5.17 - Aba "Traçado dos Cabos" da viga exemplo.

Figura 5.18 - Quadro de coordenadas dos pontos de contorno do traçado dos cabos. 58

Figura 5.19 - Diagrama do traçado dos cabos da viga exemplo.

Figura 5.20 - Perdas completas da viga exemplo.

Figura 5.21 - Centroide da protensão calculado automaticamente.

Figura 5.22 - Dados de entrada para o cálculo das perdas por atrito.

Figura 5.23 - Resultado das perdas por atrito. 
Figura 5.24 - Resultado das perdas por cravação.

Figura 5.25 - Resultado das perdas por deformação imediata.

Figura 5.26 - Resultado das perdas por deformação lenta.

Figura 5.27 - Resultado das perdas por retração do concreto.

Figura 5.28 - Resultado da perda por relaxação do aço.

Figura 5.29 - Quadro de perdas da viga exemplo.

Figura 5.30 - Aba de gráficos de perdas completo.

Figura 5.31 - Quadro de tensões finais completo da viga exemplo.

Figura 5.32 - Quadro de tensões simplificado completo da viga exemplo.

Figura 5.33 - Tensões limite da viga exemplo.

Figura 5.34 - Tensões finais na Fase 1.

Figura 5.35 - Tensões finais na Fase 2.

\section{ÍNDICE DE TABELAS}

Tabela 2.1 - Especificações de cordoalhas.

Tabela 2.2 - Quantidade de cordoalhas possível por cabo em função do diâmetro nominal....23

Tabela 2.3 - Tipos de perdas na força de protensão.

Tabela 2.4 - Valores característicos superiores da deformação especifica de retração e do coeficiente de fluência.

Tabela 4.1 - Coeficiente $\gamma_{\mathrm{f}}$ de ponderação das ações atuantes...............................42

Tabela 4.2 - Coeficiente $\gamma_{\mathrm{f}}$ de ponderação das ações atuantes..............................48

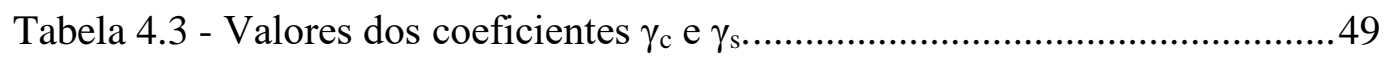

Tabela 5.1- Comparação com o resultado manual da força de protensão. ............56

Tabela 5.2 - Comparação dos resultados obtidos e os calculados manualmente..60 


\section{Pontifícia Universidade Catálica

Tabela 5.3 - Comparação dos resultados obtidos e os calculados manualmente..61

Tabela 5.4 - Comparação dos resultados obtidos e os calculados manualmente..62

Tabela 5.5 - Valores característicos superiores da deformação específica de retração e do coeficiente de fluência 62

Tabela 5.6 - Comparação do resultado obtido e os calculados manualmente. .....63

Tabela 5.7 - Comparação do resultado obtido e o calculado manualmente. ........63

Tabela 5.8 - Comparação do resultado obtido e o calculado manualmente. ........64

Tabela 5.9 - Comparação dos resultados obtidos e os calculados manualmente..69

Tabela 5.10 - Comparação dos resultados obtidos e os calculados manualmente. .70

\section{ÍNDICE DE GRÁFICOS}

Gráfico 2.1 - Resistência dos diferentes tipos de aço.

Gráfico 2.2 - Comparação de $\sigma_{0}$ após perdas por atrito e cravação....................... 31

Gráfico 5.1 - Perdas imediatas da viga exemplo. ...............................................65

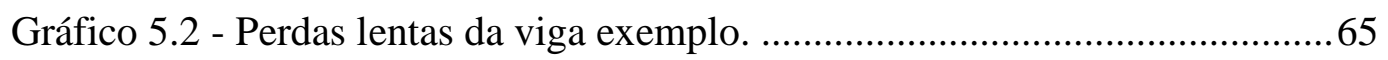

Gráfico 5.3 - Comparação entre perdas por atrito e por cravação da viga exemplo......65

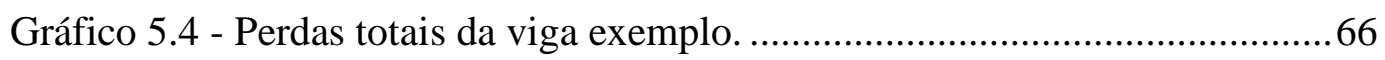




\section{INTRODUÇÃO}

O concreto é um material amplamente utilizado na construção civil. Isto se dá a sua grande resistência à compressão, custos reduzidos e maior capacidade de moldagem do material, apesar disto o material também apresenta desvantagens, dentre elas sua baixa resistência à tração. Como forma de superar esta fraqueza do material foi criada a ideia da introdução de uma armadura metálica capaz de agir junto ao concreto e combater os efeitos de tração. Assim no concreto protendido busca-se a utilização dessa armadura de forma ativa, aplicando uma força de compressão no concreto de forma a o pré-comprimir lhe concedendo maior capacidade de lidar com as tensões que ocorreriam na forma de tração sobre o elemento estrutural.

O concreto protendido apresenta inúmeras características que o tornam uma opção mais vantajosa em certas ocasiões quando comparado à uma armadura passiva convencional, como, por exemplo, maior controle quanto a fissurações das peças e a capacidade de superar vãos de grande proporção.

Com a evolução da humanidade e da computação o trabalho do engenheiro calculista tem se tornado fortemente conectado a softwares de cálculo capazes de agilizar contas e fornecer resultados mais confiáveis e constantes. Assim se torna de extrema importância o contato de alunos de engenharia civil com estes softwares e com ferramentas que os permitam programar seus próprios programas e planilhas. No caso do concreto protendido ocorre um déficit no mercado de softwares de cálculo estrutural acessíveis à alunos e indivíduos que trabalhem de forma independente, sendo muitas vezes este cálculo executado por meio de planilhas computadorizas feitas por empresas de engenharia para seu uso interno ou através de softwares com um alto custo para a obtenção de licenças. 


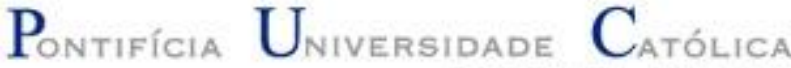 \\ DO RIO DE JANEIRO}

É importante ressaltar que apesar da defesa quanto à necessidade do contato de alunos de engenharia com softwares de cálculo estrutural, este deve ser tratado como calculadoras no apoio e agilização de contas, nunca substituindo a necessidade do aprendizado da teoria e técnicas por trás do dimensionamento estrutural.

\subsection{Objetivo}

Este trabalho tem como principal objetivo o desenvolvimento de uma ferramenta computacional capaz de realizar o dimensionamento de uma viga de concreto protendido. Este programa deve ser feito de forma a apresentar uma interface gráfica de fácil utilização, podendo ser empregado tanto no dimensionamento quanto no ensino do cálculo de elementos estruturais protendidos tendo em vista a falta no mercado de um programa deste tipo de fácil acesso. 


\section{FUNDAMENTAÇÃO TEÓRICA}

\subsection{Concreto Protendido}

O concreto protendido pode ser definido como um material submetido a um estado prévio e permanente de tensões de compressão com o objetivo de anular ou reduzir significativamente os efeitos de tração.

Estando sob o efeito de um carregamento, uma viga de concreto apresentará momentos fletores que resultarão em tensões de tração. Sabe-se que o concreto apresenta uma baixa resistência à tração, em torno de $10 \%$ de sua resistência à compressão, portanto é necessário um reforço do material para que ele suporte estes carregamentos. Assim foi desenvolvida a ideia do concreto armado, a colocação de uma armadura de aço dentro do elemento de concreto de forma a lhe ajudar a lidar com as tensões de tração. Na utilização de uma armadura passiva tradicional é considerado que o concreto irá fissura sob o efeito da tração e neste momento o aço irá começar a trabalhar.

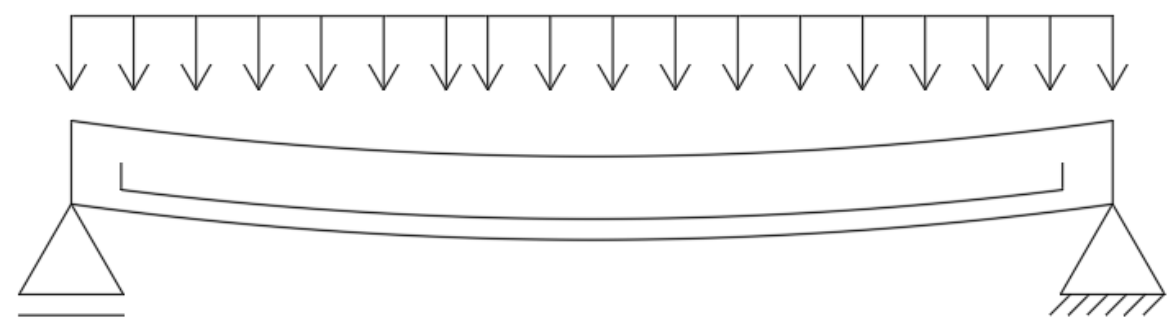

Figura 2.1 - Esquema de viga de concreto armado tradicional. Fonte: Autor.

Já no caso da utilização de armadura ativa, protensão, o aço é utilizado para submeter o elemento de concreto a um estado prévio de compressão de forma que o carregamento não resultará em tensões de tração, mas sim descomprimindo o concreto. Assim se busca 


\section{Pontifícia Universidade Catálica $_{\text {a }}$

utilizar a grande capacidade de resistência à compressão do concreto para resistir às ações das solicitações em serviço.

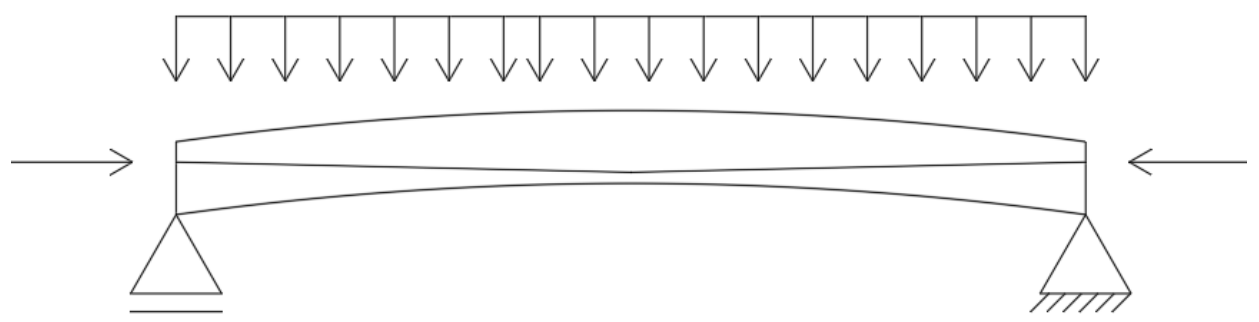

Figura 2.2 - Esquema de viga de concreto protendido.

Fonte: Autor.

Assim também é possível a utilização do concreto protendido para a eliminação de fissurações no elemento estrutural. Isto permite que o concreto se mantenha no estádio 1, podendo, portanto, ser tratado como um material elástico e linear.

\subsubsection{Vantagens e desvantagens}

\section{Vantagens:}

- Controle de fissuras;

- Permite vencer grandes vãos;

- Maior durabilidade, já que anula totalmente ou parcialmente as tensões de tração;

- Redução das dimensões transversais, devido ao uso de aços de alta resistência e concretos de maior resistência;

- Diminuição da flecha, a protensão atua de forma similar à contra-flecha;

- Maior resistência à fadiga;

- Permite criar diversos sistemas construtivos, como, por exemplo, balanços sucessivos e pré-moldados. 


\section{Desvantagens:}

- Perdas na força de protensão ao longo do tempo;

- Necessidade de controle mais rigoroso na execução;

- Necessidade de mão de obra e equipamento especializado;

- Necessidade de maiores cuidados com proteção da armadura contra corrosão.

\subsubsection{Sistemas de protensão}

\section{Concreto protendido com aderência inicial (pré-tracionado):}

A armadura de aço é posicionada e tracionada antes do lançamento do concreto sendo utilizadas peças de suporte independentes do concreto. A ligação da armadura com o concreto é realizada durante o endurecimento do concreto com a ancoragem sendo realizada devido ao efeito Hoyler.

\section{Concreto protendido com aderência posterior (pós-tracionado):}

O estiramento da armadura é realizado após o endurecimento do concreto utilizando como apoio o próprio elemento estrutural através de cabos. A aderência é criada posteriormente de modo permanente.

\section{Concreto protendido sem aderência (pós-tracionado):}

Similar ao método anterior porem sem a criação de aderência com o concreto.

\subsubsection{Aço}

As armaduras de aço utilizadas na protensão podem ser feitas no formato de fios ou cordoalhas. As cordoalhas são compostas por um conjunto de fios de mesmo diâmetro nominal encordoados num formato helicoidal podendo serem feitas com 7 ou 3 fios. 


\section{Pontifícia Universidade Catálica $_{\text {a }}$ \\ DO RIO DE JANEIRO}

Tanto os fios quanto as cordoalhas podem ser classificadas quanto à sua relaxação como sendo de relaxação normal (RN) ou de relaxação baixa (RB).

Estes aços também apresentam melhor desempenho do que os utilizados para armadura convencional.

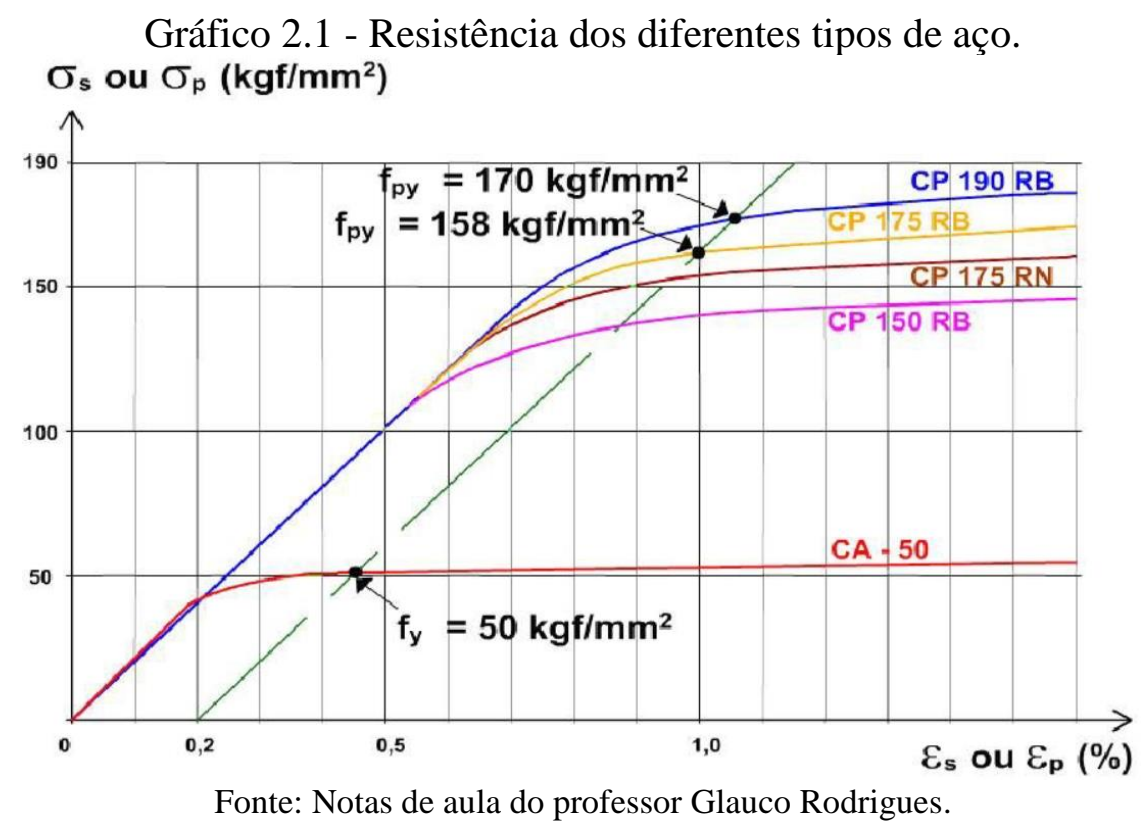

\subsection{Dados das seções da viga}

Para o Dimensionamento da viga de concreto protendido inicialmente é necessária a determinação da geometria da viga e suas propriedades. No desenvolvimento do software foram consideradas 3 possíveis regiões da viga, apoio, transição e intermediária, sendo as seções das regiões de apoio e intermediária constantes ao longo de seu comprimento.

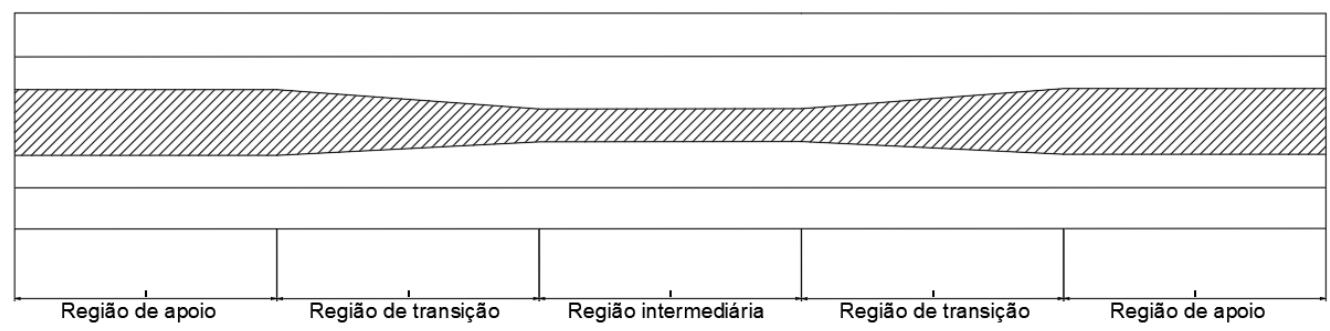

Figura 2.3 - Corte esquemático das diferentes regiões da viga.

Fonte: Autor. 


\section{Pontifícia Universidade Catálica

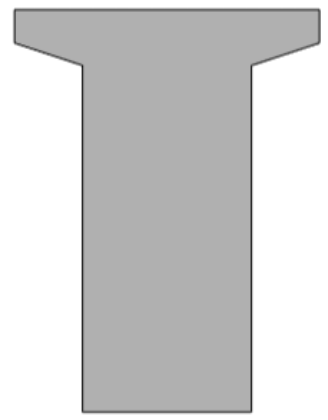

Figura 2.4 - Esquema de seção da viga na região do apoio. Fonte: Autor.

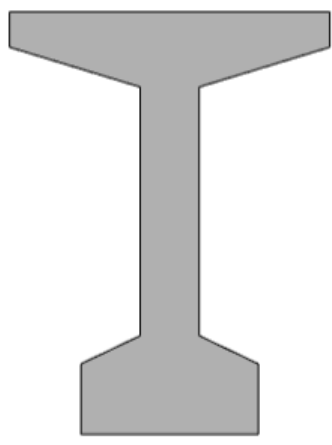

Figura 2.5 - Esquema da viga na região intermediária. Fonte: Autor.

A partir das informações das geometrias das seções da viga são retiradas as propriedades geométricas que serão utilizadas ao longo de todo o dimensionamento da armadura de protensão.

Estas propriedades são:

\subsection{1 Área Total da seção $\left(\mathrm{A}_{\mathrm{t}}\right)$}

A área total de uma seção pode ser obtida a partir do somatório das áreas individuais das regiões mais simples que as compõem. Considerando os formatos típicos para vigas protendidas, estas regiões mais simples podem ser consideradas retangulares e triangulares.

$A_{\text {Retângulo }}=$ Base $*$ Altura 
$A_{\text {Triângulo }}=\frac{\text { Base } * \text { Altura }}{2}$

$A_{T}=\sum A_{\text {individuais }}$

\subsubsection{Altura do centroide da seção (y)}

A posição do centroide pode ser obtida de forma similar à área total sendo resultado de uma média ponderada dos centroides de áreas menores.

$y_{\text {Retângulo }}=\frac{\text { Altura }}{2}$

$y_{\text {Triângulo }}=\frac{\text { Altura }}{3}$

$y_{i}=\frac{\sum \text { Área } a_{n} * y_{n}}{\sum \text { Área } a_{n}}$

$y_{s}=$ Altura $_{\text {Total }}-y_{i}$

Onde,

yi é a altura do centroide em relação à face inferior da seção;

$\mathrm{y}_{\mathrm{s}}$ é a altura do centroide em relação à face superior da seção;

\subsubsection{Momento de Inércia (I)}

O momento de inércia é uma das propriedades mais relevantes de uma seção e seu valor é obtido de forma análoga às das propriedades anteriores. 


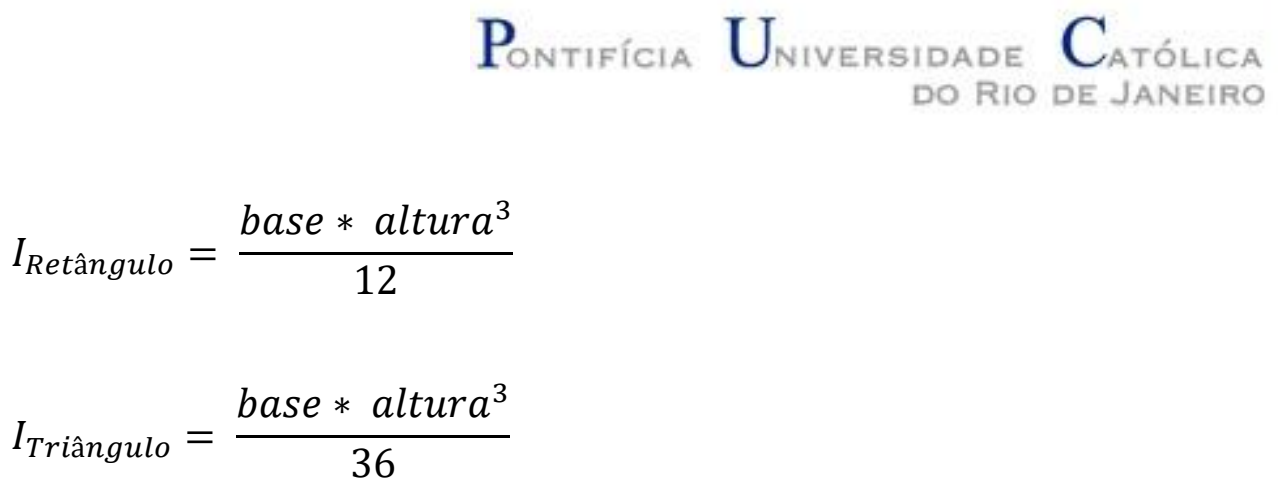

A partir dos valores individuais das áreas que compõe a seção é possível utilizar o teorema dos eixos paralelos para a determinação do momento de inercia total.

$I_{\text {total }}=\sum I_{n}+\left(A_{n} * d_{n}^{2}\right)$

Onde,

$\mathrm{I}_{\mathrm{n}}$ é o momento de inercia da área individual que faz parte da seção;

$\mathrm{A}_{\mathrm{n}}$ é o valor da área individual;

$d_{n}$ é a distância entre o centroide da área individual e o centroide da seção total;

\subsubsection{Módulo resistente elástico (W)}

Esta propriedade pode ser obtida a partir dos valores do momento de inercia total e da altura do centroide. Assim como no caso da altura do centroide, é útil o cálculo desta propriedade tanto em relação à face superior da seção quanto à face inferior.

$$
\begin{aligned}
& W_{\text {superior }}=\frac{I}{y_{s}} \\
& W_{\text {inferior }}=\frac{I}{y_{i}}
\end{aligned}
$$




\subsection{Ações atuantes}

As ações atuantes sobre uma estrutura são classificadas como permanente, variáveis e excepcionais. Para este trabalho foram consideradas carga de peso próprio, carga permanente devido aos elementos construtivos fixos e das instalações permanentes, carga acidental e carga variável móvel.

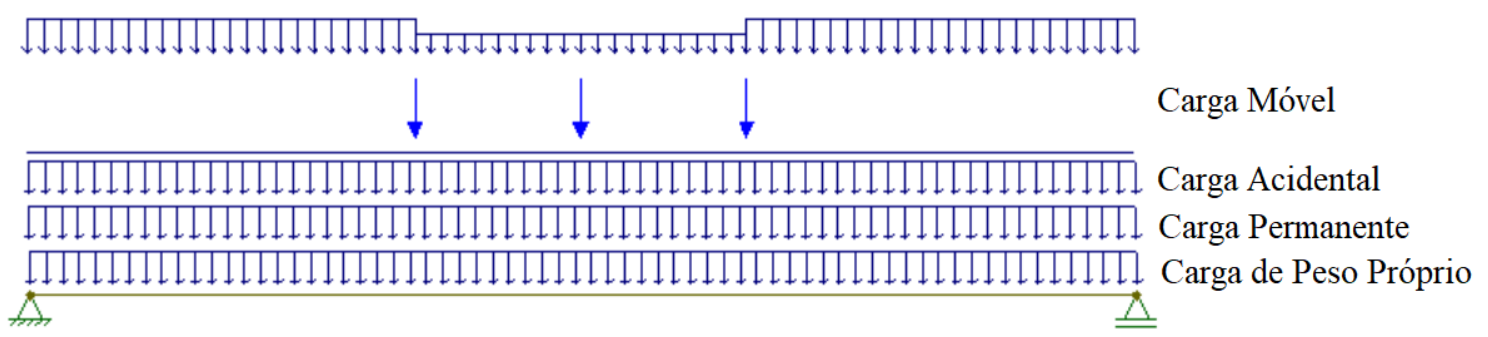

Figura 2.6 - Cargas atuantes sobre uma viga. Fonte: Autor.

Os valores para carga permanente e carga acidental podem ser definidos pelo calculista ou retirados da norma ABNT NBR 6120/2019 - Ações para o cálculo de estruturas de edificações, assim sendo somente necessário entrar em detalhes quanto à definição da carga de peso próprio e de carga variável móvel.

\subsubsection{Carga de Peso Próprio}

A carga de peso próprio é obtida a partir do peso específico do concreto armado e a área da seção da viga. Tendo em vista a possibilidade de uma viga com seção variável ao longo de seu comprimento, a seguinte fórmula é utilizada para a determinação desta ação.

$\operatorname{Carga}_{p p}=\frac{\sum A_{n} * L_{n}}{\sum L_{n}} * \gamma_{\text {concreto armado }}$

Onde,

$\mathrm{A}_{\mathrm{n}}$ é a área da seção; 
$\mathrm{L}_{\mathrm{n}}$ é o comprimento da região com a seção constante;

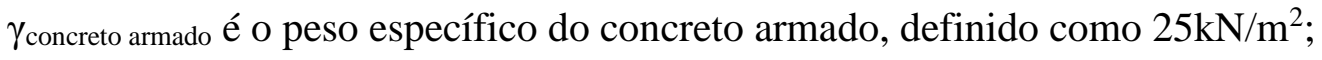

\subsubsection{Carga variável Móvel}

Para a execução do cálculo de carga móvel atuante sobre a viga primeiro foi utilizada a norma ABNT NBR 7188/2013 (Carga móvel rodoviária e de pedestres em pontes, viadutos, passarelas e outras estruturas) para a determinação dos trens tipo e dos coeficientes de ponderação destas forças. Deste modo foram consideradas três tipos possíveis de carregamento, os trens tipo TB-450 e TB-240 para ações em pontes e viadutos e, para passarelas, carga de passeio de pedestres. Para o desenvolvimento do software, os trens tipos brasileiros foram convertidos em trens tipo longitudinal simplificado para a execução dos cálculos de momento fletor e cortante.

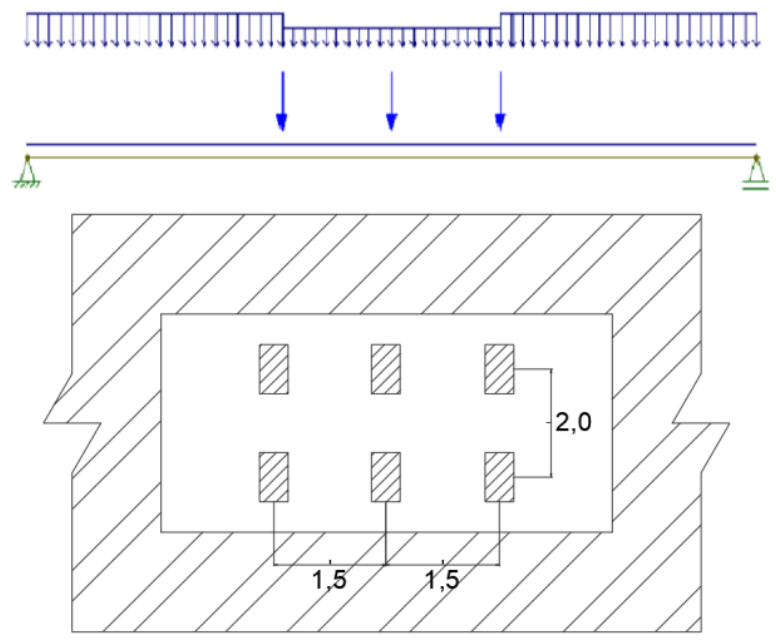

Figura 2.7 - Esquema de um trem tipo e seu carregamento. Fonte: Autor.

A carga móvel rodoviária TB-450 consiste de um veículo com 6 rodas resultando em $75 \mathrm{kN}$ por roda distribuídas em 3 eixos afastados 1,5 metros entre si e com uma carga de multidão de $5,0 \mathrm{kN} / \mathrm{m}^{2}$. 


\section{Pontifícia Universidade Catálica

Já a carga TB-240 representa um veículo com 6 rodas resultando em $40 \mathrm{kN}$ por roda distribuídas em 3 eixos afastados 1,5 metros entre si e com uma carga de multidão de 4,0 $\mathrm{kN} / \mathrm{m}^{2}$.

No caso da carga de pedestre em passarelas é considerada uma carga uniformemente distribuída de $5,0 \mathrm{kN} / \mathrm{m}^{2}$.

Além da determinação das cargas também é necessário o cálculo de três coeficientes de ponderação. Estes coeficientes são o Coeficiente de Impacto Vertical (CIV), Coeficiente do Número de Faixas (CNF) e Coeficiente de Impacto Adicional (CIA). Todas as forças verticais pontuais e de multidão das cargas móveis devem ser multiplicadas por estes três coeficientes.

- Coeficiente de Impacto Vertical (CIV):

$C I V=1,35$, para estruturas com vão inferior a 10 metros;

$C I V=1+1,06 *\left(\frac{10}{L+50}\right)$

Onde,

L é o vão em metros.

- Coeficiente do Número de Faixas (CNF):

$C N F=1-0,05 *(n-2)>0,9$

Onde, 


\section{Pontifícia Universidade Catálica

n é o número inteiro de faixas de trafego carregadas sobre o tabuleiro.

- Coeficiente de Impacto Adicional (CIA):

$C I A=1,25$, para obras em concreto ou mistas;

CIA $=1,15$, para obras em aço.

\subsection{Diagramas}

Para o dimensionamento de uma viga é importante o traçado dos diagramas de momento fletor e de cortante. De forma a tornar as contas mais práticas e tendo em vista a necessidade de considerar duas fases de carregamento para a verificação da protensão, cada carregamento foi considerado isoladamente e depois combinado.

\subsubsection{Peso Próprio, Permanente e Acidental}

Para os carregamentos de peso próprio, permanente, e acidental, que apresentam valores de carregamento constantes uniformemente distribuídos, estes esforços podem ser calculados ao longo da viga utilizando as formulas apresentada a seguir.

$$
\begin{aligned}
& M_{x}=\left(\frac{q * L * x}{2}\right)-\left(\frac{q * x^{2}}{2}\right) ; \\
& N_{x}=\left(\frac{q * L}{2}\right)-\left(q * x^{2}\right) ;
\end{aligned}
$$

Onde,

$\mathrm{M}_{\mathrm{x}}$ é o momento fletor no ponto x; 
$\mathrm{N}_{\mathrm{x}}$ é o força cortante no ponto $\mathrm{x}$;

q é a carga linearmente distribuída na viga;

L é o comprimento da viga.

\subsubsection{Variável móvel}

No caso de cargas moveis é necessário o traçado de envoltórias de mínimos e máximos. Estas envoltórias devem ser calculadas em seções selecionadas. No caso deste programa, apesar da automação permitir a execução de dezenas de seções, foi escolhida a execução deste cálculo para 11 seções ao longo da viga. Esta escolha se deu não somente para o cálculo das envoltórias, mas também de forma a tornar mais efetivas outras áreas do dimensionamento.

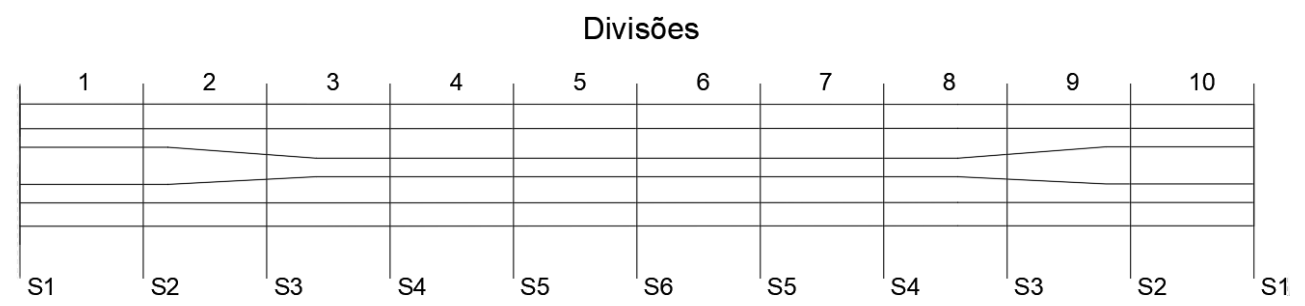

Figura 2.8 - Divisões e seções da viga numerados.

Fonte: Autor.

Os valores de mínimo e máximo de uma dada seção são determinados a partir das linhas de influência (LI), sendo as LIs funções que expressam como uma resposta em uma seção varia para uma carga vertical unitária que percorre a estrutura.

Tendo em vista o objetivo desse trabalho, foram programadas as funções das LIs para cortante e momento fletor específicos para o caso de uma viga bi-apoiada isostática. Assim estas funções se dão como é mostrado a seguir. 


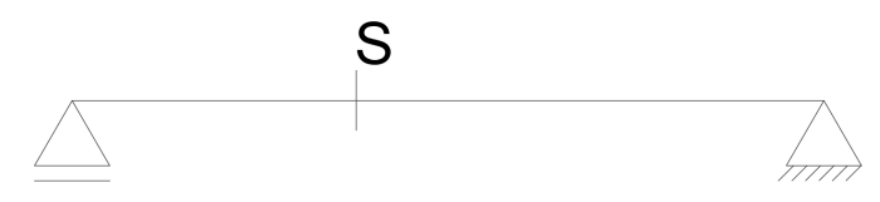

Figura 2.9 - Esquema de viga isostática com seção S. Fonte: Autor.

Cortante:

$x<s \rightarrow Q_{s}(x)=\frac{x}{L}$

$x \geq s \rightarrow Q_{s}(x)=\frac{-(L-x)}{L}$.

Onde,

S é a seção estudada;

$\mathrm{Q}_{\mathrm{s}}(\mathrm{x})$ é o valor de LI no ponto $\mathrm{x}$;

Lé o comprimento total do vão.

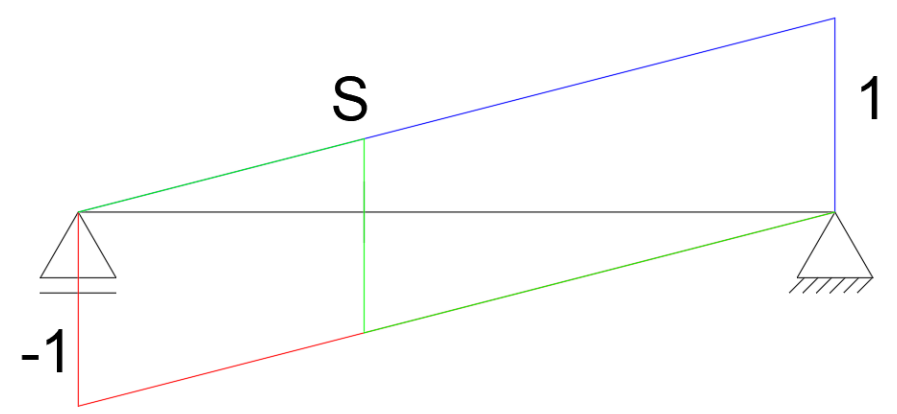

Figura 2.10 - Esquema da LI na seção S para cortante. Fonte: Autor.

Momento fletor:

$x<s \rightarrow M_{s}(x)=\frac{-x}{L} *(L-x)$ 
$x \geq s \rightarrow M_{s}(x)=\frac{L-x}{L} * x$.

Onde,

S é a seção estudada;

$\mathrm{M}_{\mathrm{s}}(\mathrm{x})$ é o valor de LI no ponto $\mathrm{x}$;

L é o comprimento total do vão.

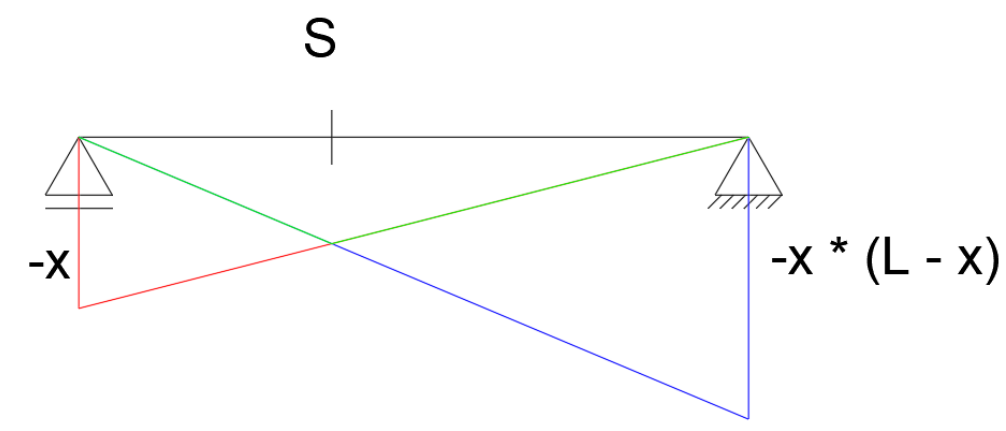

Figura 2.11 - Esquema da LI na seção S para momento fletor. Fonte: Autor.

A partir das LIs é possível obter os valores de mínimos e máximos para cada seção aplicando a carga móvel da forma mais "favorável” ou "desfavorável” e multiplicando seu valor pela área gerada pela LI.

A partir das informações da geometria da área de influência e do trem tipo utilizado é possível calcular o trem tipo longitudinal simplificado de forma a simplificar o calculo do momento fletor e cortante.

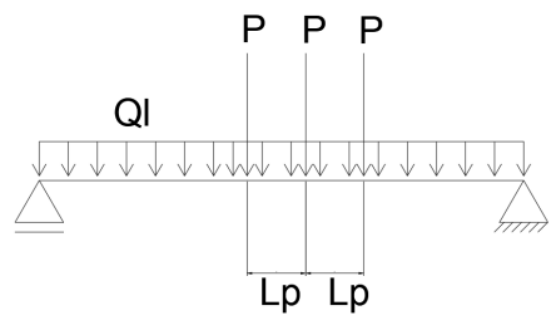

Figura 2.12 - Esquema do carregamento móvel sobre uma viga. Fonte: Autor. 
Cortante:

$V_{\text {máx }}(x)=\left(Q_{l} * \frac{x * \frac{x}{L}}{2}\right)+\left(P * \frac{x}{L}\right)+\left(P * \frac{x-L_{p}}{L}\right)+\left(P * \frac{x-\left(2 * L_{p}\right)}{L}\right)$

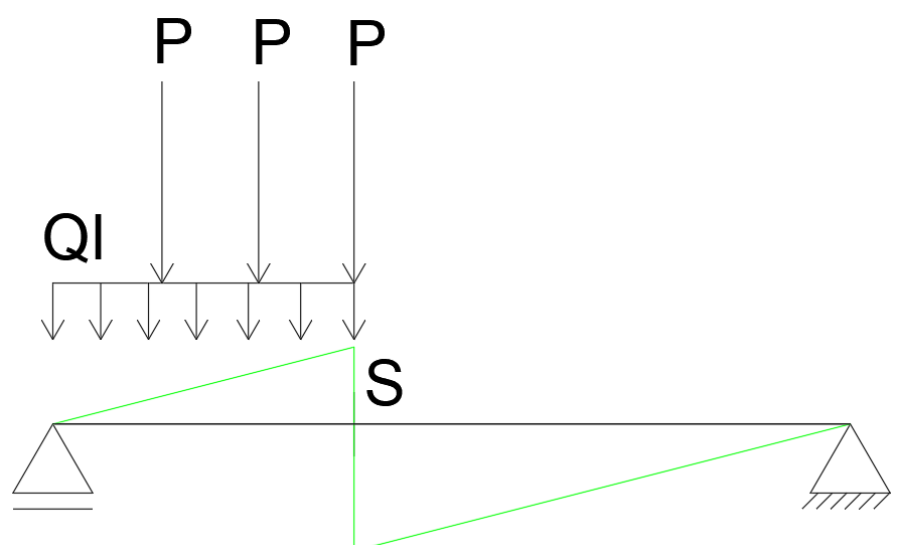

Figura 2.13 - Esquema do carregamento para o cálculo do cortante máximo na seção S. Fonte: Autor.

$V_{\text {min }}(x)=\left(Q_{l} * \frac{(L-x) * \frac{(L-x)}{L}}{2}\right)+\left(P * \frac{(L-x)}{L}\right)+\left(P * \frac{(L-x)+L_{p}}{L}\right)+\left(P * \frac{(L-x)+\left(2 * L_{p}\right)}{L}\right)$

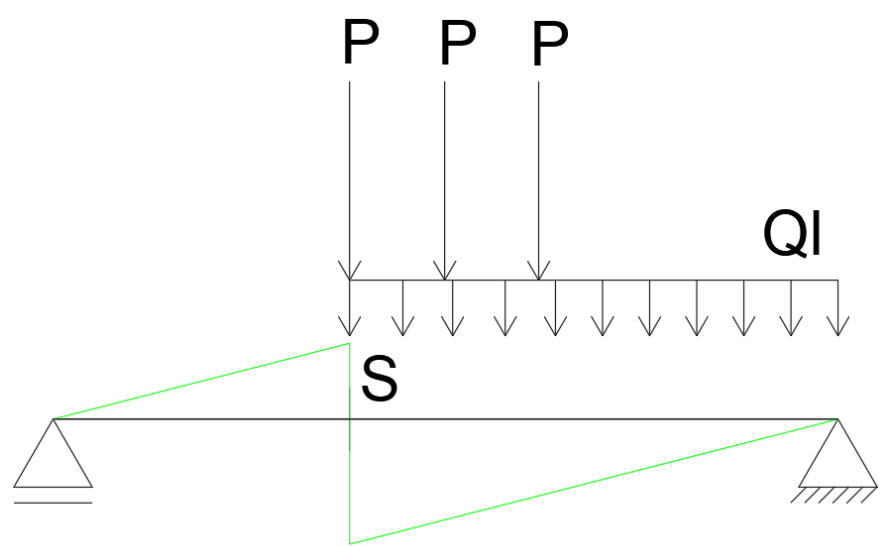

Figura 2.14 - Esquema do carregamento para o cálculo do cortante mínimo na seção S. Fonte: Autor. 


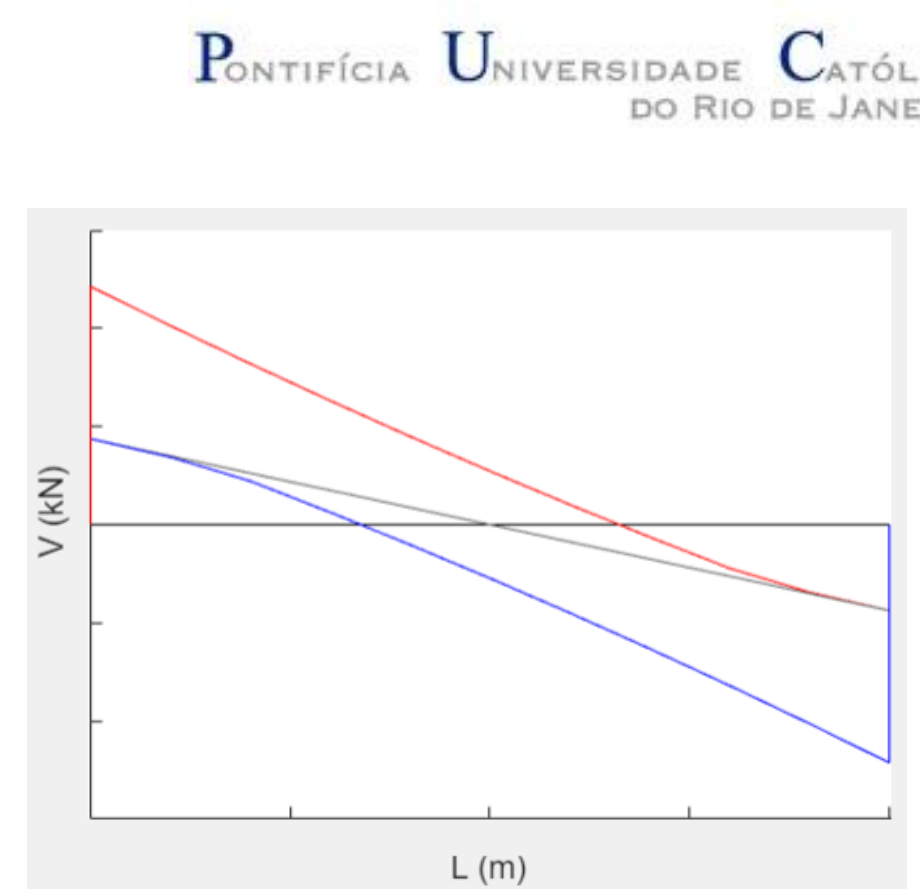

Figura 2.15 - Envoltórias de cortante. Fonte: Autor.

Momento fletor:

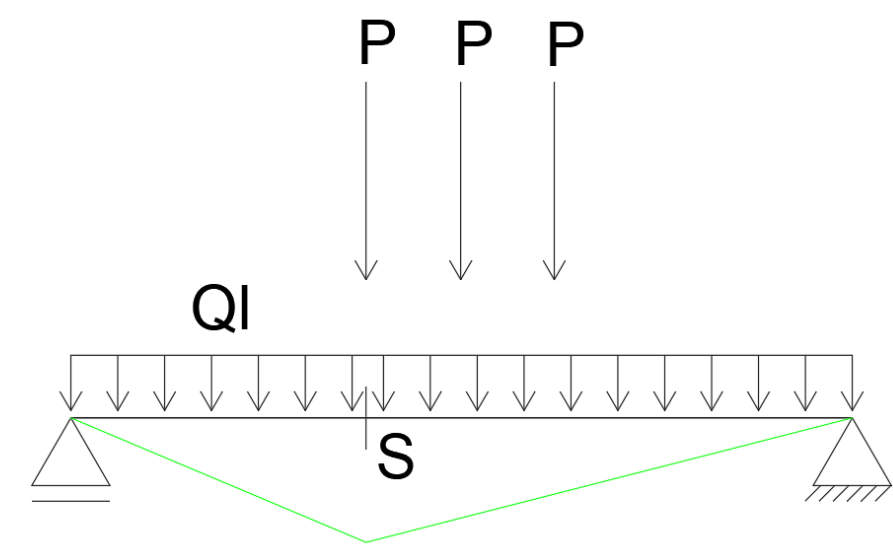

Figura 2.16 - Esquema do carregamento para o cálculo do momento fletor máximo na seção S.

Fonte: Autor.

Como a viga é isostática o momento mínimo é nulo

$M_{\text {min }}=0$ 


\section{Pontifícia Universidade Catálica

Já o momento máximo depende da posição da seção $\mathrm{S}$ em relação ao meio do vão.

Para $\mathrm{x}<\mathrm{L} / 2$ :

$$
\begin{gathered}
M_{\text {máx }}(x)=\left(Q_{l} * \frac{x *\left(\frac{-x}{L} *(L-x)\right)}{2}\right)+\left(Q_{l} * \frac{(L-x) *\left(\frac{(L-x)}{L} * x\right)}{2}\right)+\left(P *\left(\frac{(L-x)}{L} * x\right)\right) \\
+\left(P *\left(\frac{\left(L-\left(x+L_{p}\right)\right)}{L} * x\right)\right)+\left(P *\left(\frac{\left(L-\left(x+\left(2 * L_{p}\right)\right)\right)}{L} * x\right)\right)
\end{gathered}
$$

$\operatorname{Para} \mathrm{x}=\mathrm{L} / 2$ :

$$
\begin{gathered}
M_{\text {máx }}(x)=\left(Q_{l} * \frac{x *\left(\frac{-x}{L} *(L-x)\right)}{2}\right)+\left(Q_{l} * \frac{(L-x) *\left(\frac{(L-x)}{L} * x\right)}{2}\right)+\left(P *\left(\frac{(L-x)}{L} * x\right)\right) \\
+\left(P *\left(\frac{-\left(x-L_{P}\right)}{L} *(L-x)\right)\right)+\left(P *\left(\frac{\left(L-\left(x+L_{p}\right)\right)}{L} * x\right)\right)
\end{gathered}
$$

Para $\mathrm{x}>\mathrm{L} / 2$ :

$$
\begin{gathered}
M_{\text {máx }}(x)=\left(Q_{l} * \frac{x *\left(\frac{-x}{L} *(L-x)\right)}{2}\right)+\left(Q_{l} * \frac{(L-x) *\left(\frac{(L-x)}{L} * x\right)}{2}\right)+\left(P *\left(\frac{(L-x)}{L} * x\right)\right) \\
+\left(P *\left(\frac{-\left(x-L_{P}\right)}{L} *(L-x)\right)\right)+\left(P *\left(\frac{-\left(x-\left(2 * L_{P}\right)\right)}{L} *(L-x)\right)\right)
\end{gathered}
$$




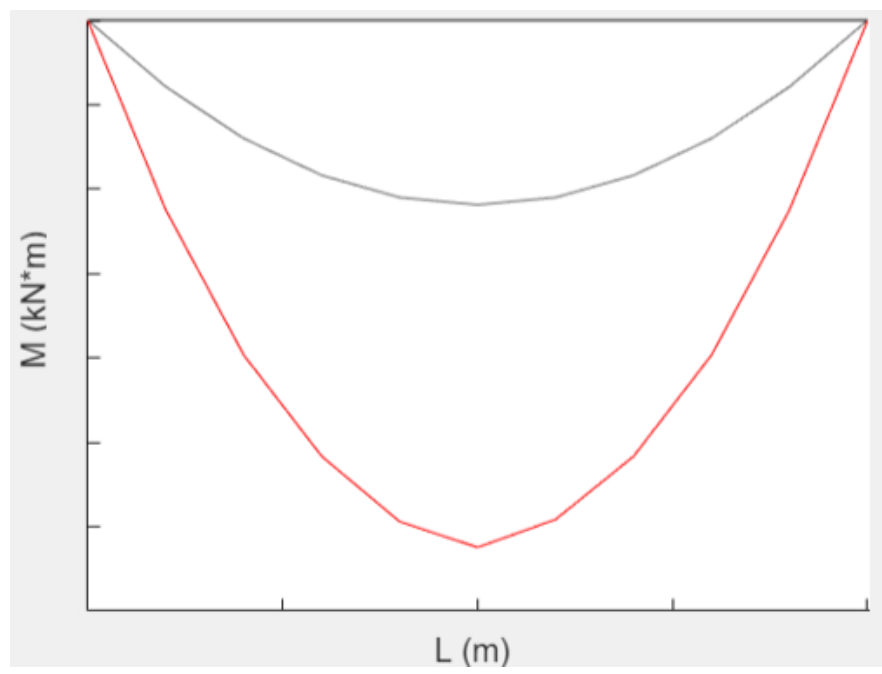

Figura 2.17 - Envoltórias de momento fletor. Fonte: Autor.

Onde,

$\mathrm{V}_{\text {máx }}(\mathrm{x})$ é o valor do cortante máximo em x;

$\mathrm{V}_{\min }(\mathrm{x})$ é o valor do cortante mínimo em $\mathrm{x}$;

Qmáx (x) é o valor do momento máximo em x;

$\mathrm{Q}_{\min }(\mathrm{x})$ é o valor do momento mínimo em x;

P é a carga pontual móvel;

$\mathrm{L}_{\mathrm{p}}$ é a distância entre as cargas pontuais moveis $\mathrm{P}$;

Q é a carga linear móvel;

L é o comprimento total do vão.

\subsection{Pré-dimensionamento}

A partir do diagrama de momento fletor é possível obter as tensões máximas. Devido ao fato de ser considerada uma viga bi-apoiada isostática, foi definido que esta tensão 


\section{Pontifícia Universidade Catálica \\ DO RIO DE JANEIRO}

máxima se encontraria no meio do vão de modo a simplificar cálculo do prédimensionamento. Utilizando-se das propriedades geométricas da seção da viga, a tensão máxima atuante e a excentricidade média dos cabos de protensão é possível calcular a Força de Protensão máxima que os cabos necessitam suportar.

Neste Ponto do processo também é possível realizar uma verificação da seção projetada para a viga. Utilizando-se dos momentos máximos, o $\mathrm{f}_{\mathrm{ck}}$ do concreto e uma estimativa das perdas de tensão de protensão é possível calcular o modulo resistente elástico mínimo necessário que deve ser comparado ao calculado para a seção.

$W_{i, \min }=\frac{M}{\frac{2}{3} * f_{c k}-\text { Perdas }}$

Onde,

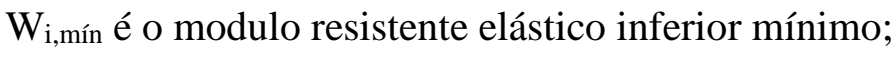

M é o momento máximo atuante;

$\mathrm{f}_{\mathrm{ck}}$ é a resistência característica à compressão do concreto;

Perdas são as perdas de tensão de protensão estimadas inicialmente como $2 \mathrm{MPa}$.

A armadura de protensão, assim como uma armadura convencional, busca combater a tração e, portanto, para o pré-dimensionamento será considerada a tensão máxima de tração na região abaixo do centroide da seção.

$\sigma_{t, m a ́ x}+\frac{F_{p}}{A}+\frac{F_{p} * e}{W_{i}}=0$ 
Portanto,

$$
F_{p}=-\frac{\sigma_{t, m a ́ x}}{\frac{1}{A}+\frac{e}{W_{i}}} * \gamma_{p}
$$

Onde,

$\mathrm{F}_{\mathrm{p}}$ é a força de protensão;

$\sigma_{\mathrm{t}, \text { máx é a tensão máxima de tração; }}$

A é a área da seção;

e é a excentricidade do centroide dos cabos de protensão;

$\mathrm{W}_{\mathrm{i}}$ é o modulo resistente elástico inferior da seção;

$\gamma_{\mathrm{p}}$ é o coeficiente de ponderação da força de protensão para a consideração de perdas.

Tendo a força que a protensão deve suportar é possível realizar uma primeira escolha do tipo de cordoalha, sua quantidade e distribuição

Tabela 2.1 - Especificações de cordoalhas.

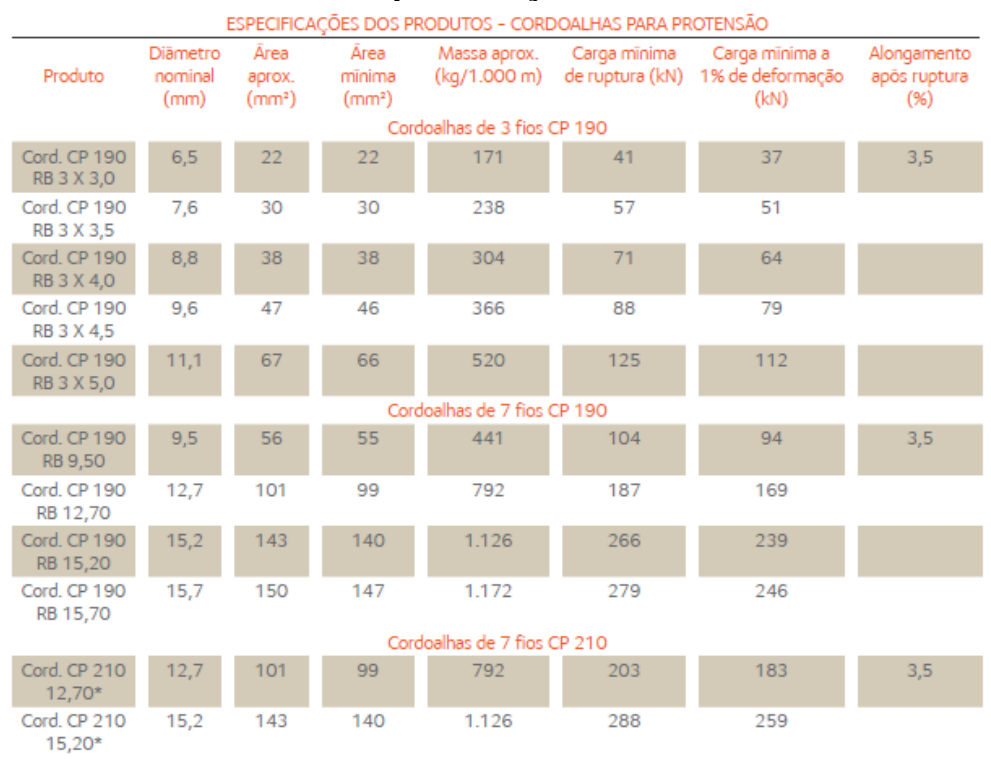

Fonte: Catálogo de fios e cordoalhas para concreto protendido ArcelorMittal 


$$
n_{\text {cordoalhas }}=\frac{F_{p}}{\left(\frac{N_{c}}{\gamma_{s}}\right)}
$$

Onde,

$\mathrm{n}_{\text {cordoalhas }}$ é o número total de cordoalhas;

$F_{p}$ é a força de protensão calculada;

$\mathrm{N}_{\mathrm{c}}$ é a carga mínima a $1 \%$ de deformação do aço selecionado;

$\gamma_{\mathrm{s}}$ é o coeficiente de ponderação da resistência do aço, igual a 1,15.

Já a quantidade de cabos é decidida seguindo o esquema apresentado a seguir.

Tabela 2.2 - Quantidade de cordoalhas possível por cabo em função do diâmetro nominal.

\begin{tabular}{|c|c|c|c|c|c|c|c|c|c|c|}
\hline$\varnothing$ & & 1 & 2 & 4 & 6 & 7 & 9 & 12 & 16 & 19 \\
\hline 12.7 & $\begin{array}{l}\text { вanth } \\
\text { Trooverta }\end{array}$ & (-) & $\begin{array}{l}\text { : } \\
\text { : }\end{array}$ & $\begin{array}{l}80 \\
\because 0\end{array}$ & $\Leftrightarrow$ & $\begin{array}{l}\Leftrightarrow 8 \\
\because 8\end{array}$ & & (8) & & \%8: \\
\hline 15.2 & $\begin{array}{l}\text { винти } \\
\text { тroverta }\end{array}$ & (๑) & $\begin{array}{l}\text { : } \\
\text { ? }\end{array}$ & $\begin{array}{l}8 \\
\because 8\end{array}$ & $\begin{array}{l}\because 0 \\
\because 8\end{array}$ & & $\begin{array}{l}88 \\
8: 8\end{array}$ & $\begin{array}{l}\text { \%: } \\
\% \\
\%\end{array}$ & $\begin{array}{l}\text { \% } \\
\text { \% }\end{array}$ & \\
\hline
\end{tabular}

Fonte: catálogo MAC Protensão.

\subsection{Traçado dos cabos}

O posicionamento dos cabos de protensão é algo que deve ser levado em conta durante seu dimensionamento, sendo muitas vezes ideal a sua colocação de forma a “acompanhar" o diagrama de momento fletor. Este fato se dá já que a compressão 


\section{Pontifícia Universidade Catálica

projetada para o momento máximo poderia gerar um esmagamento do concreto numa região da viga mais próxima das extremidades onde há um momento menor.

Os cálculos desenvolvidos nesta seção foram baseados nas formulas e métodos desenvolvidos por Rokilane Rezende (Rezende, 2020).

Assim, neste projeto, foram consideradas três trechos do cabo representadas por diferentes equações. Um trecho inicial linear, seguido por um parabólico e um constante que devem ser espelhados após o meio da viga.

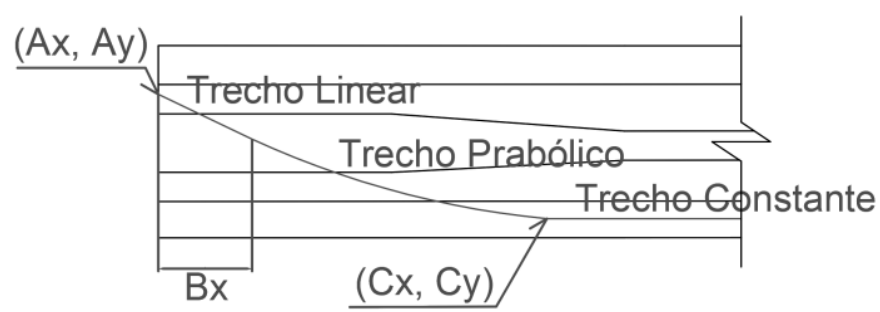

Figura 2.18 - Esquema dos trechos do traçado dos cabos. Fonte: Autor.

Desta forma, para criar uma curva continua, serão aplicadas como condições de contorno e dados de entrada do usuário no programa a posição de introdução do cabo, o ponto onde o trecho parabólico se inicia e a posição onde o cabo se torna constante.

Assim é possível chegar no seguinte sistema de equações para se obter as constantes necessárias para o traçado:

$$
\begin{aligned}
& b_{1}=A_{y} \\
& -a_{2} *\left(B_{x}-A_{x}\right)-b_{1}+a_{2} *\left(B_{x}-A_{x}\right)^{2}+b_{2} *\left(B_{x}-A_{x}\right)+c_{2}=0 \\
& -a_{1}+2 * a_{2} *\left(B_{x}-A_{x}\right)+b_{2}=0 \\
& a_{2} *\left(C_{x}-A_{x}\right)^{2}+b_{2} *\left(C_{x}-A_{x}\right)+c_{2}-c_{3}=0 \\
& 2 * a_{2} *\left(C_{x}-A_{x}\right)+b_{2}=0 \\
& c_{3}=C_{y}
\end{aligned}
$$




\section{Pontifícia Universidade Catálica $_{\text {a }}$

Onde,

$\mathrm{A}_{\mathrm{x}}$ é a coordenada $\mathrm{X}$ do ponto de introdução do cabo;

$A_{y}$ é a coordenada $\mathrm{Y}$ do ponto de introdução do cabo;

$\mathrm{B}_{\mathrm{x}}$ é a coordenada em X onde o trecho parabólico se inicia;

$\mathrm{C}_{\mathrm{X}}$ é a coordenada $\mathrm{X}$ em que se inicia o trecho constante;

$\mathrm{C}_{\mathrm{y}}$ é a coordenada $\mathrm{Y}$ em que se inicia o trecho constante;

$a_{1}$ é a primeira constante da equação linear;

$b_{1}$ é a segunda constante da equação linear;

a é a primeira constante da equação parabólica;

$\mathrm{b}_{2}$ é a segunda constante da equação parabólica;

$c_{2}$ é a terceira constante da equação parabólica;

$c_{3}$ é a constante da equação constante;

Este sistema de equação pode ser resolvido utilizando uma operação matricial apresentada a seguir.

$[B]=[C] *[A]^{-1}$

Onde, 


\section{Pontifícia Universidade Catálica

0
$-\left(B_{x}-A_{x}\right)$
-1
0
0
0
$[A]=\square$

$[B]=\left[\begin{array}{l}a_{1} \\ b_{1} \\ a_{2} \\ b_{2} \\ c_{2} \\ c_{3}\end{array}\right]$

$[C]=\left[\begin{array}{c}A_{y} \\ 0 \\ 0 \\ 0 \\ 0 \\ C_{y}\end{array}\right]$

$\begin{array}{cccc}0 & 0 & 0 & 0 \\ \left(B_{x}-A_{x}\right)^{2} & \left(B_{x}-A_{x}\right) & 1 & 0 \\ 2 *\left(B_{x}-A_{x}\right) & 1 & 0 & 0 \\ \left(C_{x}-A_{x}\right)^{2} & \left(C_{x}-A_{x}\right) & 1 & -1 \\ 2 *\left(C_{x}-A_{x}\right) & 1 & 0 & 0 \\ 0 & 0 & 0 & 1\end{array}$

Tendo encontrado as equações e tendo os dados de entrada fornecidos pelo usuário é possível realizar o traçado gráfico dos cabos.

\subsection{Força na armadura de protensão}

Durante a execução da protensão o macaco aplicará uma força sob os cabos. Esta força apresenta limites que serão tratados nas equações a seguir.

- Armadura pré-tracionada

$0,77 * f_{p t k} \leq \sigma_{p i} \leq 0,90 * f_{p y k}$, Para aço de classe $R N$;

$0,77 * f_{p t k} \leq \sigma_{p i} \leq 0,85 * f_{p y k}$, Para aço de classe $R B$. 
- Armadura pós-tracionada

$0,74 * f_{p t k} \leq \sigma_{p i} \leq 0,87 * f_{p y k}$, Para aço de classe $R N$

$0,74 * f_{p t k} \leq \sigma_{p i} \leq 0,82 * f_{p y k}$, Para aço de classe $R B$

$0,80 * f_{p t k} \leq \sigma_{p i} \leq 0,88 * f_{p y k}$, Para cordoalhas engraxadas e aço de classe $R B$

Onde,

$\sigma_{i}$ é a armadura de protensão na saída do aparelho de tração;

$\mathrm{f}_{\mathrm{ptk}}$ é o valor da resistência à tração da cordoalha;

$\mathrm{f}_{\text {pyk }}$ é valores característicos da resistência ao escoamento convencional da cordoalha.

\subsection{Perdas}

Após a aplicação da força de protensão ocorrerão perdas de tensão devidos à interação entre os materiais e as próprias características do aço e concreto. Estas perdas podem ser divididas em dois tipos: perdas imediatas e perdas lentas.

As perdas imediatas são resultado do atrito entre o cabo e a bainha ao ser aplicada a força de protensão, à acomodação das peças de ancoragem após a liberação do macaco e à deformação imediata do elemento estrutural devido à aplicação da força de protensão.

As perdas lentas ocorrem devido à fluência do concreto, à retração do concreto devido à sua cura e ao relaxamento natural dos cabos ao longo do tempo.

Tabela 2.3 - Tipos de perdas na força de protensão.

\begin{tabular}{|c|c|}
\hline \multicolumn{2}{|c|}{ Perdas de Protensão } \\
\hline Imediatas & Lentas \\
\hline Atrito & Fluência \\
\hline Cravação & Retração \\
\hline Deformação Imediata & Relaxação \\
\hline
\end{tabular}

Fonte: Notas de aula do Professor Glauco Rodrigues. 


\subsubsection{Perdas por atrito}

A perda por atrito ocorre pela interação entre o cabo e a bainha durante a execução da força de protensão, sendo acentuada nas curvas devido aos desvios de trajetória dos cabos e à constituição da bainha.

$\sigma_{x}=\sigma_{0} e^{-\mu *\left(\sum \alpha+\beta * L\right)}$

$\Delta \sigma_{\text {atrito }, n}=\sigma_{0}-\sigma_{x, n}$

Onde,

$\Delta \sigma_{\text {atrito,n }}$ é a perda por atrito na região n;

$\sigma_{\mathrm{x}, \mathrm{n}}$ é a tensão pós perdas por atrito na seção n;

$\sigma_{0}$ é a tensão aplicada pelo macaco;

$\mu$ é o coeficiente de atrito aparente entre o cabo e a bainha;

$\Sigma \alpha$ é a soma dos valores absolutos dos ângulos de desvios dos cabos, nas seções de cálculo, em relação à seção 1;

$\beta$ é a ondulação media por metro;

L é o comprimento acumulado do cabo desde a extremidade da viga, até cada seção analisada, ou seja $L=n \ell$, onde n é o número da seção e $\ell$ é o comprimento de cada trecho.

O valor de $\beta$ é pode variar entre 0,015 e $0,006 \mathrm{rad} / \mathrm{m}$.

O valor de $\mu$ deve ser, dependendo da condição de projeto: 
0,50 - Entre cabo e concreto sem bainha;

0,30 - Entre barras ou fios com mossas e saliências e bainhas metálicas;

0,25 - Entre fios lisos paralelos ou trançados e bainha metálica;

0,10 - Entre fios lisos paralelos ou traçados e bainhas metálicas lubrificadas.

Para a execução do cálculo das perdas por atrito é considerada uma simplificação na distribuição dos cabos pelas seções assumindo um único cabo homogeneizando a seção transversal. Este cabo é "traçado" assumindo sua posição como sendo a média das excentricidades de todos os cabos em cada seção avaliada.

\subsubsection{Perdas por cravação}

As perdas por cravação ocorrem devido à acomodação das cunhas de cravação após a liberação dos cabos do macaco. Estas perdas também podem ser chamadas de perdas por encunhamento.

Nos sistemas que utilizam cunha individual para cada fio ou cordoalha, observam-se os seguintes valores médios de retorno devido ao encunhamento, para uma dada carga máxima:

Fio $\quad \phi=7 \mathrm{~mm} \quad \delta=5 \mathrm{~mm}$

Cordoalha $\phi=12,5 \mathrm{~mm} \delta=6 \mathrm{~mm}$ ou $\delta=5 \mathrm{~mm}$ (cunha cravada com macaco)

Essas perdas podem ser calculadas igualando a energia de retorno das cordoalhas com a energia de atrito atuante no interior do cabo. Sabe-se que a função que descreve a perda de energia por atrito em cada seção se aproxima à uma função linear. Pode-se, 


\section{Pontifícia Universidade Catálica

portanto, calculando as áreas acumuladas para cada trecho, obter-se o valor da perda de energia por unidade de comprimento para cada trecho.

$\Delta u_{n}=\Delta u_{n-1} * \frac{\left((2 * n-1) * l *\left(\sigma_{x, n}-\sigma_{x, n-1}\right)\right)}{2}$

Onde,

n é o número da seção;

$\sigma_{\mathrm{x}}$ é a tensão pós perdas por atrito;

1 é a distância entre as seções.

Calculando-se a energia de cravação total, pode-se determinar uma queda na curva abaixo da tensão do meio do vão e determina-se o eixo de simetria:

$\Delta=\frac{U-\Delta u_{5}}{5 * l}$
$\sigma=\sigma_{x, 6}-\Delta$

Onde,

$\Delta$ é o fator de simetria;

$\sigma$ é o eixo de simetria em MPa.

A perda por cravação é dada então por:

$\sigma_{n}=\sigma-\left(\sigma_{x, n}-\sigma\right)$ 


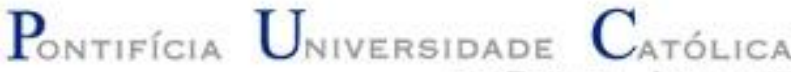

$\Delta \sigma_{\text {cravação,n }}=\sigma_{x, n}-\sigma_{n}$

Onde,

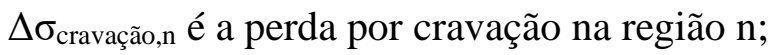

$\sigma_{\mathrm{x}, \mathrm{n}}$ é a tensão devido à força de protensão na região $\mathrm{n}$ após as perdas por atrito;

$\sigma_{\mathrm{n}}$ é a tensão devido à força de protensão na região $\mathrm{n}$ após as perdas por cravação.

No gráfico a seguir é possível observar a simetria resultante das perdas por atrito e por cravação ao longo da viga.

Gráfico 2.2 - Comparação de $\sigma_{0}$ após perdas por atrito e cravação.

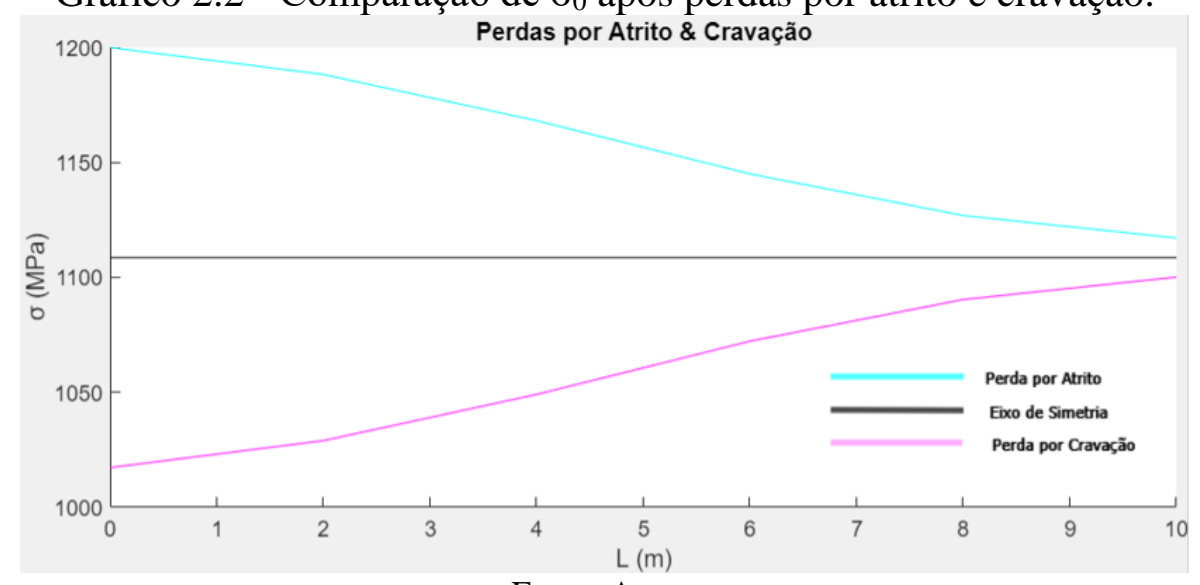

Fonte: Autor.

\subsubsection{Perdas por deformação imediata}

Após receber a força de protensão o elemento estrutural apresentará uma deformação elástica imediata. Com isso também ocorrerá um encurtamento nas armaduras de protensão devido à sua aderência ao concreto, gerando um alivio de tensões e, assim, a perda de deformação imediata. Portanto serão igualadas as deformações do concreto e do aço em cada seção. 
$\Delta \sigma_{\text {deformação imediata,x }}=\varepsilon_{c} * E_{a} * \frac{n-1}{2 * n}$

Onde,

$\varepsilon_{c}=\frac{\sigma_{c}}{E_{c 28}}$

$E_{c 28}=5600 * \sqrt{f_{c k}}$

$\Delta \sigma_{\text {deformação imediata,x }}$ é a perda por deformação imediata na seção x;

$\varepsilon_{c}$ é o encurtamento do concreto;

Ea é o modulo de elasticidade longitudinal da armadura de protensão, igual a 195GPa;

n é o número de cabos;

$\sigma_{c}$ é a tensão atuante na seção devido à força de protensão e ao momento devido ao peso próprio do elemento estrutural;

$\mathrm{E}_{\mathrm{c}}$ é o modulo de elasticidade do concreto.

\subsubsection{Perdas por deformação lenta}

Ao longo da vida útil do elemento estrutural ocorrerá um encurtamento gradativo dos cabos conforme o concreto se deforma devido à tensão de protensão. Com isto haverá uma perda na força de protensão. Similar ao caso anterior será considerada uma deformação igual para o concreto e para a armadura.

$\Delta \sigma_{\text {deformação lenta,x }}=\varepsilon_{f, x} * E_{a}$ 
Onde,

$\varepsilon_{f, x}=\frac{\sigma_{c, x}}{E_{c 28}} * \varphi\left(t_{\infty}, t_{0}\right)$

$E_{c 28}=5600 * \sqrt{f_{c k}}$

$\Delta \sigma_{\text {deformação lenta,x }}$ é a perda por deformação lenta na seção x;

$\varepsilon_{\mathrm{f}}$ é o encurtamento do concreto;

$E_{a}$ é o modulo de elasticidade longitudinal da armadura de protensão, igual a 195GPa;

n é o número de cabos;

$\sigma_{c}$ é a tensão atuante na seção devido à força de protensão e ao momento total sob o elemento estrutural;

$\mathrm{E}_{\mathrm{c} 28}$ é o modulo de elasticidade do concreto;

$\varphi($ to,t0) é o coeficiente de fluência.

O coeficiente de fluência pode ser retirado da Tabela 2.4 apresentada a seguir, retirada da NBR 6118, a partir da umidade ambiente e da espessura fictícia da viga. 


\section{Pontifícia Universidade Catálica \\ DO RIO DE JANEIRO}

Tabela 2.4 - Valores característicos superiores da deformação especifica de retração e do coeficiente de fluência.

\begin{tabular}{|c|c|c|c|c|c|c|c|c|c|c|}
\hline \multicolumn{3}{|c|}{$\begin{array}{c}\text { Umidade média } \\
\text { ambiente } \\
\%\end{array}$} & \multicolumn{2}{|c|}{40} & \multicolumn{2}{|c|}{55} & \multicolumn{2}{|c|}{75} & \multicolumn{2}{|c|}{90} \\
\hline \multicolumn{3}{|c|}{$\begin{array}{l}\text { Espessura fictícia } \\
2 A_{\mathrm{c}} / u \\
\mathrm{~cm}\end{array}$} & 20 & 60 & 20 & 60 & 20 & 60 & 20 & 60 \\
\hline \multirow{3}{*}{$\begin{array}{c}\varphi\left(t_{\infty}, t_{0}\right) \\
\text { Concreto } \\
\text { das classes } \\
\text { C20 a C45 }\end{array}$} & \multirow{9}{*}{$\begin{array}{c}t_{0} \\
\text { dias }\end{array}$} & 5 & 4,6 & 3,8 & 3,9 & 3,3 & 2,8 & 2,4 & 2,0 & 1,9 \\
\hline & & 30 & 3,4 & 3,0 & 2,9 & 2,6 & 2,2 & 2,0 & 1,6 & 1,5 \\
\hline & & 60 & 2,9 & 2,7 & 2,5 & 2,3 & 1,9 & 1,8 & 1,4 & 1,4 \\
\hline$\varphi\left(t_{\infty}, t_{0}\right)$ & & 5 & 2,7 & 2,4 & 2,4 & 2,1 & 1,9 & 1,8 & 1,6 & 1,5 \\
\hline $\begin{array}{l}\text { Concreto } \\
\text { das classes }\end{array}$ & & 30 & 2,0 & 1,8 & 1,7 & 1,6 & 1,4 & 1,3 & 1,1 & 1,1 \\
\hline C50 a C90 & & 60 & 1,7 & 1,6 & 1,5 & 1,4 & 1,2 & 1,2 & 1,0 & 1,0 \\
\hline \multirow{3}{*}{$\varepsilon_{\mathrm{cs}}\left(t_{\infty}, t_{0}\right) \%$} & & 5 & $-0,53$ & $-0,47$ & $-0,48$ & $-0,43$ & $-0,36$ & $-0,32$ & $-0,18$ & $-0,15$ \\
\hline & & 30 & $-0,44$ & $-0,45$ & $-0,41$ & $-0,41$ & $-0,33$ & $-0,31$ & $-0,17$ & $-0,15$ \\
\hline & & 60 & $-0,39$ & $-0,43$ & $-0,36$ & $-0,40$ & $-0,30$ & $-0,31$ & $-0,17$ & $-0,15$ \\
\hline
\end{tabular}

Fonte: ABNT NBR 6118/2014.

\subsubsection{Perda por retração}

A perda por retração se deve à perda de volume natural do concreto resultante de sua solidificação. Para o cálculo desta ação é utilizada o valor de deformação especifica $\varepsilon_{\mathrm{cs}}$ que pode ser obtido na mesma tabela apresentada no item anterior retirada da NBR 6118. Admite-se também na pós-tensão, de forma simplificada, que a deformação do concreto é igual à do aço.

$\Delta \sigma_{\text {retração }}=\varepsilon_{c S}\left(t_{\infty}, t_{0}\right) * E_{a}$

Onde,

$\Delta \sigma_{\text {retração }}$ é a perda por retração;

$\varepsilon_{c s}$ é o valor da deformação especifica no infinito;

$\mathrm{E}_{\mathrm{a}}$ é o modulo de elasticidade do aço, igual a $195 \mathrm{GPa}$. 


\subsubsection{Perda por relaxação}

Devido à relaxação do aço uma cordoalha tracionada e mantida com comprimento constante apresentará uma perda de tração. O valor desta perda é normalmente fornecido pelo fabricante no formato de uma porcentagem da tensão na armadura de protensão no instante da aplicação da força de tração.

$\Delta \sigma_{\text {relaxação }}=P_{\text {relaxação }} * \sigma_{0}$

Onde,

$\Delta \sigma_{\text {relaxação é a perda por relaxação; }}$

Prelaxação é o valor da perda máxima em \%;

$\sigma_{0}$ é a tensão aplicada na armadura pelo macaco.

\subsection{Tensões limites}

Durante o dimensionamento do concreto protendido é necessário a verificação da armadura em dois momentos. Uma primeira verificação ( $1^{\text {a }}$ Fase ou Fase 1$)$ considera o momento no qual as cordoalhas são primeiramente tensionadas e uma segunda ( $2^{\mathrm{a}}$ Fase ou Fase 2) considera a estrutura já terminada e em uso.

Para a $1^{\mathrm{a}}$ Fase portanto são consideradas como tensões limites $50 \%$ do $\mathrm{f}_{\mathrm{cd}}$, levando em conta o processo de ganho de resistência do concreto e o momento que a armadura é tensionada, e $\mathrm{f}_{\mathrm{td}}$, considerado neste trabalho como sendo igual a $10 \%$ do $\mathrm{f}_{\mathrm{cd}}$ nominal do concreto utilizado.

$\sigma_{t, l i m}=0,1 * \frac{f_{c k}}{1,4}$ 
$\sigma_{c, l i m}=0,5 * \frac{f_{c k}}{1,4}$

Onde,

$\sigma_{t, \lim }$ é a tensão limite de tração na Fase 1;

$\sigma_{\mathrm{c}, \mathrm{lim}}$ é a tensão limite de compressão na Fase 1;

$\mathrm{f}_{\mathrm{ck}}$ é a resistência característica do concreto.

$\mathrm{Na} 2^{\mathrm{a}}$ Fase as tensões limites são o $\mathrm{f}_{\mathrm{cd}}$ e $\mathrm{f}_{\mathrm{td}}\left(10 \%\right.$ do $\left.\mathrm{f}_{\mathrm{cd}}\right)$ nominal do concreto.

$\sigma_{t, l i m}=0,1 * \frac{f_{c k}}{1,4}$

$\sigma_{c, l i m}=\frac{f_{c k}}{1,4}$

Onde,

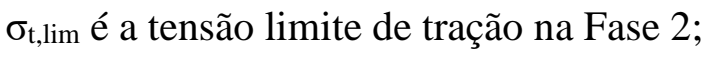

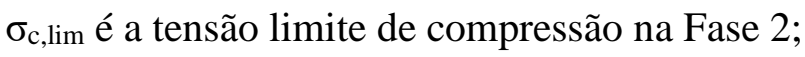

$\mathrm{f}_{\mathrm{ck}}$ é a resistência característica do concreto.

\subsection{Tensões finais}

As tensões finais devem ser avaliadas do mesmo modo como discutido no item 2.8, levando em conta duas fases de carregamento distintas no tempo. 


\section{Pontifícia Universidade Catálica

Durante a $1^{\mathrm{a}}$ Fase de carregamento deve ser considerado como carga atuante o peso próprio do elemento estrutural e a carga de protensão sendo afetada somente pelas perdas imediatas.

$$
\begin{aligned}
& \sigma_{i}(x)=\frac{M_{p p}(x) * y_{i}(x)}{I(x)}-\left(\frac{F_{\text {cabos }}(x)}{A_{t}(x)}+\frac{F_{c a b o s}(x) * e(x) * y_{i}(x)}{I(x)}\right) \\
& \sigma_{s}(x)=-\frac{M_{p p}(x) * y_{s}(x)}{I(x)}+\left(-\frac{F_{c a b o s}(x)}{A_{t}(x)}+\frac{F_{c a b o s}(x) * e(x) * y_{s}(x)}{I(x)}\right)
\end{aligned}
$$

Onde,

$$
F_{\text {cabos }}(x)=\left(\sigma_{\text {macaco }}-\sigma_{\text {Perdas imediatas }}\right) * A_{\text {cabo }} * n_{\text {cabos }} ;
$$

$\sigma_{\mathrm{i}}(\mathrm{x})$ é a tensão na face inferior da seção $\mathrm{x}$;

$\sigma_{\mathrm{s}}(\mathrm{x})$ é a tensão na face superior da seção x;

$\mathrm{M}_{\mathrm{pp}}(\mathrm{x})$ é o momento devido ao peso próprio na seção x;

$\mathrm{y}_{\mathrm{i}}(\mathrm{x})$ é a altura do centroide em relação à face inferior na seção $\mathrm{x}$;

$\mathrm{y}_{\mathrm{s}}(\mathrm{x})$ é a altura do centroide em relação à face superior na seção $\mathrm{x}$;

e(x) é a excentricidade da armadura na seção x;

Já na $2^{\mathrm{a}}$ Fase devem aplicadas o resto das cargas permanente e variáveis além de considerar as perdas lentas atuando sob as tensões resultantes da protensão.

$$
\sigma_{i}(x)=\frac{M_{t}(x) * y_{i}(x)}{I(x)}-\left(\frac{F_{c a b o s}(x)}{A_{t}(x)}+\frac{F_{c a b o s}(x) * e(x) * y_{i}(x)}{I(x)}\right)
$$




$$
\begin{array}{r}
\text { Pontificia }_{\text {Uiversidade }} \text { C }_{\text {Atólica }} \\
\sigma_{s}(x)=-\frac{M_{t}(x) * y_{s}(x)}{I(x)}+\left(-\frac{F_{\text {cabos }}(x)}{A_{t}(x)}+\frac{F_{\text {cabos }}(x) * e(x) * y_{s}(x)}{I(x)}\right)
\end{array}
$$

Onde,

$F_{\text {cabos }}(x)=\left(\sigma_{\text {macaco }}-\sigma_{\text {Perdas totais }}\right) * A_{\text {cabo }} * n_{\text {cabos }} ;$

$\sigma_{\mathrm{i}}(\mathrm{x})$ é a tensão na face inferior da seção $\mathrm{x}$;

$\sigma_{\mathrm{s}}(\mathrm{x})$ é a tensão na face superior da seção $\mathrm{x}$;

$\mathrm{M}_{\mathrm{t}}(\mathrm{x})$ é o momento total devido a todos os carregamentos na seção x;

$\mathrm{y}_{\mathrm{i}}(\mathrm{x})$ é a altura do centroide em relação à face inferior na seção $\mathrm{x}$;

$\mathrm{y}_{\mathrm{s}}(\mathrm{x})$ é a altura do centroide em relação à face superior na seção $\mathrm{x}$;

e(x) é a excentricidade da armadura na seção x; 


\section{METODOLOGIA}

Este trabalho busca criar uma interface gráfica pela qual as contas demonstradas anteriormente são executadas de forma automatizada. Para isto foi utilizado o programa MATLAB App Designer versão R2021b da empresa MathWorks, este programa permite a utilização das funções matemáticas do programa MATLAB através de uma linguagem própria baseada em C para a criação de aplicativos que podem ser rodados sem a necessidade de instalação do próprio MATLAB.

Assim este projeto busca automatizar as seguintes áreas:

- Obtenção das propriedades geométricas das seções de uma viga bia-apoiada;

- Traçado dos diagramas de momento fletor e cortante;

- Cálculo da força de protensão;

- Quantidade de cordoalhas necessárias;

- Cálculo das perdas;

- Verificação do dimensionamento.

Nos capítulos a seguir serão apresentadas a interface gráfica desenvolvida e os resultados obtidos através de sua utilização. 


\section{DESIGN DO SOFTWARE}

A interface gráfica do aplicativo desenvolvido funciona se utilizando de múltiplas abas para as diferentes etapas do dimensionamento de uma viga protendida.

\subsection{Dados da viga}

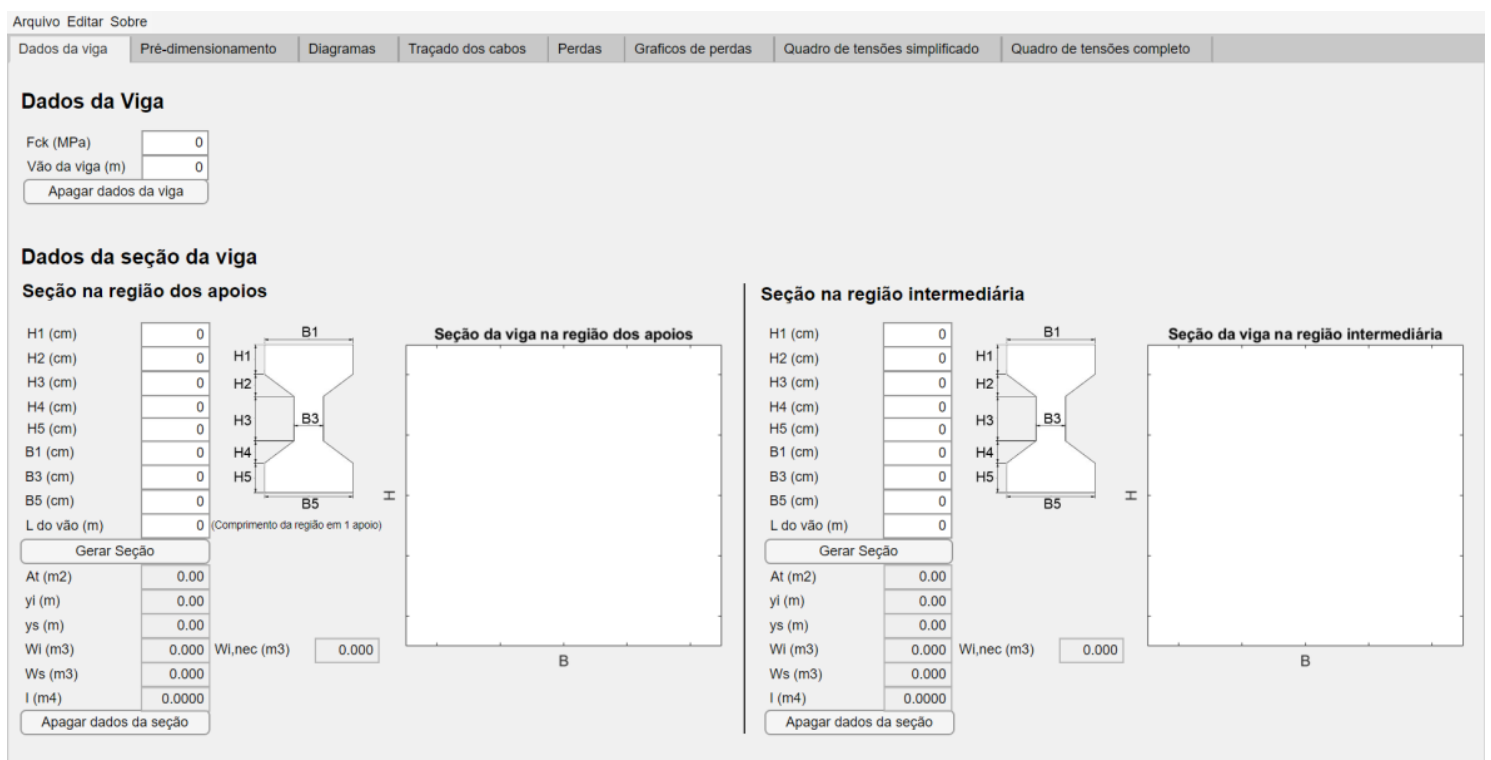

Figura 4.1 - Aba "Dados da viga" do programa desenvolvido. Fonte: Autor.

Nesta aba o usuário deve fornecer o $\mathrm{f}_{\mathrm{ck}}$ do concreto utilizado, o vão da viga e a geometria das seções da viga.

Como explicado anteriormente, é possível dimensionar uma viga com seção variável. Para fazer isso é necessário incluir dados para a "Seção na região dos apoios" e "Seção na região intermediária" incluindo o comprimento L no qual esta seção é constante, a região de transição e seus dados são calculados automaticamente. Caso somente uma seção seja preenchida o programa assume uma viga de seção constante.

Ao clicar no botão "Gerar Seção" as propriedades geométricas da seção serão calculadas e o desenho da seção serão gerados. 


\section{Pontifícia Universidade Catálica $_{\text {a }}$}

\subsection{Pré-Dimensionamento}

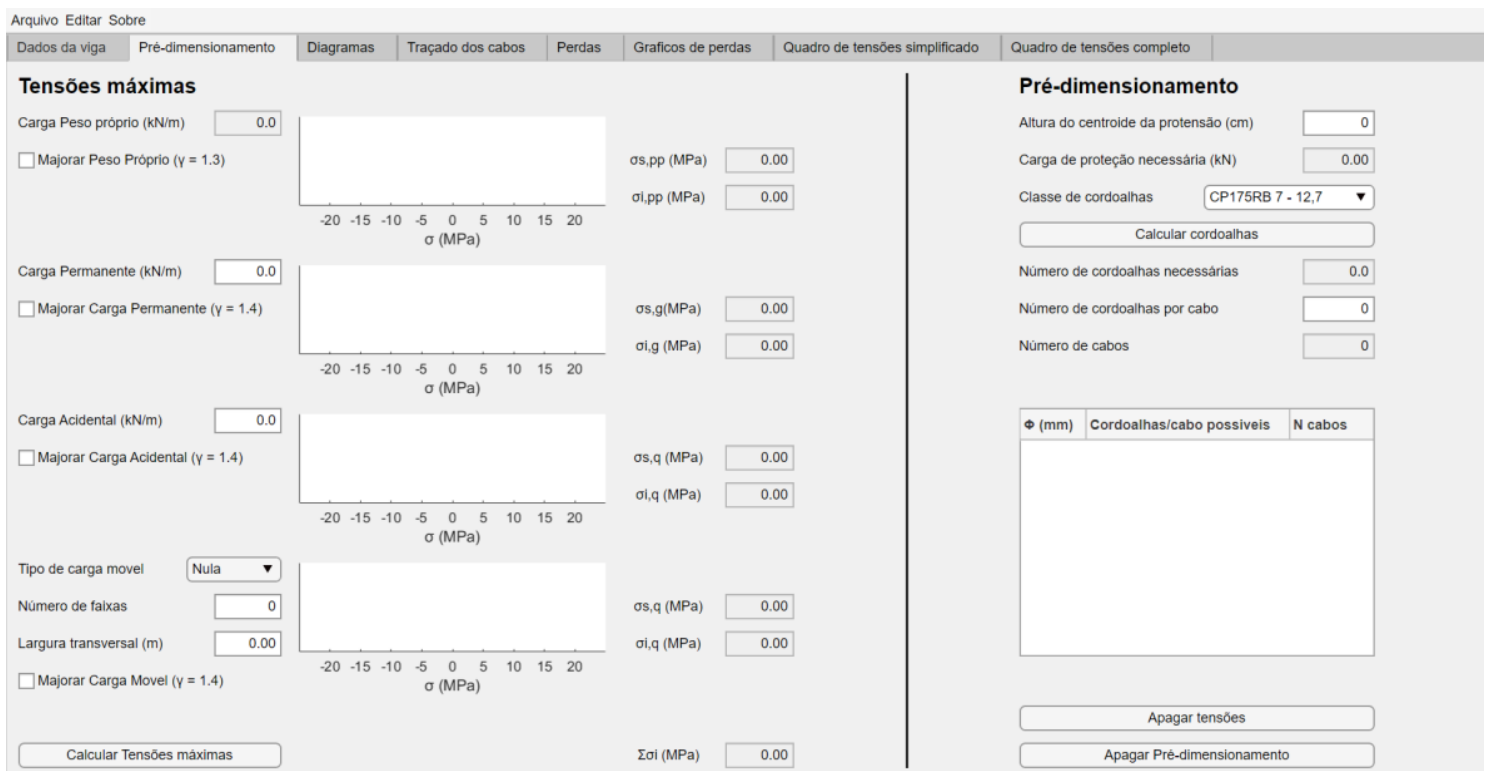

Figura 4.2 - Aba "Pré-Dimensionamento" do programa desenvolvido. Fonte: Autor.

Nesta aba o usuário deve preencher os valores dos carregamentos atuantes sobre a viga e os dados necessários para o cálculo da força de protensão além da determinação do tipo de cordoalha utilizado, sua quantidade e distribuição.

Dentre as cargas a única calculada de forma automática conforme foi descrito no item 2.4.1. Todas as cargas podem ser majoradas de forma automática através da caixa de seleção que se encontra em baixo do valor do carregamento, os valores dos coeficientes de ponderação são determinados automaticamente baseados nos valores $\gamma_{\mathrm{f}}$ da norma NBR 6118/2014 porém podem ser alterados pelo usuário na aba Editar Parâmetros descrita no item 4.9. 


\section{Pontifícia Universidade Catálica

Tabela 4.1 - Coeficiente $\gamma_{\mathrm{f}}$ de ponderação das ações atuantes.

\begin{tabular}{|c|c|c|c|c|c|c|c|c|}
\hline \multirow{3}{*}{$\begin{array}{c}\text { Combinações } \\
\text { de ações }\end{array}$} & \multicolumn{8}{|c|}{ Ações } \\
\hline & \multicolumn{2}{|c|}{$\begin{array}{l}\text { Permanentes } \\
\text { (g) }\end{array}$} & \multicolumn{2}{|c|}{$\begin{array}{l}\text { Variáveis } \\
\qquad(q)\end{array}$} & \multicolumn{2}{|c|}{$\begin{array}{l}\text { Protensão } \\
\qquad(p)\end{array}$} & \multicolumn{2}{|c|}{$\begin{array}{l}\text { Recalques de } \\
\text { apoio } \\
\text { e retração }\end{array}$} \\
\hline & $D$ & $F$ & $G$ & $T$ & $D$ & $F$ & $D$ & $F$ \\
\hline Normais & $1,4^{a}$ & 1,0 & 1,4 & 1,2 & 1,2 & 0,9 & 1,2 & 0 \\
\hline $\begin{array}{l}\text { Especiais ou } \\
\text { de construção }\end{array}$ & 1,3 & 1,0 & 1,2 & 1,0 & 1,2 & 0,9 & 1,2 & 0 \\
\hline Excepcionais & 1,2 & 1,0 & 1,0 & 0 & 1,2 & 0,9 & 0 & 0 \\
\hline $\begin{array}{l}\text { onde } \\
\quad \text { é desfavor } \\
\text { a Para as carga } \\
\text { cialmente as } \\
\end{array}$ & ma & s, esse & & & & próp & & $\begin{array}{l}\text { ra. } \\
\text { espe- }\end{array}$ \\
\hline
\end{tabular}

Fonte: ABNT NBR 6118/2014.

Na região do Pré-dimensionamento o usuário deve fornecer o valor da altura do centroide de protensão que gerará o cálculo da força de protensão. Tendo feito isto o usuário poderá preencher a classe da cordoalha, sua quantidade e distribuição em cabos.

\subsection{Diagramas}

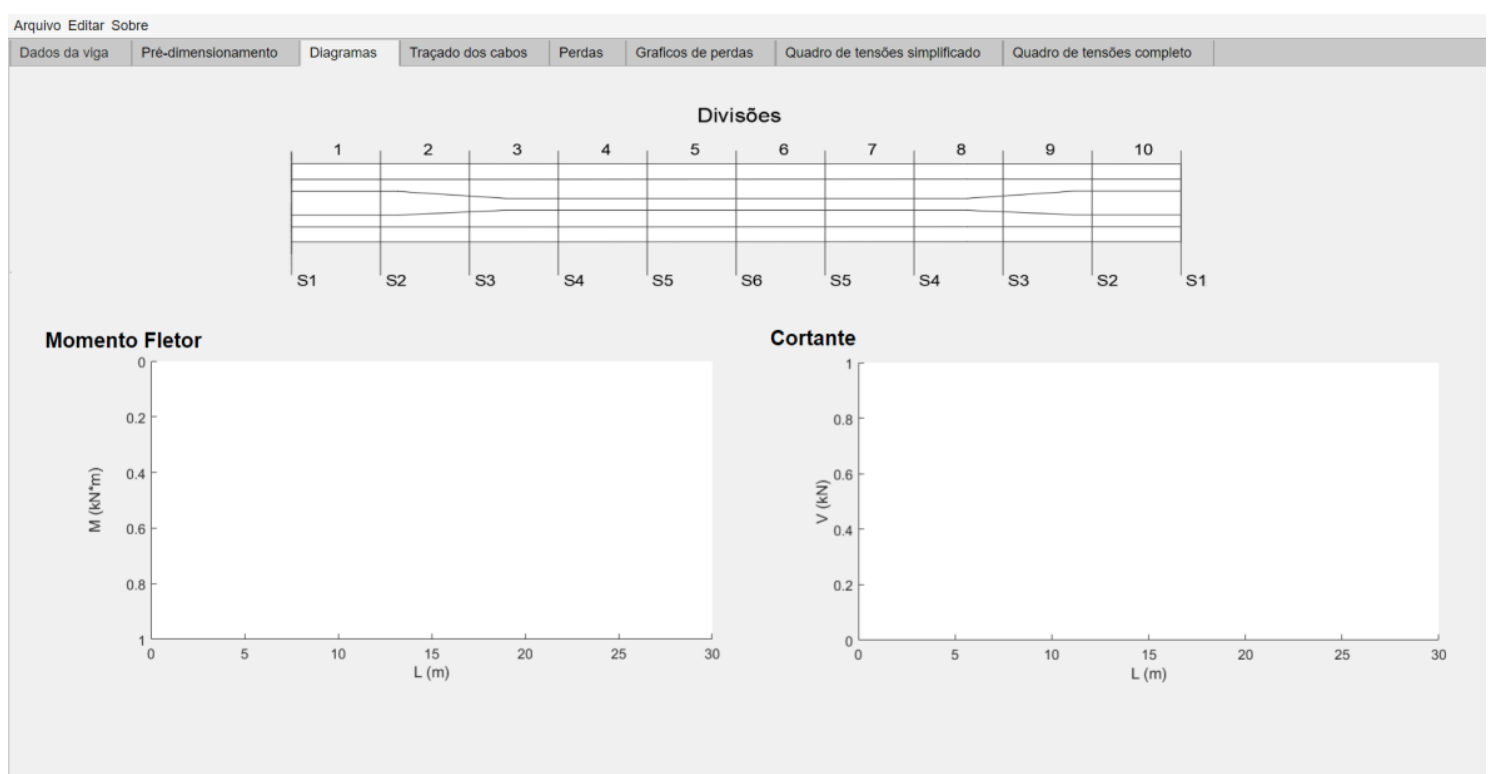

Figura 4.3 - Aba "Diagramas" do programa desenvolvido. Fonte: Autor.

Os diagramas de momento fletor e cortante serão automaticamente gerados após a determinação dos carregamentos. 


\section{Pontifícia Universidade Catálica $_{\text {a }}$

\subsection{Traçado dos cabos}

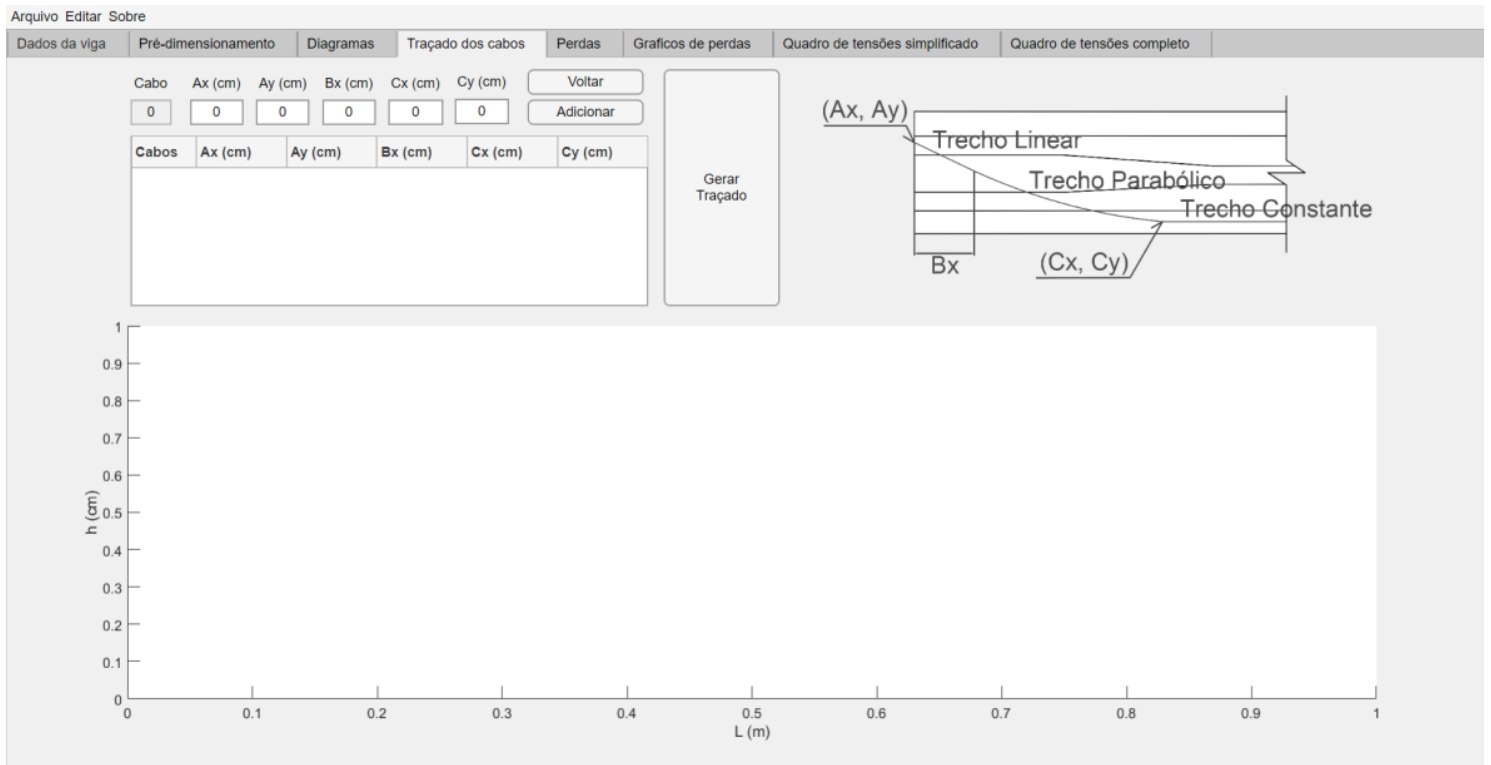

Figura 4.4 - Aba "Traçado dos cabos" do programa desenvolvido. Fonte: Autor.

Após o preenchimento do pré-dimensionamento é possível executar o traçado dos cabos. O usuário deve preencher os dados da geometria do cabo conforme descritos no item 2.6 e, após o fornecimento dos dados de todos os cabos, é possível gerar o diagrama com o desenho dos cabos. 


\section{Pontif́́cia Universidade C Cátólica

\subsection{Perdas}

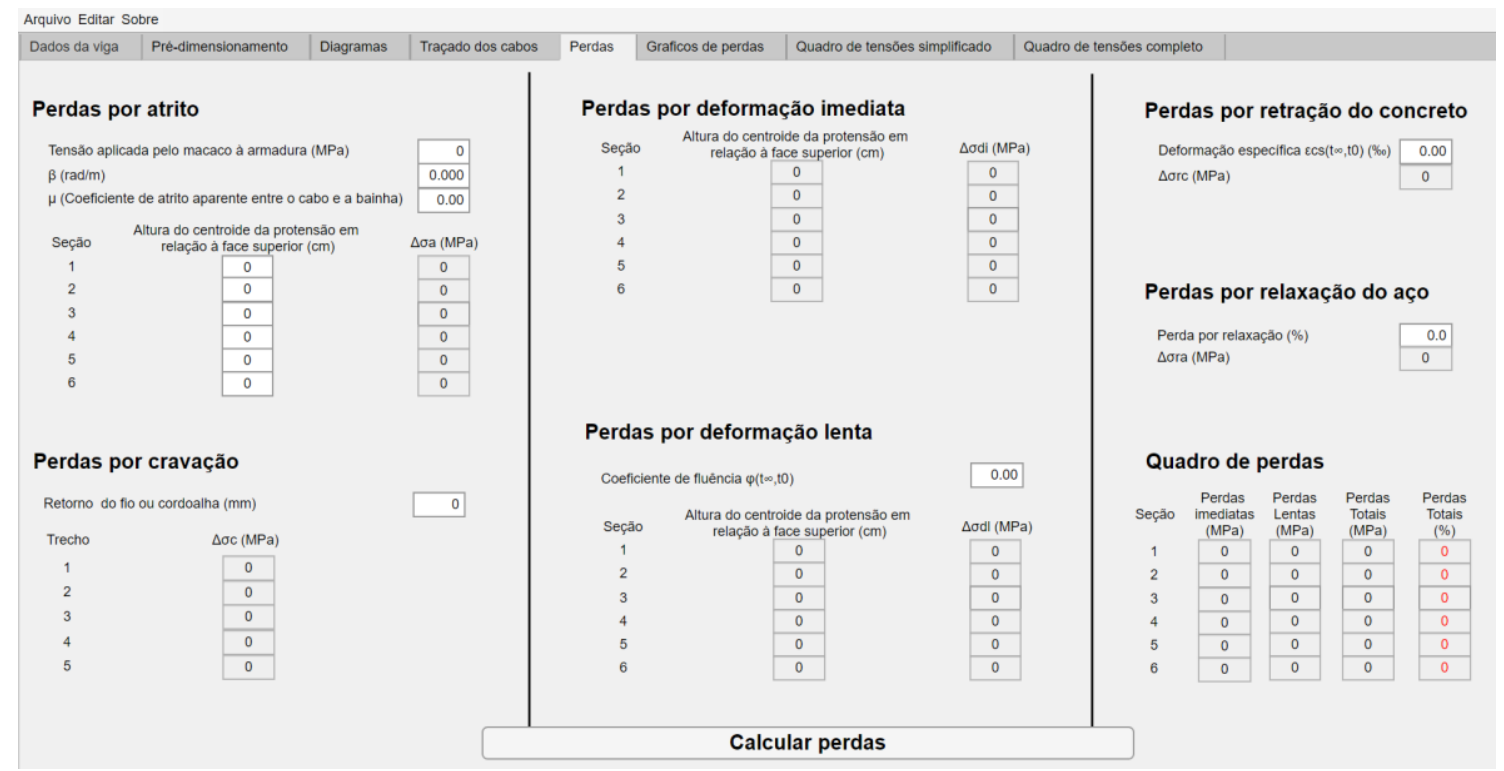

Figura 4.5 - Aba "Perdas" do programa desenvolvido.

Fonte: Autor.

Como discutido no item 2.8, a aba "Perdas" possui o cálculo das perdas imediatas e lentas que ocorrem sobre a força de protensão além de um quadro final com as perdas nas diferentes seções tanto em valor de tensão (MPa) e em porcentagem. Apesar da automação permitir a execução dos cálculos para um grande número de seções, foi definido uma divisão da viga em 10 regiões e a avaliação das perdas em seis seções tendo em vista que os valores começariam a se espelhar a partir do meio do vão, essa escolha foi feita por questão de praticidade e por se considerar que trará resultados verossímeis.

\section{Divisões}

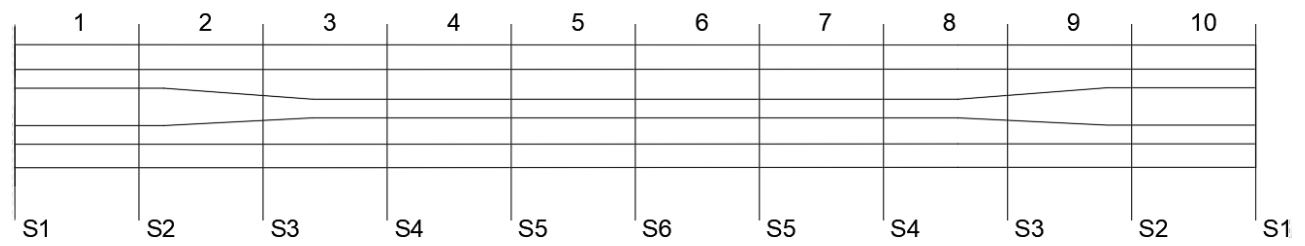

Figura 4.6 - Divisões e seções da viga numerados.

Fonte: Autor. 


\section{Pontifícia Universidade Catálica

Para o cálculo das perdas pro atrito, deformação imediata e deformação lenta é necessário saber a posição do centroide de protensão. Esse valor pode ser definido de duas formas, caso o usuário preencha a aba "Traçado dos cabos" (4.4) o cálculo destes centroides será executado de forma automática pelo programa porem também é possível o preenchimento manual pelo próprio usuário na região do cálculo de perdas por atrito de forma independente ao traçado dos cabos.

\subsection{Gráficos de perdas}

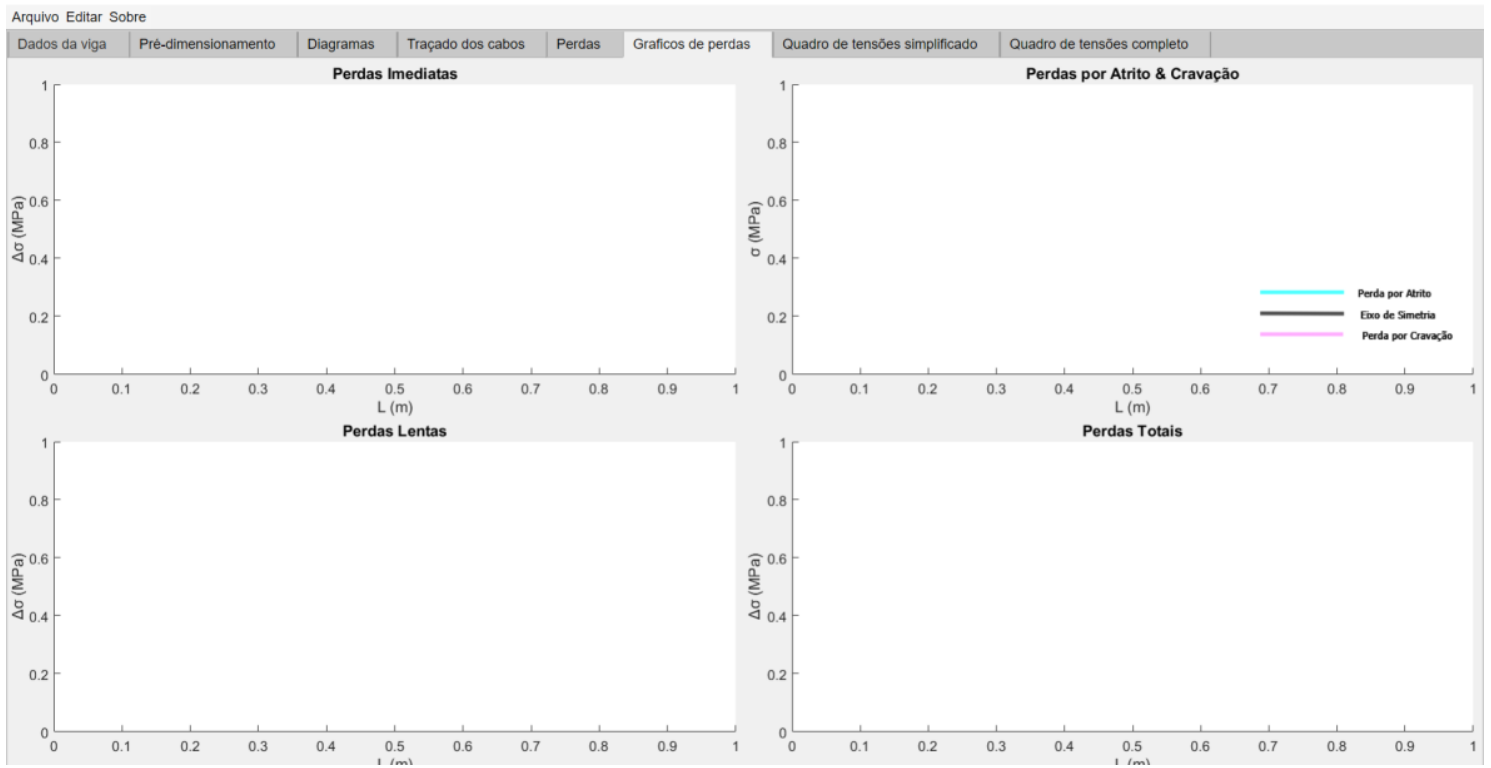

Figura 4.7 - Aba "Gráficos de perdas" do programa desenvolvido. Fonte: Autor.

Contendo quatro gráficos diferentes referentes às perdas, esta aba é preenchida automaticamente após o cálculo das perdas de força de protensão ao longo da viga. São mostradas nesta aba os valores das perdas imediatas, perdas lentas, perdas totais uma comparação da força de protensão após a perda por atrito e a por cravação, demonstrando sua simetria, ao longo do comprimento da viga. 


\subsection{Quadro de tensões simplificado}

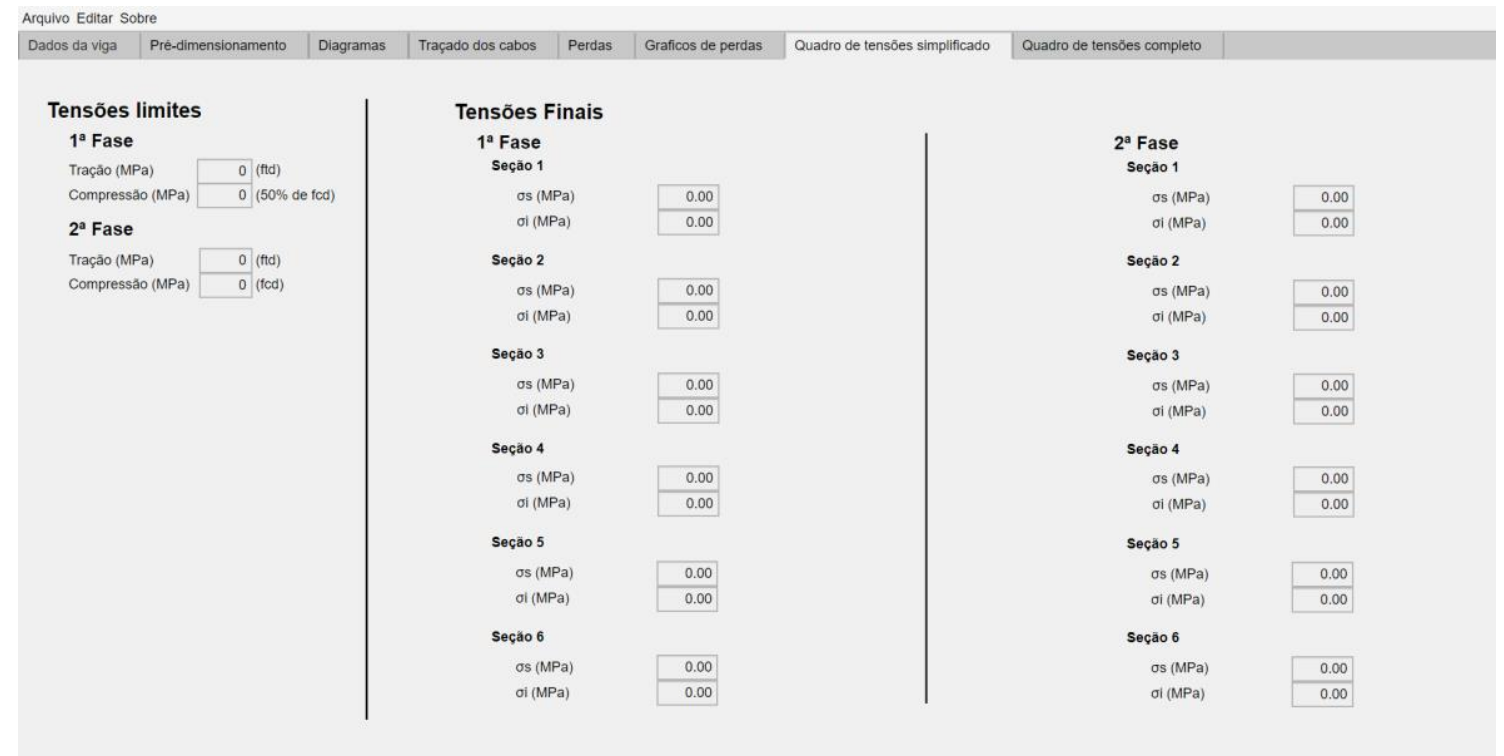

Figura 4.8 - Aba "Quadro de tensões simplificado" do programa desenvolvido. Fonte: Autor.

Nesta aba é possível observar os valores das tensões limites calculados automaticamente a partir do valor de $\mathrm{f}_{\mathrm{ck}}$ fornecido pelo usuário na aba "Dados da viga" e as tensões finais calculadas após o cálculo das perdas. Estes valores seguem a lógica de duas fases como é explicado no item 2.9 e 2.10 deste trabalho.

Caso algum valor de tensão final se encontre fora dos limites calculados este número aparecerá com coloração vermelha, caso contrário o valor aparecerá verde. 


\subsection{Quadro de tensões completo}

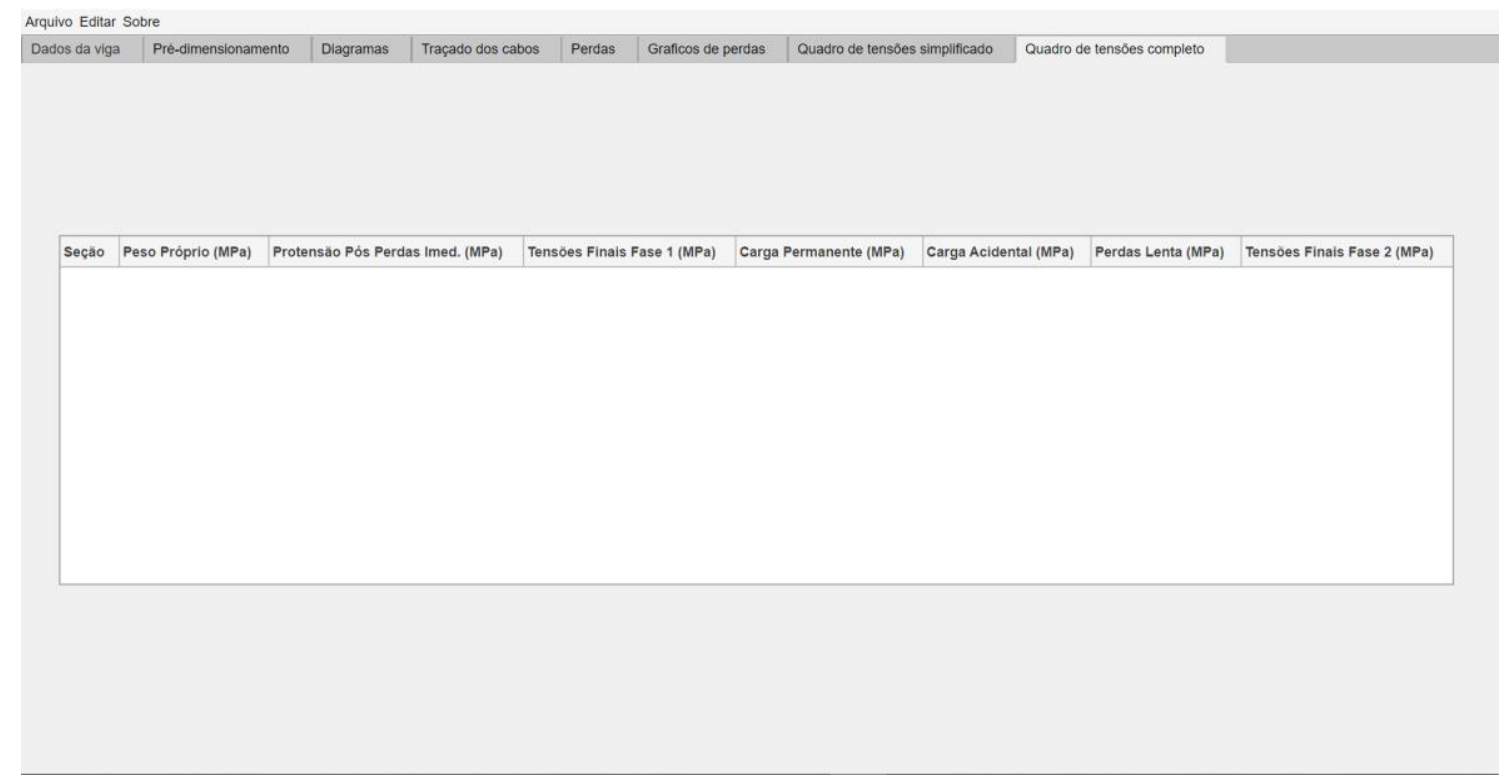

Figura 4.9 - Aba "Quadro de tensões completo" do programa desenvolvido. Fonte: Autor.

Demonstrando os cálculos das tensões finais de forma mais completa permitindo a avaliação por parte do usuário quanto a possíveis mudanças e maior controle sobre o dimensionamento, nesta aba são mostrados para as diferentes seções os valores das tensões devido às diferentes cargas, a tensão resultante da protensão após as perdas imediatas, as perdas lentas em forma de tensão e os valores de tensão final na Fase 1 e 2. 


\subsection{Editar parâmetros}

\begin{tabular}{|l|}
\hline A Parâmetros \\
Coeficiente yc do Concreto: \\
\hline 1.4 \\
Coeficiente ys do Aço: \\
\hline 1.15 \\
Coeficiente yf da carga de Peso Próprio: \\
\hline 1.3 \\
\hline Coeficiente yf da carga Permanente: \\
\hline 1.4 \\
\hline Coeficiente yf da carga Acidental: \\
\hline 1.4 \\
\hline Coeficiente yf da carga Acidental Móvel: \\
\hline 1.4 \\
\hline Coeficiente yf da ação da Força de Protensão: \\
\hline 1.2 \\
\hline
\end{tabular}

Figura 4.10 - Aba "Editar Parâmetros" do programa desenvolvido. Fonte: Autor.

O programa apresenta em sua programação os valores para diferentes coeficientes relevantes para o cálculo definidos conforme a norma ABNT NBR 6118/2014. Estes coeficientes são os coeficientes de ponderação de ações $\left(\gamma_{\mathrm{f}}\right)$ para cargas permanentes, variáveis e de protensão, e os coeficientes de ponderação das resistências no estado-limite ultimo do concreto $\left(\gamma_{c}\right)$ e aço $\left(\gamma_{s}\right)$. Estes valores podem ser alterados nesta aba pelo usuário caso deseje.

Tabela 4.2 - Coeficiente $\gamma_{\mathrm{f}}$ de ponderação das ações atuantes.

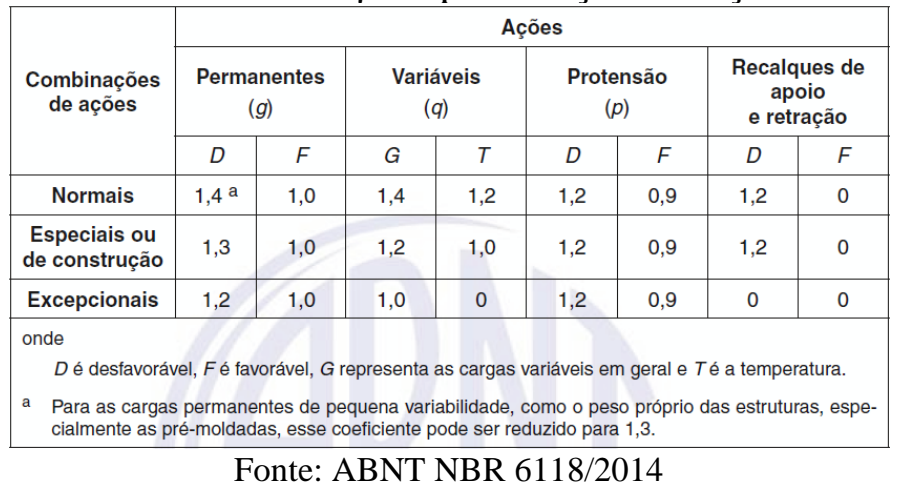


Tabela 4.3 - Valores dos coeficientes $\gamma_{\mathrm{c}}$ e $\gamma_{\mathrm{s}}$.

\begin{tabular}{|c|c|c|}
\hline Combinaçōes & $\begin{array}{c}\text { Concreto } \\
\gamma_{\mathrm{c}}\end{array}$ & $\begin{array}{c}\text { Aço } \\
\gamma_{\mathrm{S}}\end{array}$ \\
\hline Normais & 1,4 & 1,15 \\
\hline Especiais ou de construção & 1,2 & 1,15 \\
\hline Excepcionais & 1,2 & 1,0 \\
\hline
\end{tabular}

Fonte: ABNT NBR 6118/2014 


\section{RESULTADOS}

Neste capitulo serão apresentados os resultados obtidos através do aplicativo desenvolvido. Os resultados gerados são resultado da automação das formulas apresentadas anteriormente neste trabalho.

Os valores obtidos levam em conta uma viga bi-apoiada para um projeto de passarela com um vão de 20 metros e concreto $\mathrm{f}_{\mathrm{ck}} 50$. As regiões de apoio e transição medem ambas 1 metro. Os cálculos de validação da planilha são apresentados nos anexos A.

\subsection{Dados da viga}

Inicialmente são definidos os dados do material e da geometria da viga.

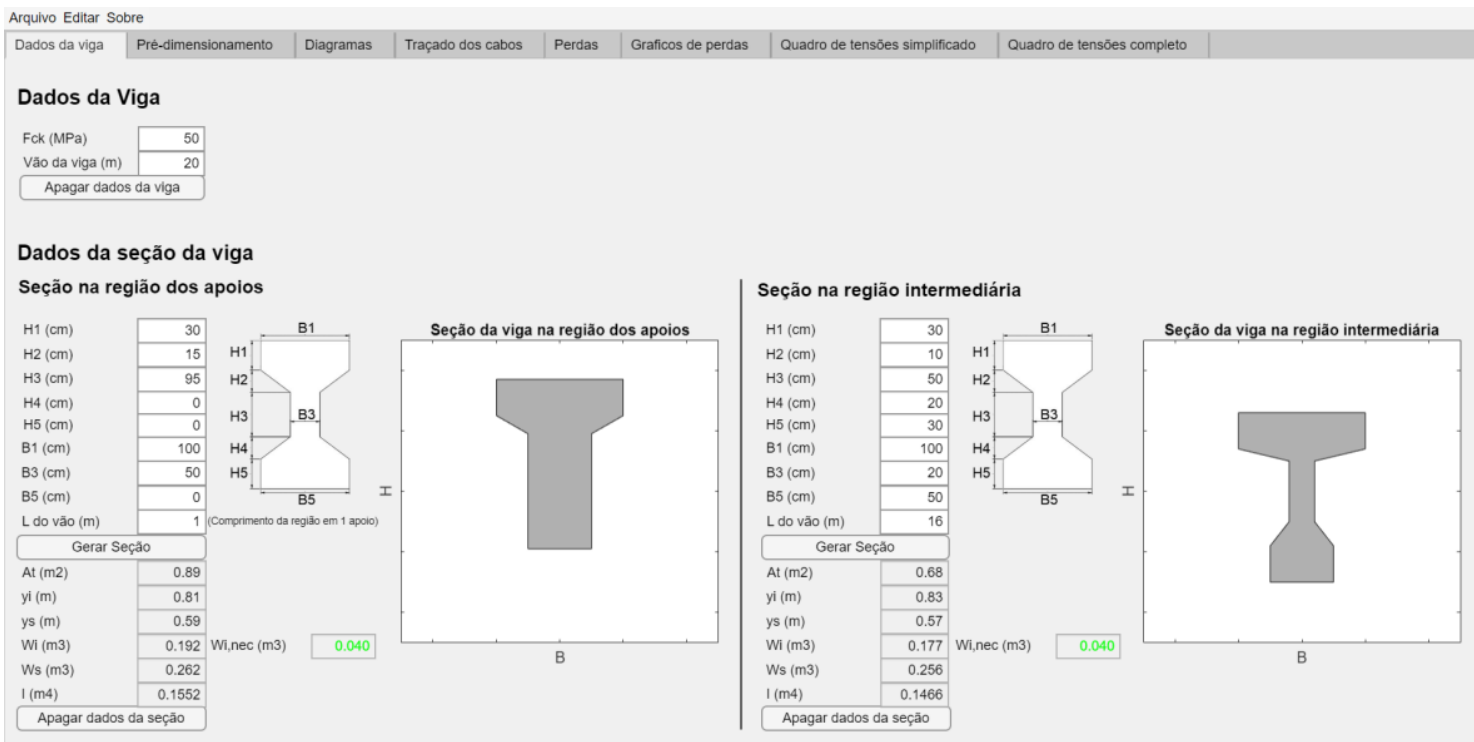

Figura 5.1 - Aba "Dados da viga" do programa preenchida. Fonte: Autor.

\subsubsection{Dados da viga}

Primeiramente são definidos a resistência característica de compressão do concreto e o vão da viga. 


\section{Pontifícia U UIVERS

\begin{tabular}{|c|c|}
\hline Fck (MPa) & 50 \\
\hline Vão da viga (m) & 20 \\
\hline \multicolumn{2}{|c|}{ Apagar dados da viga } \\
\hline
\end{tabular}

Figura 5.2 - $\mathrm{f}_{\mathrm{ck}}$ e comprimento do vão da viga exemplo. Fonte: Autor.

\subsubsection{Dados da seção da viga}

Em seguida deve-se definir a geometria das seções na região de apoio e na intermediaria da viga. Após a definição da geometria, os valores de $A_{t}, y_{i}, y_{s}, W_{i}, W_{s}, I$ e Carga de peso próprio serão calculadas de forma automatizada e o diagrama da seção da viga ao clicar no botão "Gerar seção".

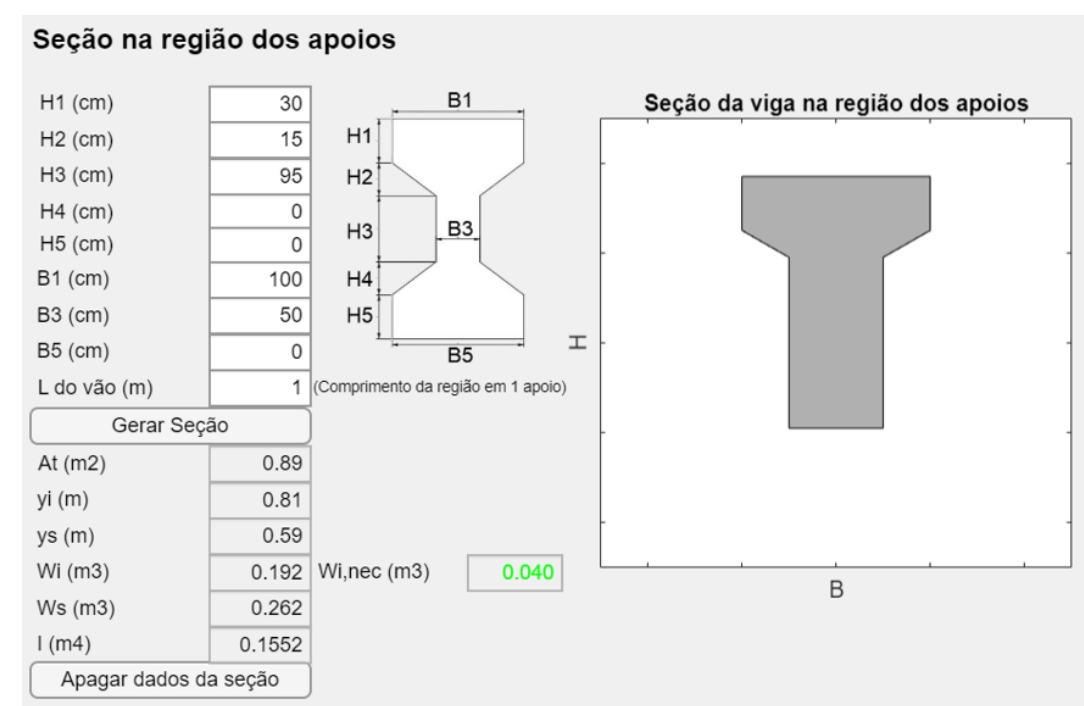

Figura 5.3 - Dados da seção na região do apoio da viga exemplo. Fonte: Autor. 


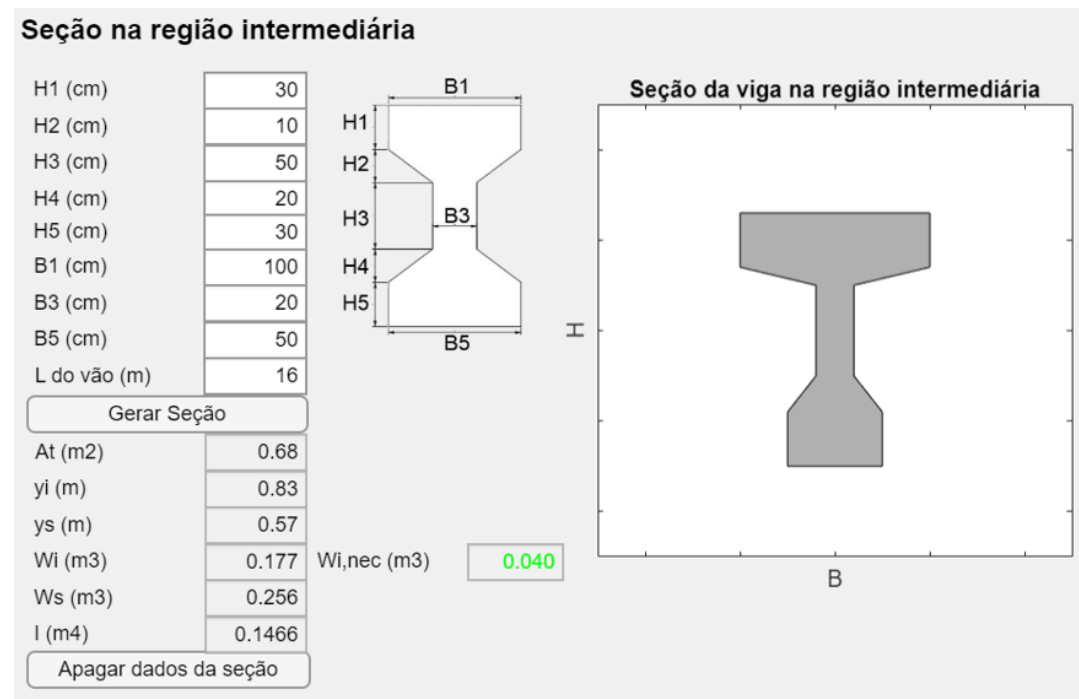

Figura 5.4 - Dados da seção na região intermediária da viga exemplo. Fonte: Autor.

\subsection{Tensões máximas}

Tendo determinado as seções da viga o próximo passo é a definição dos carregamentos atuantes. A definição dos carregamentos atuantes resultará no traçado dos diagramas de momento fletor e cortante e, a partir dos momentos máximos, a tensão máxima de tração atuante na viga. Este valor de tensão máximo será utilizado no prédimensionamento da armadura de protensão ainda na mesma aba do software. 


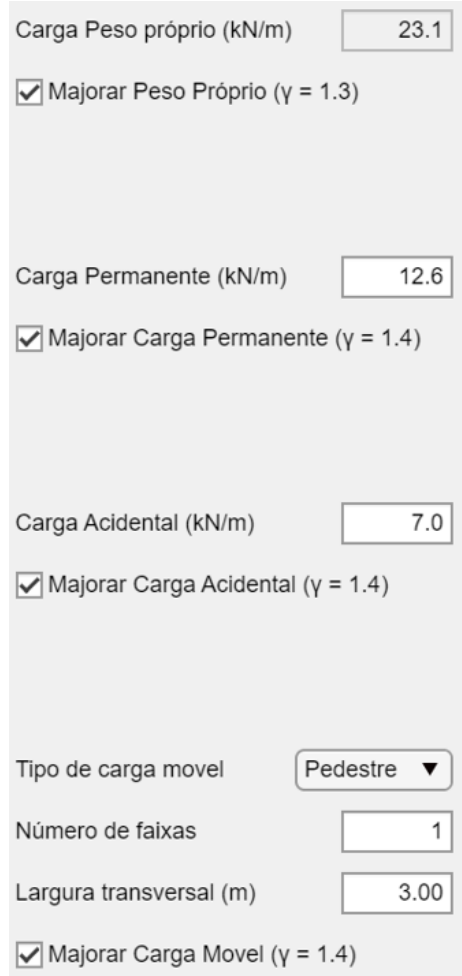

Figura 5.5 - Carregamentos atuantes sob a viga exemplo. Fonte: Autor.

Para a execução desta demonstração foi definido uma carga permanente de $9 \mathrm{kN} / \mathrm{m}$, carga acidental de $5 \mathrm{kN} / \mathrm{m}$ e uma carga móvel de pedestres $\left(5 \mathrm{kN} / \mathrm{m}^{2}\right)$ num comprimento transversal de 3 metro. A carga de peso próprio foi definida automaticamente como definido no item anterior e todas as cargas foram majoradas pelos coeficientes padrões do programa.

\begin{tabular}{|l|}
\hline Coeficiente yf da carga de Peso Próprio: \\
\hline 1.3 \\
\hline Coeficiente yf da carga Permanente: \\
\hline 1.4 \\
\hline Coeficiente yf da carga Acidental: \\
\hline 1.4 \\
\hline Coeficiente yf da carga Acidental Móvel: \\
\hline 1.4 \\
\hline
\end{tabular}

Figura 5.6 - Coeficientes de ponderação das cargas. Fonte: Autor. 


\section{Pontifícia Universidade Católica

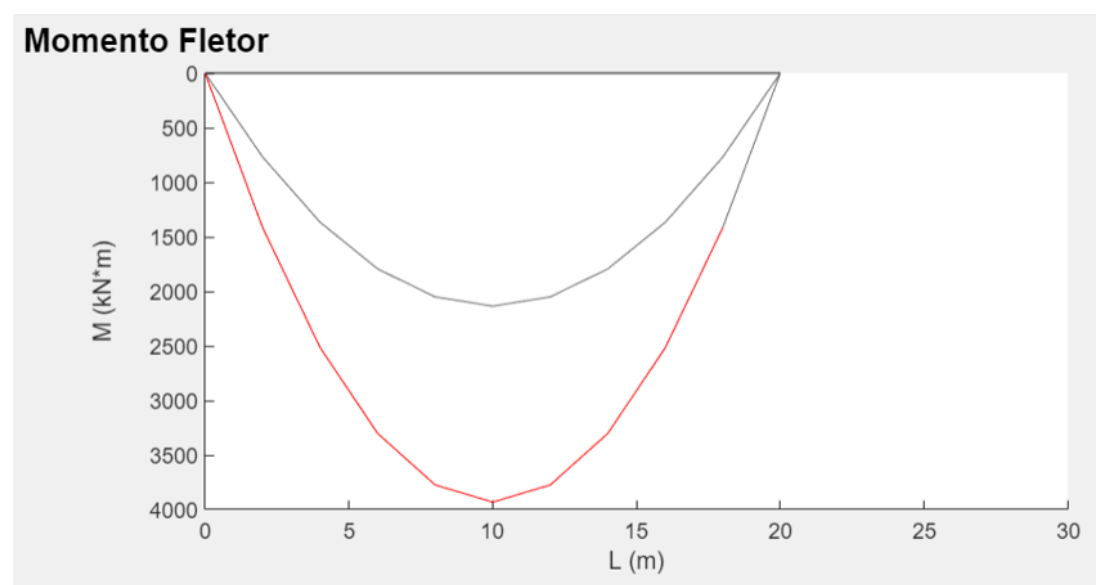

Figura 5.7 - Diagrama de momento fletor desenhado pelo programa. Fonte: Autor.

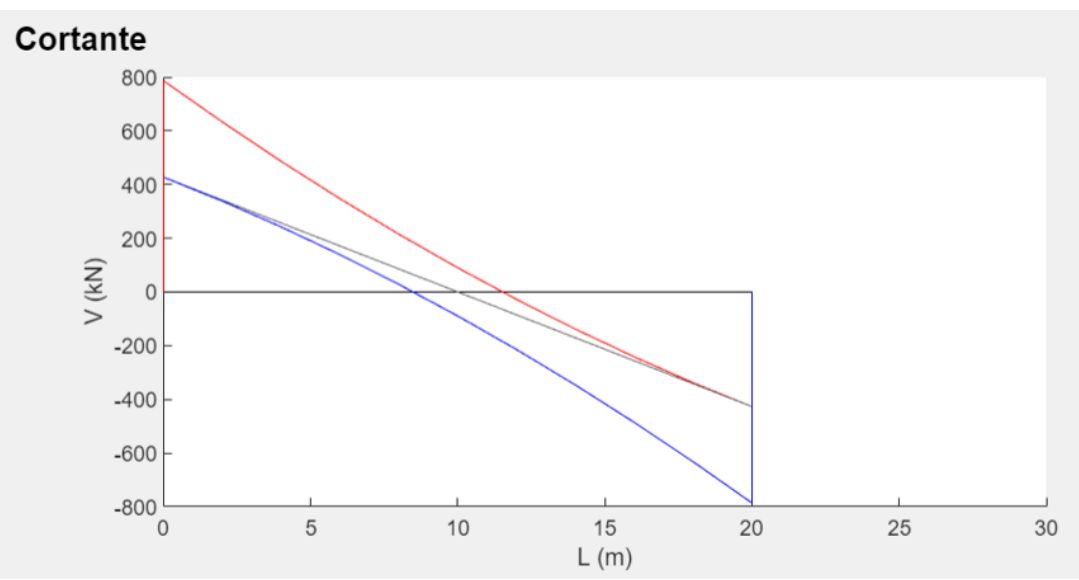

Figura 5.8 - Diagrama de cortante desenhado pelo programa. Fonte: Autor.

Para a verificação do diagrama de momento fletor e cortante foi utilizado o software de analise estrutural FTool.

$$
\begin{gathered}
C_{\text {linear }}=23,1+12,6+7,0=42,7 \mathrm{kN} / \mathrm{m} \\
C_{\text {móvel }}=(5 * 3 * 1,4) * C I A * C I V * C N F=(5 * 3 * 1,4) * 1,25 * 1,15 * 0,9 \\
=27,2 \mathrm{kN} / \mathrm{m}
\end{gathered}
$$

$\stackrel{42.70 \mathrm{kNm}}{\stackrel{\mathrm{kNm}}{\triangle}}$

Figura 5.9 - Carregamento linear atuante sobre a viga no FTool. Fonte: FTool. 
$27.20 \mathrm{kN} / \mathrm{m}$

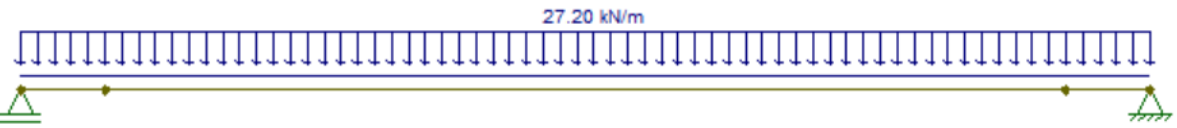

Figura 5.10- Carregamento móvel atuante sobre a viga no FTool. Fonte: FTool.

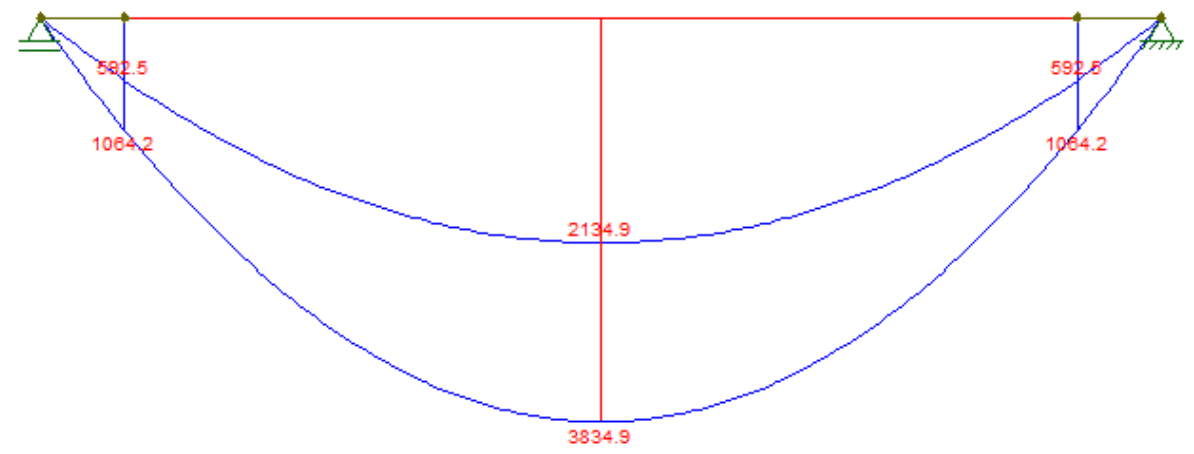

Figura 5.11 - Diagrama de momento fletor desenhado pelo programa FTool. Fonte: FTool.

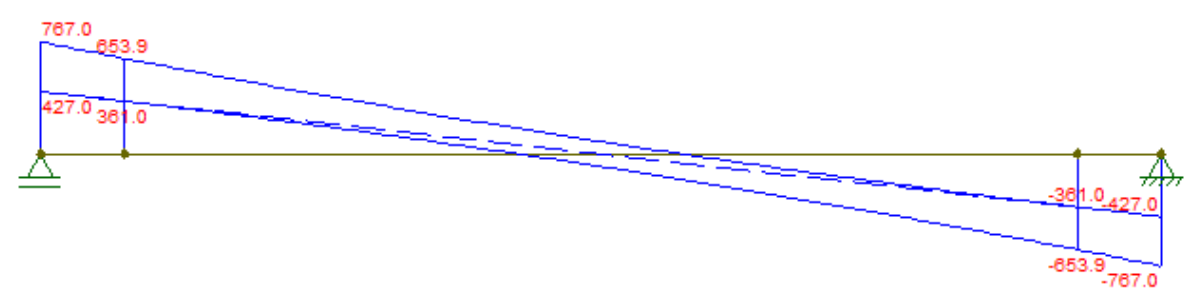

Figura 5.12 - Diagrama de cortante desenhado pelo programa FTool. Fonte: FTool.

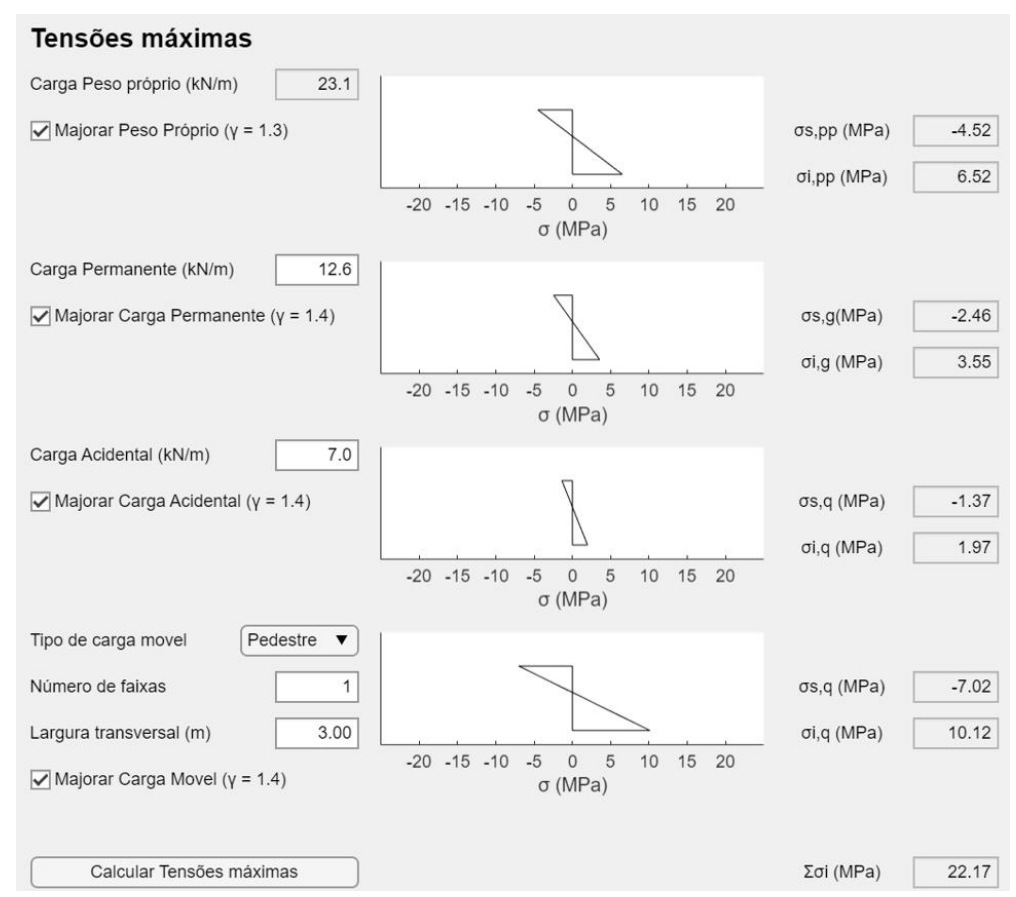

Figura 5.13 - Quadro de carregamentos completo da viga exemplo. Fonte: Autor. 
Após a obtenção destes valores também são calculados os valores de $\mathrm{W}_{\mathrm{i} \text {,necessário }}$.

\section{\begin{tabular}{l|l|l|} 
Wi (m3) & 0.177 & Wi,nec (m3) \\
\hline
\end{tabular}}

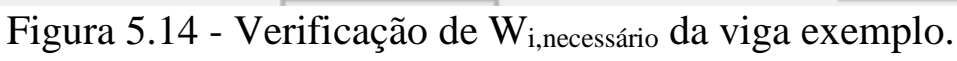

Fonte: Autor.

\subsection{Pré-dimensionamento}

Com os carregamentos definidos e a tensão máxima obtida pode-se obter a carga de protensão necessária a partir da entrada por parte do usuário da altura estimada do centroide de protensão e da formula definida em 2.5.

\section{Altura do centroide da protensão $(\mathrm{cm})$ \\ Carga de proteção necessária $(\mathrm{kN})$

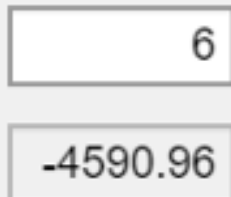

Figura 5.15 - Força de protensão da viga exemplo.

Fonte: Autor.

Tabela 5.1- Comparação com o resultado manual da força de protensão.

\begin{tabular}{|c|c|}
\hline Programa & Calc. Man. \\
\hline$-4590,96$ & $-4559,92$ \\
\hline
\end{tabular}

Fonte: Autor.

Tendo a carga de protensão necessária é possível a determinação da classe de cordoalha utilizada. Foi escolhida a utilização de cordoalhas CP175RB com 7 fios e diâmetro nominal de 15,2 milímetros. Assim serão considerados 3 cabos contendo 9 cordoalhas cada, totalizando 27 cordoalhas, um número adequado considerando o valor mínimo de 24 cordoalhas fornecido pelo software. 


\section{Pontifícia Universidade Catálica $_{\text {a }}$

\begin{tabular}{|c|c|c|c|c|}
\hline \multicolumn{5}{|c|}{ Pré-dimensionamento } \\
\hline \multicolumn{3}{|c|}{ Altura do centroide da protensão $(\mathrm{cm})$} & & 6 \\
\hline \multicolumn{3}{|c|}{ Carga de proteção necessária (kN) } & & .96 \\
\hline \multicolumn{2}{|c|}{ Classe de cordoalhas } & \multicolumn{2}{|c|}{ CP175RB 7 - 15,2 } & $\boldsymbol{\nabla}$ \\
\hline \multicolumn{5}{|c|}{ Calcular cordoalhas } \\
\hline \multicolumn{3}{|c|}{ Número de cordoalhas necessárias } & \multicolumn{2}{|c|}{24.0} \\
\hline \multicolumn{3}{|c|}{ Número de cordoalhas por cabo } & & 9 \\
\hline \multicolumn{3}{|c|}{ Número de cabos } & & 3 \\
\hline$\Phi(\mathrm{mm})$ & Cordoalha & possiveis & $\mathrm{N}$ ca & \\
\hline \multirow[t]{7}{*}{15.2} & 1 & & 25 & \\
\hline & 2 & & 13 & \\
\hline & 4 & & 7 & \\
\hline & 6 & & 5 & \\
\hline & 9 & & 3 & \\
\hline & 12 & & 3 & \\
\hline & 16 & & 2 & \\
\hline
\end{tabular}

Figura 5.16 - Quadro completo do Pré-dimensionamento da viga exemplo. Fonte: Autor.

\subsection{Traçado dos cabos}

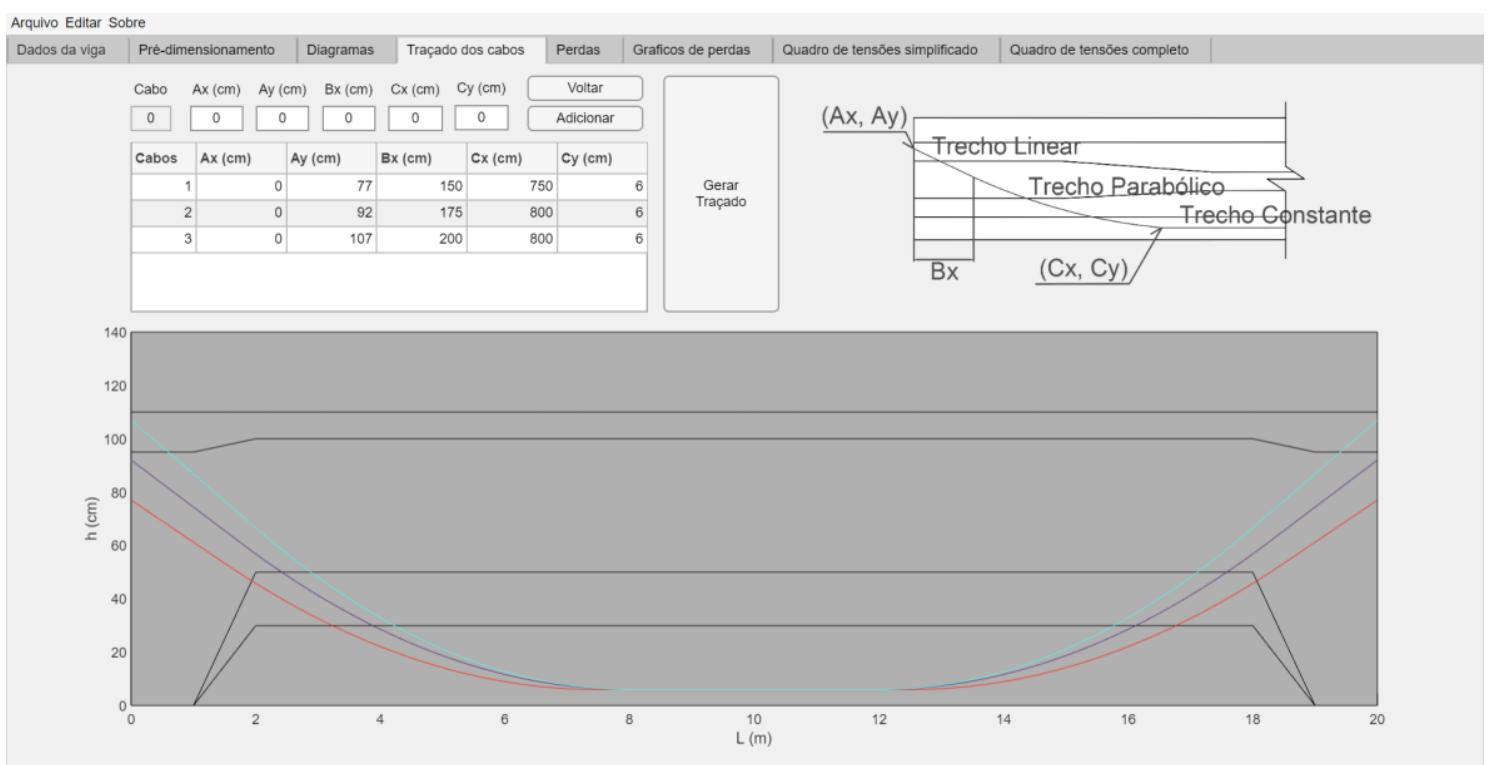

Figura 5.17 - Aba "Traçado dos Cabos" da viga exemplo. Fonte: Autor. 


\section{Pontifícia Universidade Catálica \\ DO RIO DE JANEIRO}

O traçado dos cabos é feito fornecendo as coordenadas dos pontos definidos no item 2.6 .

\begin{tabular}{|r|r|r|r|r|r|}
\hline Cabos & Ax $(\mathrm{cm})$ & Ay $(\mathrm{cm})$ & Bx $(\mathrm{cm})$ & Cx $(\mathrm{cm})$ & Cy $(\mathrm{cm})$ \\
\hline 1 & 0 & 77 & 150 & 750 & 6 \\
\hline 2 & 0 & 92 & 175 & 800 & 6 \\
\hline 3 & 0 & 107 & 200 & 800 & 6 \\
\hline & & & & & \\
\end{tabular}

Figura 5.18 - Quadro de coordenadas dos pontos de contorno do traçado dos cabos. Fonte: Autor.

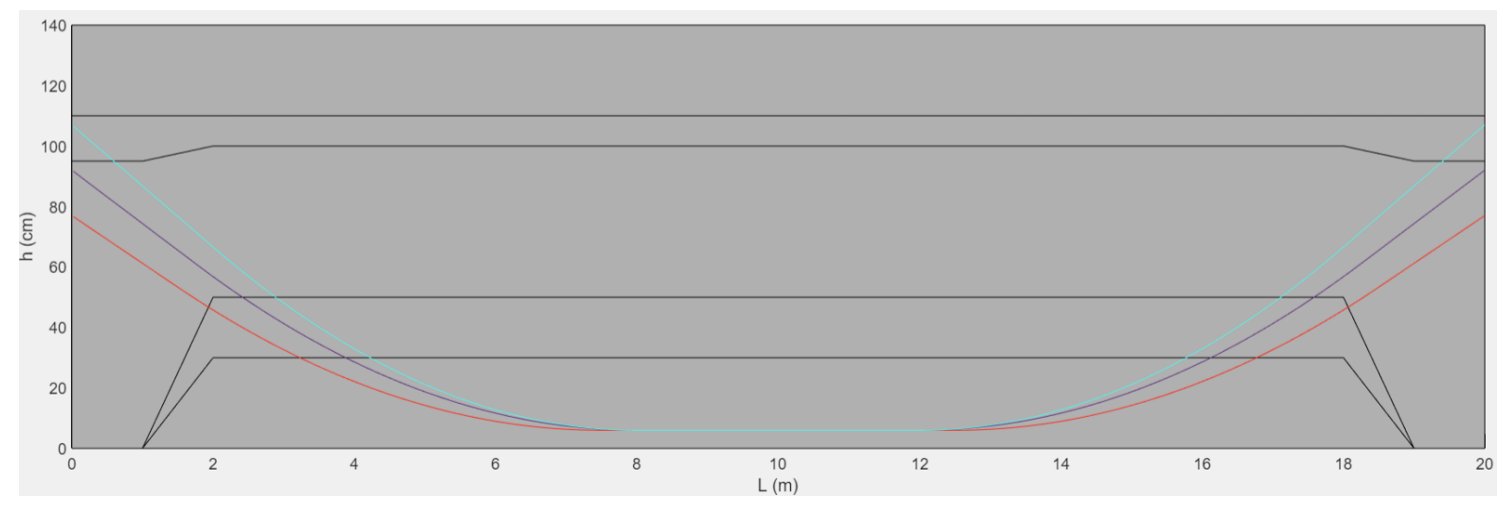

Figura 5.19 - Diagrama do traçado dos cabos da viga exemplo.

Fonte: Autor. 


\section{Pontifícia Universidade Catálica $_{\text {a }}$

\subsection{Perdas}

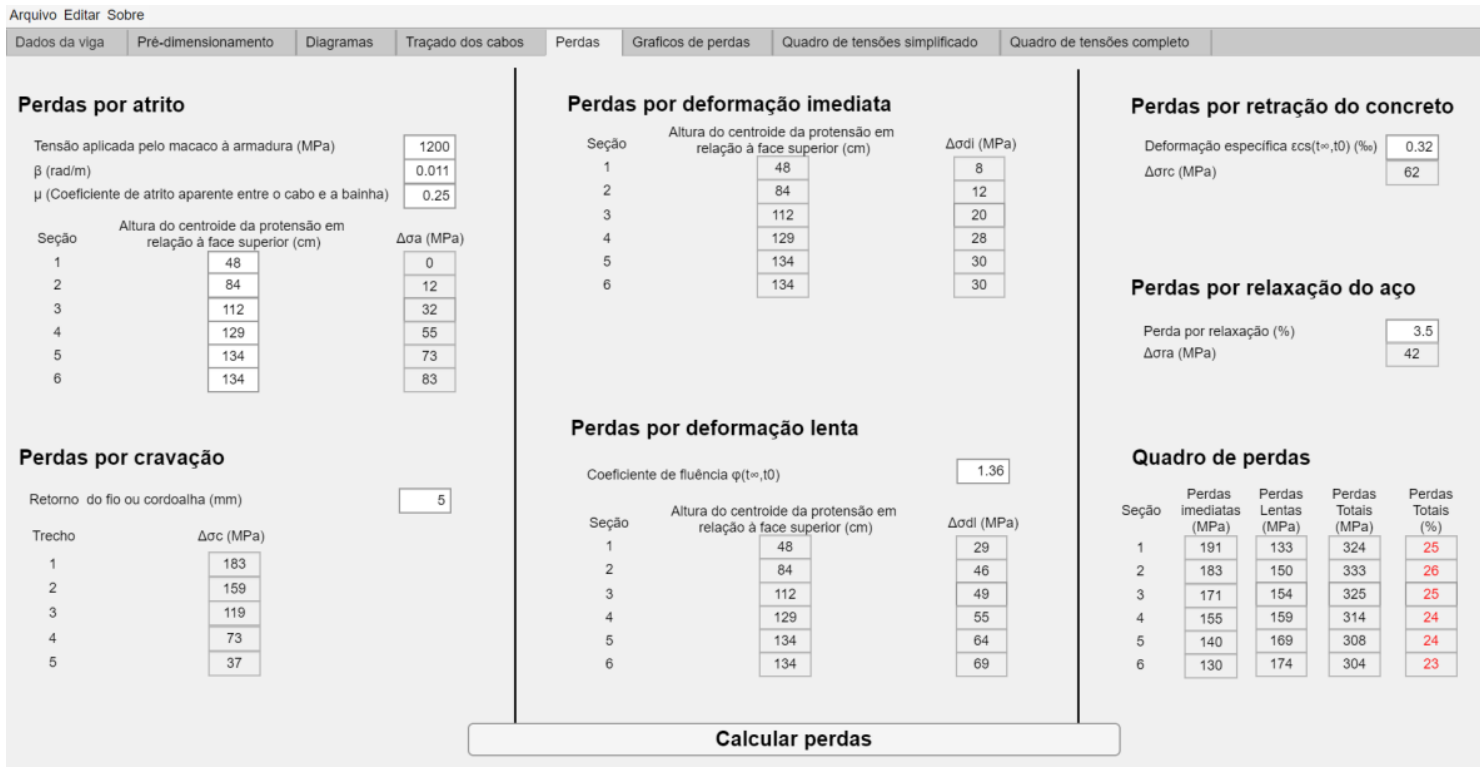

Figura 5.20 - Perdas completas da viga exemplo.

Fonte: Autor.

Os valores da altura do centroide da protensão nas seis seções $(0$ m, 2 m, 4 m, 6 m, 8 $\mathrm{m}, 10 \mathrm{~m}$ ) foram calculados automaticamente durante o traçado dos cabos.

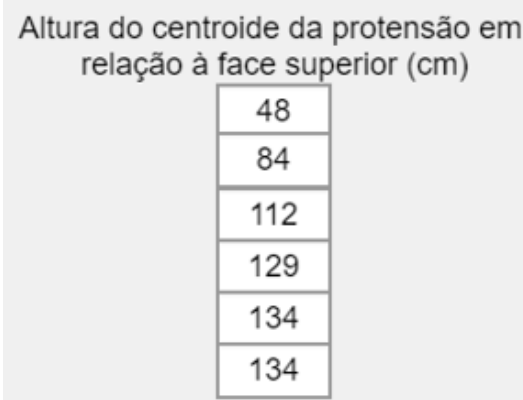

Figura 5.21 - Centroide da protensão calculado automaticamente. Fonte: Autor.

\subsubsection{Perdas por atrito}

Para os valores de entrada do cálculo das perdas por atrito foram considerados os seguintes valores respeitando os limites definidos no item 2.8. 
Tensão aplicada pelo macaco à armadura (MPa)

$\beta(\mathrm{rad} / \mathrm{m})$

\begin{tabular}{|r|}
\hline 1200 \\
\hline 0.011 \\
\hline 0.25 \\
\hline
\end{tabular}

$\mu$ (Coeficiente de atrito aparente entre o cabo e a bainha)

Figura 5.22 - Dados de entrada para o cálculo das perdas por atrito. Fonte: Autor.

\section{Perdas por atrito}
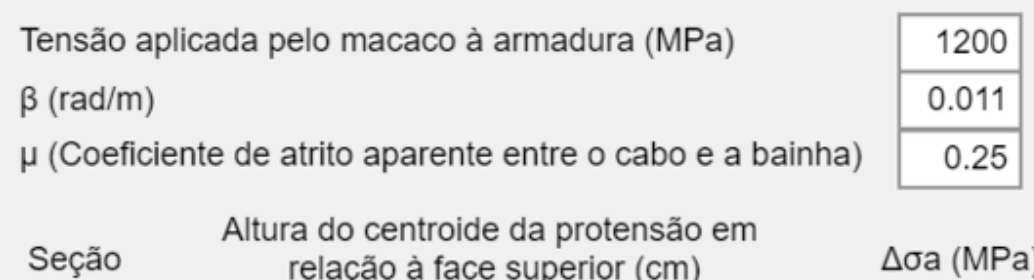

Seção relação à face superior $(\mathrm{cm})$

\begin{tabular}{|c|}
\hline 48 \\
\hline 84 \\
\hline 112 \\
\hline 129 \\
\hline 134 \\
\hline 134 \\
\hline
\end{tabular}

\begin{tabular}{|c|}
\hline 0 \\
\hline 12 \\
\hline 32 \\
\hline 55 \\
\hline 73 \\
\hline 83 \\
\hline
\end{tabular}

Figura 5.23 - Resultado das perdas por atrito. Fonte: Autor.

Tabela 5.2 - Comparação dos resultados obtidos e os calculados manualmente.

\begin{tabular}{|c|c|c|}
\hline Seção & Programa & Calc. Man. \\
\hline 1 & 0 & 0 \\
\hline 2 & 12 & 12 \\
\hline 3 & 32 & 33 \\
\hline 4 & 55 & 55 \\
\hline 5 & 73 & 74 \\
\hline 6 & 83 & 83 \\
\hline
\end{tabular}

Fonte: Autor.

\subsubsection{Perdas por cravação}

Foi definido como sendo $5 \mathrm{~mm}$ o valor de retorno devido ao encunhamento das cordoalhas. 


\section{Pontifícia Universidade Catállica $_{\text {a }}$}

\section{Perdas por cravação}

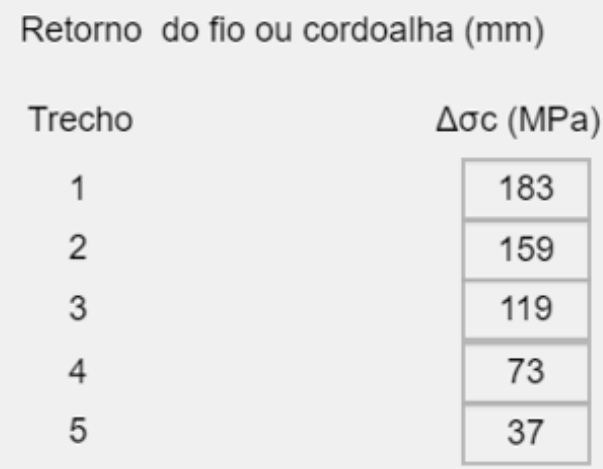

Figura 5.24 - Resultado das perdas por cravação.

Fonte: Autor.

Tabela 5.3 - Comparação dos resultados obtidos e os calculados manualmente.

\begin{tabular}{|c|c|c|}
\hline Trecho & Programa & Calc. Man. \\
\hline 1 & 183 & 184 \\
\hline 2 & 159 & 159 \\
\hline 3 & 119 & 119 \\
\hline 4 & 73 & 73 \\
\hline 5 & 37 & 36 \\
\hline
\end{tabular}

Fonte: Autor.

\subsubsection{Perdas por deformação imediata}

\section{Perdas por deformação imediata}

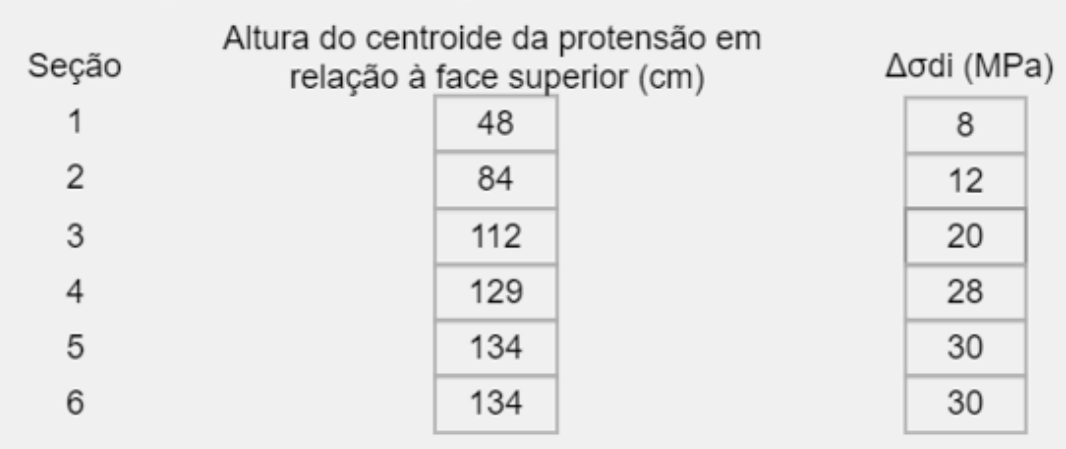

Figura 5.25 - Resultado das perdas por deformação imediata. Fonte: Autor. 
Tabela 5.4 - Comparação dos resultados obtidos e os calculados manualmente.

\begin{tabular}{|c|c|c|}
\hline Seção & Programa & Calc. Man. \\
\hline 1 & 8 & 6 \\
\hline 2 & 12 & 8 \\
\hline 3 & 20 & 12 \\
\hline 4 & 28 & 17 \\
\hline 5 & 30 & 18 \\
\hline 6 & 30 & 18 \\
\hline
\end{tabular}

Fonte: Autor.

\subsubsection{Perdas por deformação lenta}

O coeficiente de fluência foi definido como sendo 1,36 considerando os valores tabelados na norma ABNT NBR 6118 e uma umidade media ambiente de $75 \%$.

Tabela 5.5 - Valores característicos superiores da deformação específica de retração e do coeficiente de fluência.

\begin{tabular}{|c|c|c|c|c|c|c|c|c|c|c|}
\hline \multicolumn{3}{|c|}{$\begin{array}{c}\text { Umidade média } \\
\text { ambiente } \\
\%\end{array}$} & \multicolumn{2}{|c|}{40} & \multicolumn{2}{|c|}{55} & \multicolumn{2}{|c|}{75} & \multicolumn{2}{|c|}{90} \\
\hline \multicolumn{3}{|c|}{$\begin{array}{l}\text { Espessura fictícia } \\
2 A_{\mathrm{c}} / u \\
\mathrm{~cm}\end{array}$} & 20 & 60 & 20 & 60 & 20 & 60 & 20 & 60 \\
\hline \multirow{3}{*}{$\begin{array}{c}\varphi\left(t_{\infty}, t_{0}\right) \\
\text { Concreto } \\
\text { das classes } \\
\text { C20 a C45 }\end{array}$} & \multirow{9}{*}{$\begin{array}{c}t_{0} \\
\text { dias }\end{array}$} & 5 & 4,6 & 3,8 & 3,9 & 3,3 & 2,8 & 2,4 & 2,0 & 1,9 \\
\hline & & 30 & 3,4 & 3,0 & 2,9 & 2,6 & 2,2 & 2,0 & 1,6 & 1,5 \\
\hline & & 60 & 2,9 & 2,7 & 2,5 & 2,3 & 1,9 & 1,8 & 1,4 & 1,4 \\
\hline$\varphi\left(t_{\infty}, t_{0}\right)$ & & 5 & 2,7 & 2,4 & 2,4 & 2,1 & 1,9 & 1,8 & 1,6 & 1,5 \\
\hline $\begin{array}{l}\text { Concreto } \\
\text { das classes }\end{array}$ & & 30 & 2,0 & 1,8 & 1,7 & 1,6 & 1,4 & 1,3 & 1,1 & 1,1 \\
\hline C50 a C90 & & 60 & 1,7 & 1,6 & 1,5 & 1,4 & 1,2 & 1,2 & 1,0 & 1,0 \\
\hline \multirow{3}{*}{$\varepsilon_{\mathrm{cs}}\left(t_{\infty}, t_{0}\right) \% ॰$} & & 5 & $-0,53$ & $-0,47$ & $-0,48$ & $-0,43$ & $-0,36$ & $-0,32$ & $-0,18$ & $-0,15$ \\
\hline & & 30 & $-0,44$ & $-0,45$ & $-0,41$ & $-0,41$ & $-0,33$ & $-0,31$ & $-0,17$ & $-0,15$ \\
\hline & & 60 & $-0,39$ & $-0,43$ & $-0,36$ & $-0,40$ & $-0,30$ & $-0,31$ & $-0,17$ & $-0,15$ \\
\hline
\end{tabular}

Fonte: ABNT NBR 6118/2014. 


\section{Perdas por deformação lenta}

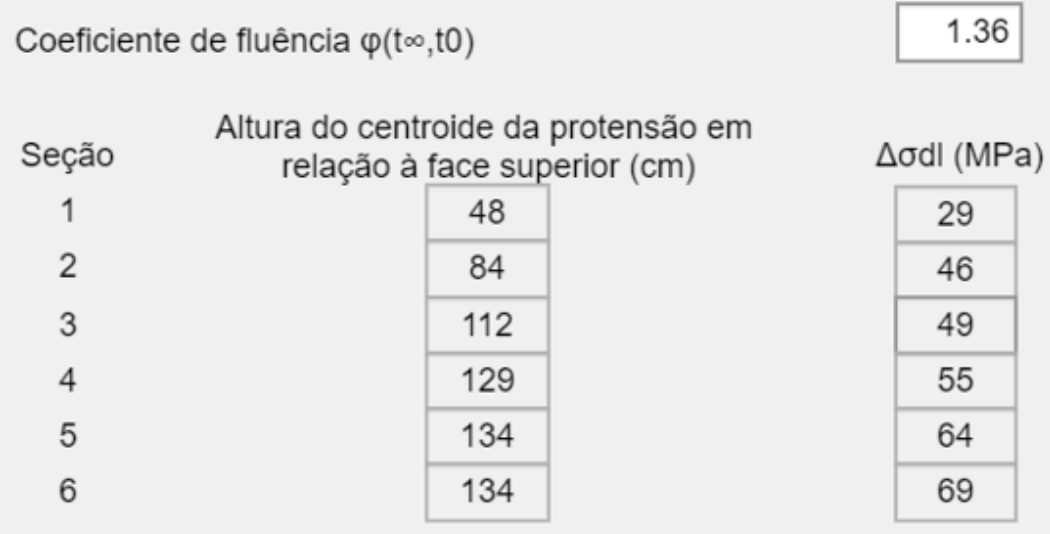

Figura 5.26 - Resultado das perdas por deformação lenta. Fonte: Autor.

Tabela 5.6 - Comparação do resultado obtido e os calculados manualmente.

\begin{tabular}{|c|c|c|}
\hline Seção & Programa & Calc. Man. \\
\hline 1 & 29 & 29 \\
\hline 2 & 46 & 33 \\
\hline 3 & 49 & 50 \\
\hline 4 & 55 & 66 \\
\hline 5 & 64 & 71 \\
\hline 6 & 69 & 70 \\
\hline
\end{tabular}

Fonte: Autor.

\subsubsection{Perdas por retração do concreto}

O valor da deformação especifica necessária para o cálculo das perdas por retração também foi retirado da tabela apresentada no item anterior como sendo igual a $0,32 \%$.

\section{Perdas por retração do concreto}

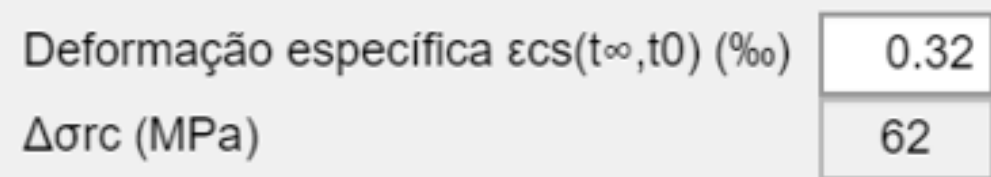

Figura 5.27 - Resultado das perdas por retração do concreto. Fonte: Autor.

Tabela 5.7 - Comparação do resultado obtido e o calculado manualmente.

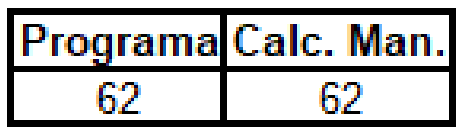

Fonte: Autor. 


\subsubsection{Perdas por relaxação do aço}

O valor da perda máxima por relaxação é fornecido pelo fabricante e neste trabalho foi considerada como tendo o valor de $3,5 \%$

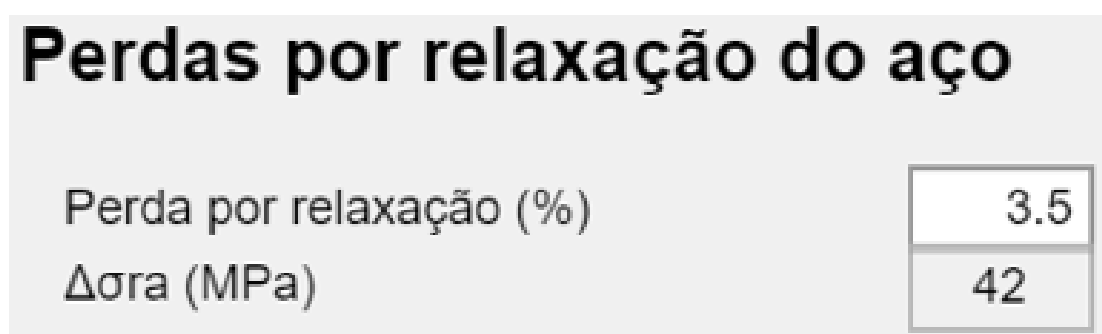

Figura 5.28 - Resultado da perda por relaxação do aço. Fonte: Autor.

Tabela 5.8 - Comparação do resultado obtido e o calculado manualmente.

\begin{tabular}{|c|c|}
\hline Programa & Calc. Man. \\
\hline 42 & 42 \\
\hline
\end{tabular}

Fonte: Autor.

\subsubsection{Quadro de perdas}

Após a obtenção dos valores de cada uma das perdas é possível gerar um quadro de perdas. Nesta região do programa foi escolhido mostrar o valor do somatório das perdas imediatas, o somatório das perdas lentas, o somatório das perdas no total em valor de tensão (MPa) e de porcentagem (\%).

\begin{tabular}{|c|c|c|c|c|}
\hline Seção & $\begin{array}{l}\text { Perdas } \\
\text { imediatas } \\
\text { (MPa) }\end{array}$ & $\begin{array}{l}\text { Perdas } \\
\text { Lentas } \\
(\mathrm{MPa})\end{array}$ & $\begin{array}{l}\text { Perdas } \\
\text { Totais } \\
\text { (MPa) }\end{array}$ & $\begin{array}{c}\text { Perdas } \\
\text { Totais } \\
(\%)\end{array}$ \\
\hline 1 & 191 & 133 & 324 & 25 \\
\hline 2 & 183 & 150 & 333 & 26 \\
\hline 3 & 171 & 154 & 325 & 25 \\
\hline 4 & 155 & 159 & 314 & 24 \\
\hline 5 & 140 & 169 & 308 & 24 \\
\hline 6 & 130 & 174 & 304 & 23 \\
\hline
\end{tabular}

Figura 5.29 - Quadro de perdas da viga exemplo. Fonte: Autor. 


\section{Pontifícia Universidade Católica $_{\text {a }}$

\subsubsection{Gráficos de perdas}

Gráfico 5.1 - Perdas imediatas da viga exemplo.

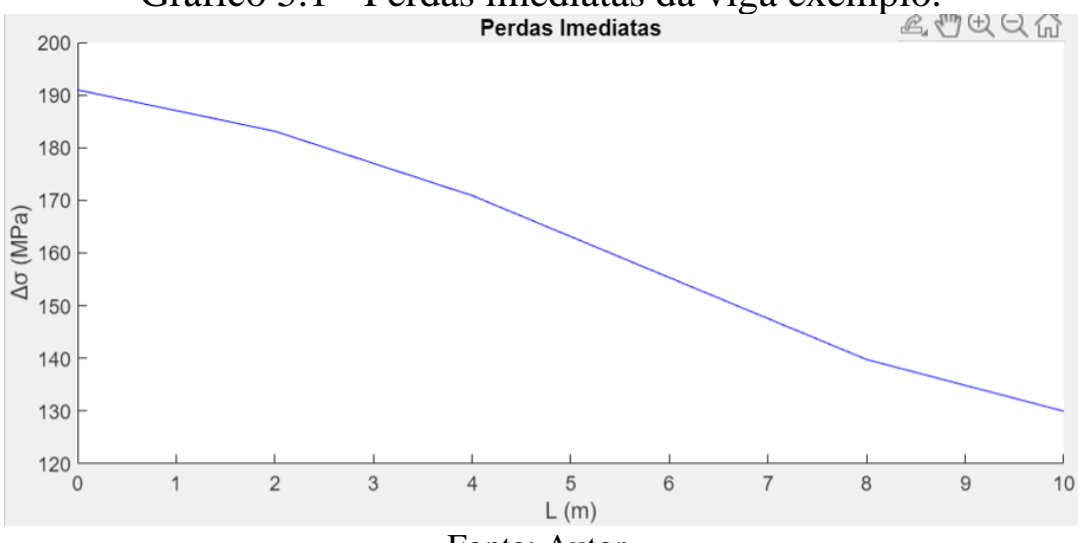

Fonte: Autor.

Gráfico 5.2 - Perdas lentas da viga exemplo.

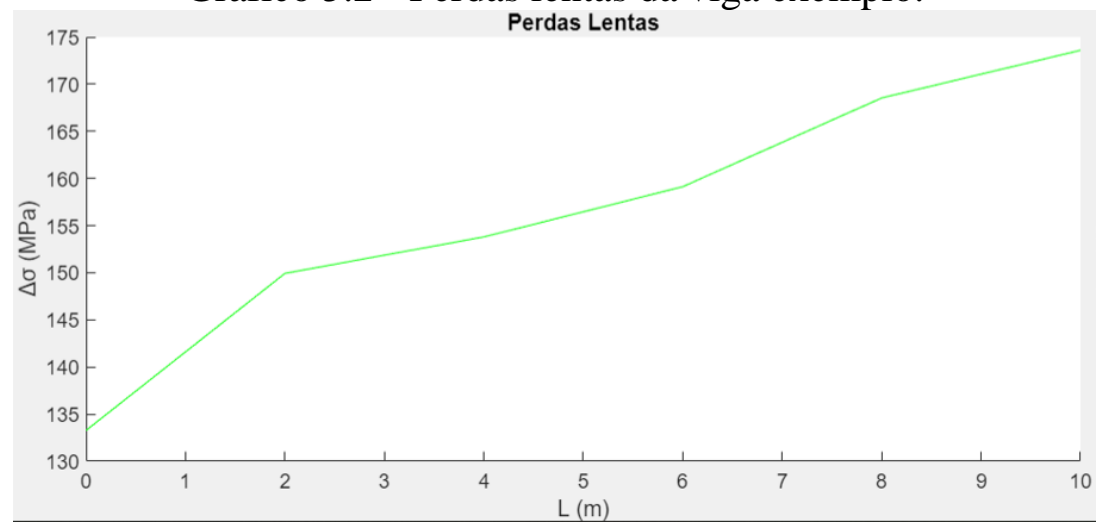

Fonte: Autor.

Gráfico 5.3 - Comparação entre perdas por atrito e por cravação da viga exemplo.

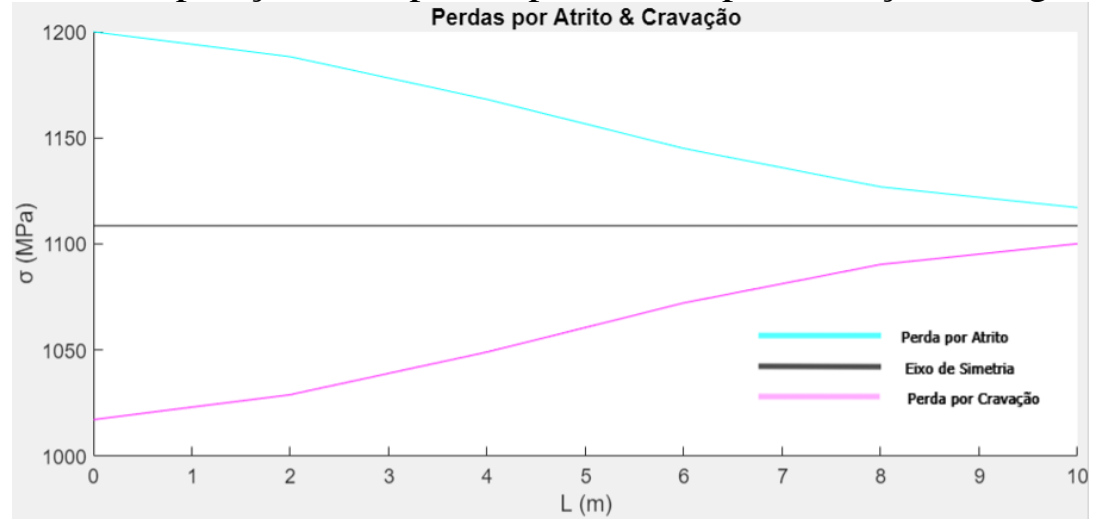

Fonte: Autor. 


\section{Pontifícia Universidade Catálica

Gráfico 5.4 - Perdas totais da viga exemplo.

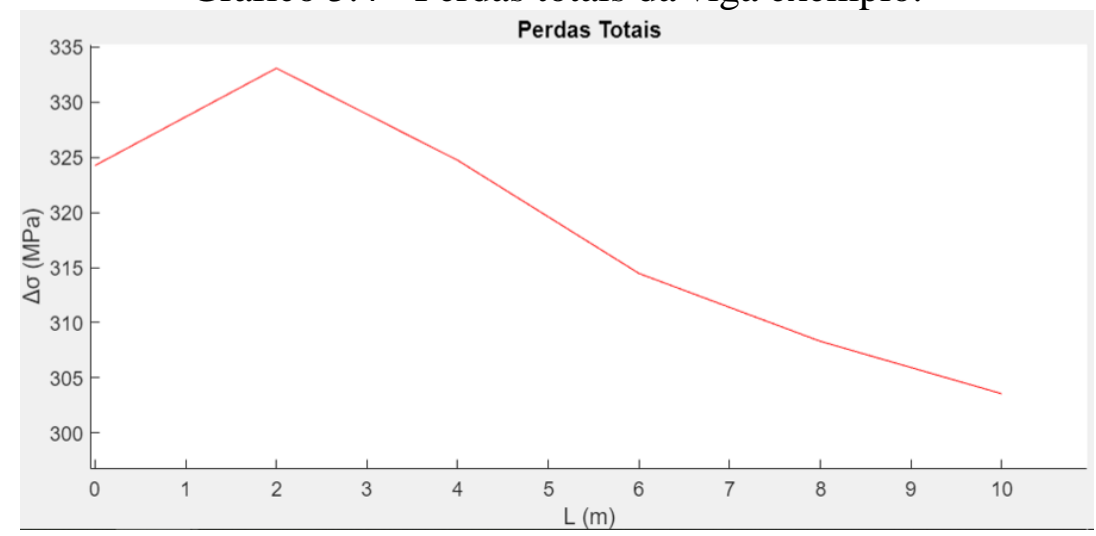

Fonte: Autor.

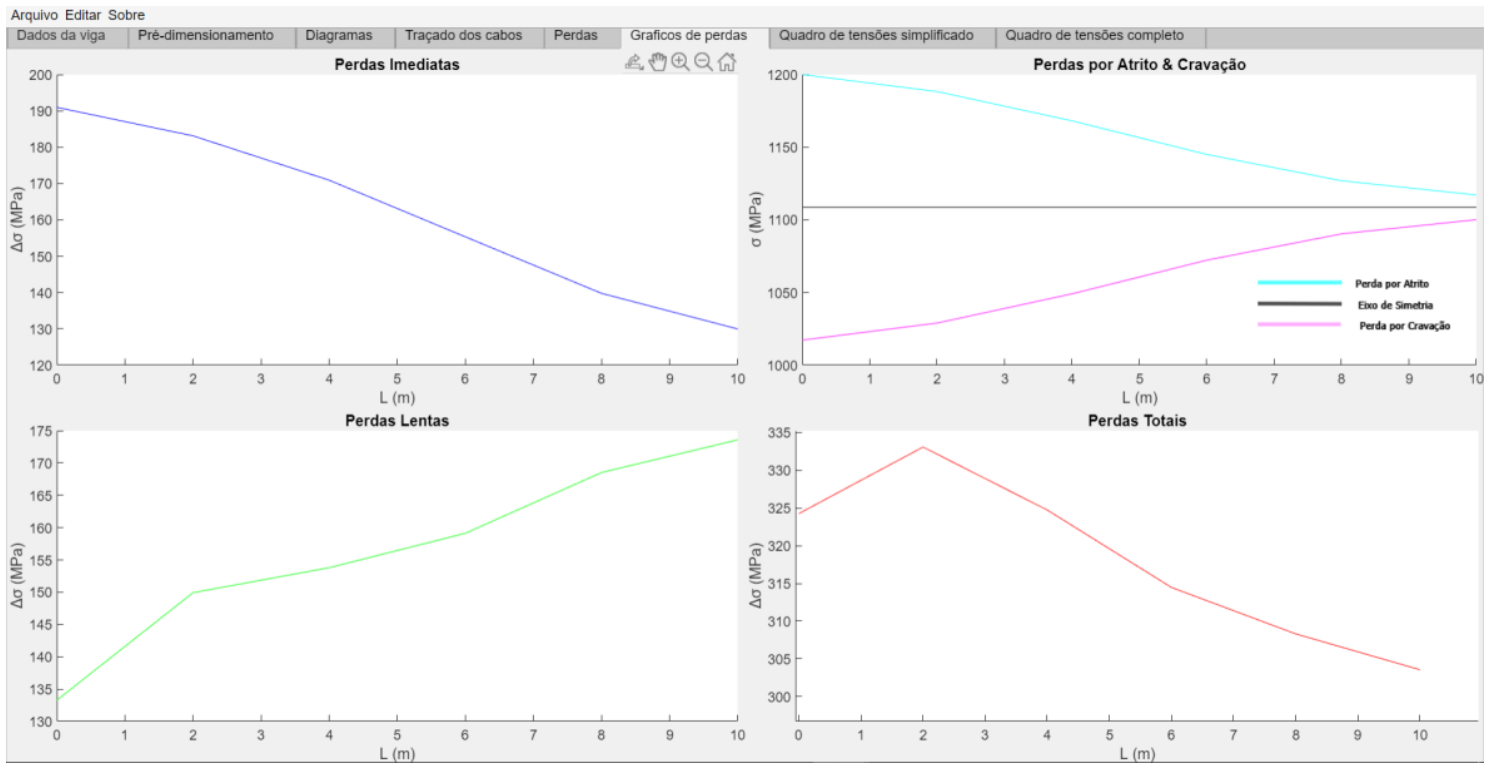

Figura 5.30 - Aba de gráficos de perdas completo.

Fonte: Autor.

\subsection{Quadro de tensões finais}

Tendo sido realizado o cálculo das perdas é possível executar o cálculo das tensões finais ao fim da Fase 1 e 2 de carregamentos. Estas tensões finais são apresentadas de duas formas ao fim do aplicativo, uma completa e uma simplificada. 


\section{Pontifícia Universidade Catállica $_{\text {a }}$

\subsubsection{Quadro Completo}

\begin{tabular}{|c|c|c|c|c|c|c|c|}
\hline Seçào & Peso Próprio (MPa) & Protensāo Pós Perdas Imed. (MPa) & Tensōes Finais Fase 1 (MPa) & Carga Permanente (MPa) & Carga Acidental (MPa) & Perdas Lenta (MPa) & Tensōes Finais Fase 2 (MPa) \\
\hline 1 Sup & -0.00 & -6.15 & -6.15 & -0.00 & -0.00 & 0.81 & -5.34 \\
\hline $1 \operatorname{lnt}$ & 0.00 & -2.15 & -2.15 & 0.00 & 0.00 & 0.28 & -1.86 \\
\hline 2 Sup & -1.63 & -1.77 & -3.39 & -0.89 & -3.02 & 0.26 & -7.04 \\
\hline $2 \ln t$ & 2.35 & -11.77 & -9.42 & 1.28 & 4.36 & 1.73 & -2.05 \\
\hline 3 Sup & -2.89 & 2.71 & -0.18 & -1.58 & -5.37 & -0.41 & -7.53 \\
\hline $3 \operatorname{lnf}$ & 4.17 & -18.39 & -14.22 & 2.27 & 7.74 & 2.75 & -1.46 \\
\hline 4 Sup & -3.80 & 5.44 & 1.64 & -2.07 & -7.05 & -0.83 & -8.30 \\
\hline $4 \operatorname{lnf}$ & 5.47 & -22.54 & -17.07 & 2.98 & 10.16 & 3.43 & -0.49 \\
\hline 5 Sup & -4.34 & 6.35 & 2.01 & -2.36 & -8.05 & -1.01 & -9.42 \\
\hline $5 \operatorname{lnf}$ & 6.26 & -24.08 & -17.82 & 3.41 & 11.61 & 3.83 & 1.03 \\
\hline 6 Sup & -4.52 & 6.41 & 1.89 & -2.46 & -8.39 & -1.04 & -10.00 \\
\hline $6 \operatorname{lnf}$ & 6.52 & -24.30 & -17.78 & 3.55 & 12.10 & 3.94 & 1.81 \\
\hline
\end{tabular}

Figura 5.31 - Quadro de tensões finais completo da viga exemplo.

Fonte: Autor.

\subsubsection{Quadro Simplificado}

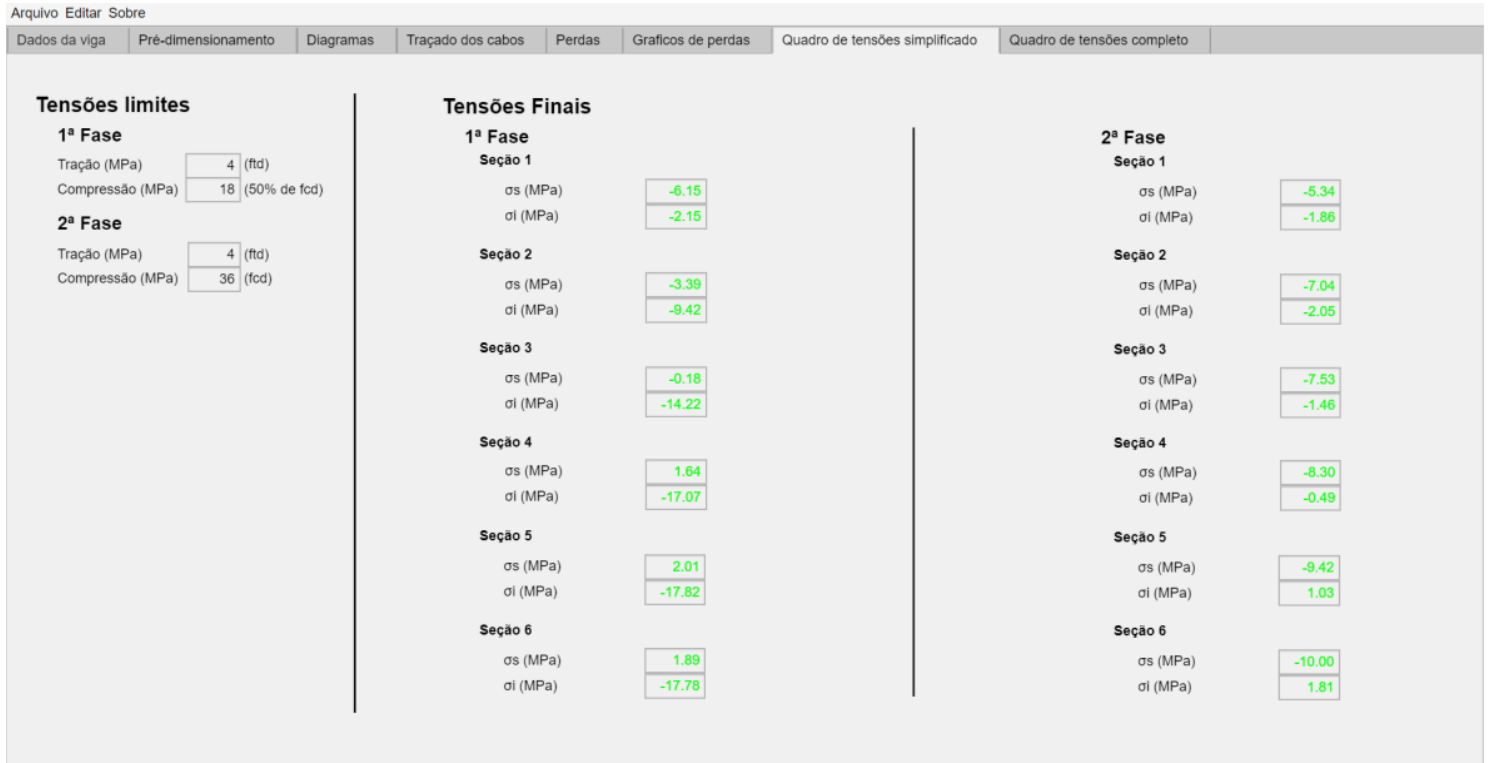

Figura 5.32 - Quadro de tensões simplificado completo da viga exemplo. Fonte: Autor.

No quadro simplificado, além das tensões finais, também é mostrado os valores das tensões limites. 


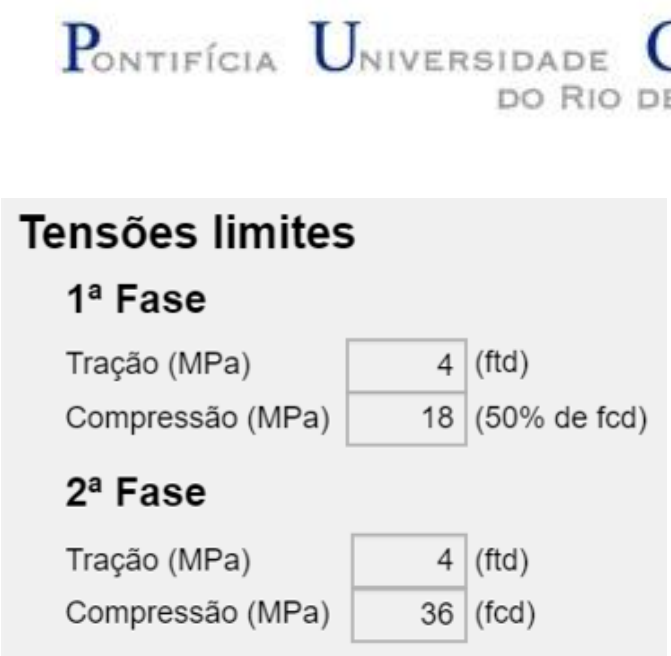

Figura 5.33 - Tensões limite da viga exemplo. Fonte: Autor.

A coloração verde nos valores de tensões finais demonstra que os resultados se encontram dentro dos limites definidos pela resistência do concreto.

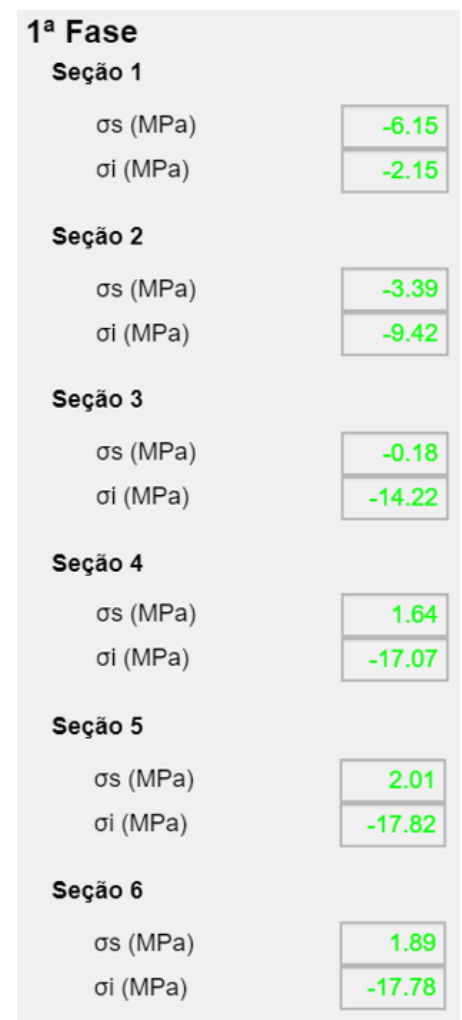

Figura 5.34 - Tensões finais na Fase 1. Fonte: Autor. 


\section{Pontifícia Universidade Catálica

Tabela 5.9 - Comparação dos resultados obtidos e os calculados manualmente.

\begin{tabular}{|c|c|c|}
\hline Seção & Programa & Calc. Man. \\
\hline \multirow{2}{*}{1} & $-6,15$ & $-4,3$ \\
\cline { 2 - 3 } & $-2,15$ & $-1,5$ \\
\hline \multirow{2}{*}{2} & $-3,39$ & $-2,8$ \\
\cline { 2 - 3 } & $-9,42$ & $-5,9$ \\
\hline \multirow{2}{*}{3} & $-0,18$ & $-1,0$ \\
\cline { 2 - 3 } & $-14,22$ & $-8,7$ \\
\hline \multirow{2}{*}{4} & 1,64 & 0,0 \\
\cline { 2 - 3 } & $-17,07$ & $-10,3$ \\
\hline \multirow{2}{*}{5} & 2,01 & 0,1 \\
\cline { 2 - 3 } & $-17,82$ & $-10,6$ \\
\hline \multirow{2}{*}{6} & 1,89 & 0,0 \\
\cline { 2 - 3 } & $-17,78$ & $-10,5$ \\
\hline
\end{tabular}

Fonte: Autor.

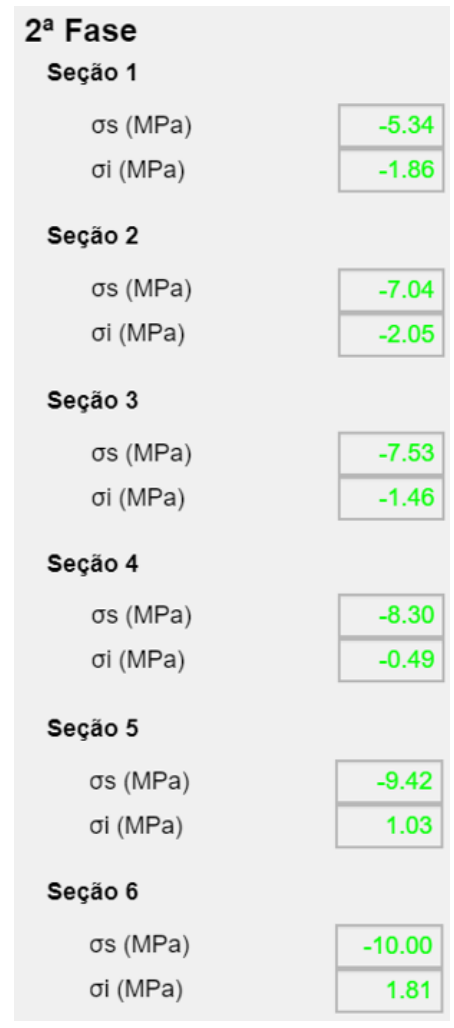

Figura 5.35 - Tensões finais na Fase 2.

Fonte: Autor. 


\section{Pontifícia Universidade Catálica DO RIO DE JANEIRO}

Tabela 5.10 - Comparação dos resultados obtidos e os calculados manualmente.

\begin{tabular}{|c|c|c|}
\hline Seção & Programa & Calc. Man. \\
\hline \multirow{2}{*}{1} & $-5,34$ & $-3,8$ \\
\cline { 2 - 3 } & $-1,86$ & $-1,3$ \\
\hline \multirow{2}{*}{2} & $-7,04$ & $-5,9$ \\
\cline { 2 - 3 } & $-2,05$ & 0,0 \\
\hline \multirow{2}{*}{3} & $-7,53$ & $-7,2$ \\
\cline { 2 - 3 } & $-1,46$ & 1,8 \\
\hline \multirow{2}{*}{4} & $-8,30$ & $-8,3$ \\
\cline { 2 - 3 } & $-0,49$ & 3,4 \\
\hline \multirow{2}{*}{5} & $-9,42$ & $-9,4$ \\
\cline { 2 - 3 } & 1,03 & 4,9 \\
\hline \multirow{2}{*}{6} & $-10,00$ & $-9,9$ \\
\cline { 2 - 3 } & 1,81 & 5,5 \\
\hline
\end{tabular}

Fonte: Autor. 


\section{CONCLUSÕES}

Este trabalho teve como objetivo o desenvolvimento de um software de cálculo estrutural capaz de ser usado para o dimensionamento de uma viga bi-apoiada de concreto protendido. Para se chegar a este objetivo foi utilizado o programa MATLAB App Designer devido a sua capacidade de desenvolver uma interface gráfica de fácil interação, o fato de ser um programa voltado para a programação de cálculos matemáticos e permitir a distribuição e instalação do software desenvolvido o utilizando sem a necessidade de instalação do MATLAB.

Utilizando o aplicativo desenvolvido é possível realizar todas as etapas para o cálculo e dimensionamento de uma viga de concreto protendido, fornecendo ao usuário gráficos que podem ser salvos de forma independente e também a habilidade de realizar um lançamento simplificado dos cabos de protensão. É importante ressaltar que apesar de o programa apresentar valores confiáveis, ainda é possível o seu aprimoramento tanto em sua interface quanto em a sua expansão para permitir o cálculo de diferentes tipos de viga, sendo o programa atualmente limitado a vigas bi-apoiadas isostáticas.

Assim acredita-se que os objetivos deste projeto foram atingidos, não só em questão do desenvolvimento do programa, mas também no estimulo ao aprendizado sobre a técnica de construção do concreto protendido. 


\section{REFERÊNCIAS BIBLIOGRÁFICAS}

1. ANJOS, Aline de Jesus dos. Uma introdução ao concreto protendido. 2015. xx f. Projeto de graduação (Bacharelado em Engenharia civil) - Faculdade de Engenharia, Universidade do Estado do Rio de Janeiro, Rio de Janeiro, 2015.

2. RODRIGUES, Glauco. CONCRETO PROTENDIDO - NOTAS DE AULA. 2013.

3. DUARTE, Evandro. Projeto e cálculo de uma viga isostatica de concreto protendido. 1995.

4. VIEIRA, Leonar Pires Ribeiro. Planilha para cálculo de pontes em vigas contínuas de concreto armado - Dimensionamento geométrico e esforços devidos ao carregamento permanente. 2019. 76f. Projeto de Graduação (Graduação em Engenharia Civil) - Faculdade de Engenharia, Universidade do Estado do Rio de Janeiro, Rio de Janeiro, 2019.

5. XIMENES, Andressa. Desenvolvimento de uma planilha auxiliar no calculo de pontes em viga isostaticas protendidas - Geometria, Esforços solicitantes e Propriedades mecânicas. -2019. 99f. Projeto de Graduação (Graduação em Engenharia Civil) - Faculdade de Engenharia, Universidade do Estado do Rio de Janeiro, Rio de Janeiro, 2019.

6. REZENDE, Rokilane. Desenvolvimento de uma planilha auxiliar no cálculo de pontes em vigas isostáticas protendidas: parametrização das propriedades mecânicas das seções e automação no cálculo das envoltórias dos esforços cortantes. - Faculdade de Engenharia, Universidade do Estado do Rio de Janeiro, RJ, Brasil, 2020.

7. Holtz, Gisele Cristina da Cunha; Martha, Luiz Fernando C. R. (Orientador); Vaz, Luiz Eloy (Co-orientador). Traçado automático de envoltórias de esforços em estruturas planas utilizando um algoritmo evolucionário. Rio de Janeiro, 2005. 123p. Dissertação de Mestrado - Departamento de Engenharia Civil, Pontifícia Universidade Católica do Rio de Janeiro.

8. ASSOCIAÇÃO BRASILEIRA DE NORMAS TÉCNICAS. NBR 6118/2014: Projeto de estruturas de concreto - Procedimento. Rio de Janeiro, 2014.

9. ASSOCIAÇÃO BRASILEIRA DE NORMAS TÉCNICAS. NBR 7188/2013: Carga móvel rodoviária e de pedestres em pontes, viadutos, passarelas e outras estruturas. Rio de Janeiro, 2013. 


\section{Anexo A}

Dados da seção na região de apoio:

$$
\begin{aligned}
& A_{t, \text { apoio }}=\sum A_{n}=(30 * 100)+2 *\left(\frac{\left.15 * \frac{(100-50)}{2}\right)+(95 * 50)}{2}=3000+375+5500=8875,0 \mathrm{~cm}^{2}=0,89 \mathrm{~m}^{2}\right. \\
& y_{i}=\frac{(3000 * 125)+(375 * 105)+(5500 * 55)}{8875}=80,8 \mathrm{~cm}=0,81 \mathrm{~m} \\
& y_{S}=(30+15+95)-80,8=59,2 \mathrm{~cm}=0,59 \mathrm{~m} \\
& I=15517070 \mathrm{~cm}^{4}=0,1552 \mathrm{~m}^{4} \\
& W_{i}=\frac{I}{y_{i}}=\frac{0,1552}{0,81}=0,192 \mathrm{~m}^{3} \\
& W_{s}=\frac{I}{y_{s}}=\frac{0,1552}{0,59}=0,262 \mathrm{~m}^{3}
\end{aligned}
$$

Dados da seção na região intermediaria:

$$
\begin{aligned}
& A_{t, \text { inter }}=\sum A_{n}=3000+400+1600+300+1500=6800,0 \mathrm{~cm}^{2}=0,68 \mathrm{~m}^{2} \\
& y_{i}=\frac{(3000 * 125)+(400 * 107)+(1600 * 70)+(300 * 37)+(1500 * 15)}{6800} \\
& =82,8 \mathrm{~cm}=0,83 \mathrm{~m} \\
& y_{s}=(30+10+50+20+30)-82,8=57,2 \mathrm{~cm}=0,57 \mathrm{~m} \\
& I=14579310 \mathrm{~cm}^{4}=0,1458 \mathrm{~m}^{4} \\
& W_{i}=\frac{I}{y_{i}}=\frac{0,1458}{0,83}=0,176 \mathrm{~m}^{3}
\end{aligned}
$$




\section{Pontifícia Universidade Católlica}

$W_{s}=\frac{I}{y_{s}}=\frac{0,1458}{0,57}=0,255 \mathrm{~m}^{3}$

Carregamentos

$$
\begin{aligned}
& C_{p p}=\frac{(0,89 * 3)+(0,68 * 17)}{(0,89+0,68)} * 25 * 1,4=23,1 \mathrm{kN} / \mathrm{m} \\
& C_{g}=9 * 1,4=12,6 \mathrm{kN} / \mathrm{m} \\
& C_{q}=5 * 1,4=7 \mathrm{kN} / \mathrm{m} \\
& C_{\text {móvel }}=(5 * 3 * 1,4) * C I A * C I V * C N F=(5 * 3 * 1,4) * 1,25 * 1,15 * 0,9 \\
& =27,2 \mathrm{kN} / \mathrm{m}
\end{aligned}
$$

$\sigma_{i, m a ́ x}=\sigma_{i, p p}+\sigma_{i, g}+\sigma_{i, q}+\sigma_{i, m o ́ v e l}=6,53+3,58+1,97+10,12=22,17 M P a$

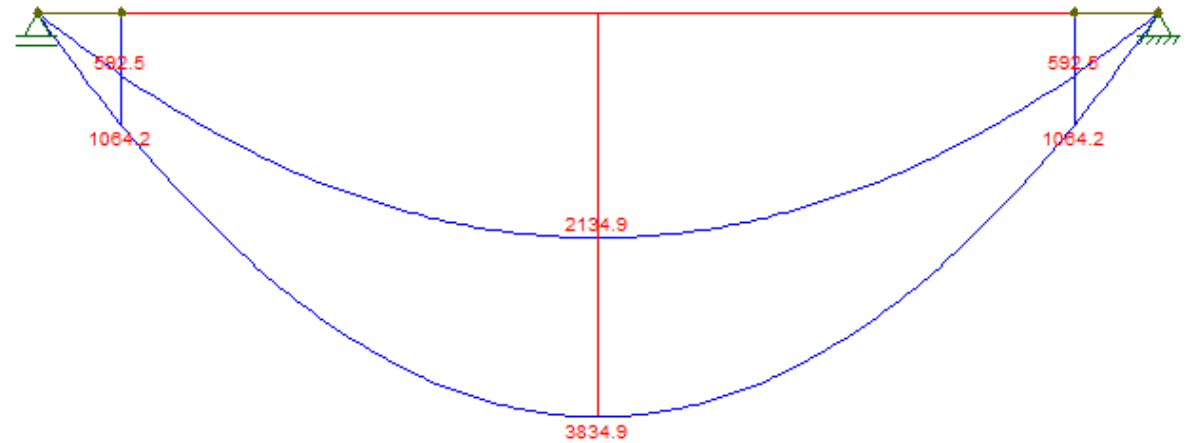

Fonte: FTool.

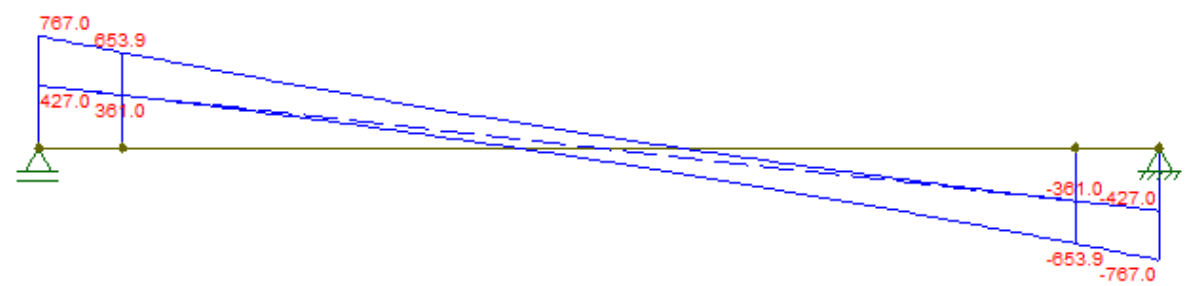

Fonte: FTool.

Pré-dimensionamento

$e=6 \mathrm{~cm}$ 


\section{Pontifícia Universidade Católlac

$F_{p}=\frac{\sigma_{i, m a ́ x}}{\frac{1}{A_{t}}+\frac{e}{W_{i}}} * \gamma_{f}=\frac{22,17}{\frac{1}{0,68}+\frac{6}{0,176}} * 1,2=4559,92 \mathrm{kN}$

$n_{\text {cordoalhas }}=\frac{4559,92}{\frac{219,7}{1,15}}=24$

$n_{\text {cordoalha } / \text { cabo }}=9$

$n_{\text {cabos }}=\frac{24}{9}=2,7 \cong 3$

Perdas

$\sigma_{0}=1200 \mathrm{MPa}$

$\beta=0,011 \mathrm{rad} / \mathrm{m}$

$\mu=0,25$

$\delta_{\text {cordoalha }}=5 \mathrm{~mm}$

$\varphi_{\left(t_{\infty}, t_{0}\right)}=1,36$

$\varepsilon_{c s}\left(t_{\infty}, t_{0}\right)=0,0032 \%$

$P_{\text {relaxação }}=3,5 \%$

Centroides:

$S 1=48 \mathrm{~cm}$

$S 2=84 \mathrm{~cm}$

$S 3=112 \mathrm{~cm}$

$S 4=129 \mathrm{~cm}$

$S 5=134 \mathrm{~cm}$

$S 6=134 \mathrm{~cm}$

- Perdas por atrito 
$S 1=0 M P a$

$S 2=12 M P a$

$S 3=33 M P a$

$S 4=55 \mathrm{MPa}$

$S 5=74 \mathrm{MPa}$

$S 6=83 \mathrm{MPa}$

- Perdas por cravação

$T 1=184 M P a$

$T 2=159 \mathrm{MPa}$

$T 3=119 \mathrm{MPa}$

$T 4=73 \mathrm{MPa}$

$T 5=36 \mathrm{MPa}$

- Perdas por deformação imediata

$$
\begin{aligned}
& S 1=6 \mathrm{MPa} \\
& S 2=8 \mathrm{MPa} \\
& S 3=12 \mathrm{MPa} \\
& S 4=17 \mathrm{MPa} \\
& S 5=18 \mathrm{MPa} \\
& S 6=18 \mathrm{MPa}
\end{aligned}
$$

- Perdas por deformação lenta

$$
\begin{aligned}
& S 1=29 \mathrm{MPa} \\
& S 2=33 \mathrm{MPa}
\end{aligned}
$$


$S 3=50 \mathrm{MPa}$

$S 4=66 \mathrm{MPa}$

$S 5=71 \mathrm{MPa}$

$S 6=70 \mathrm{MPa}$

- Perdas por retração

$\Delta \sigma=0,00032 * 195000=62 \mathrm{MPa}$

- Perdas por relaxação do aço

$\Delta \sigma=1200 * 0,035=42 \mathrm{MPa}$

- Perdas imediatas totais

$S 1=190 \mathrm{MPa}$

$S 2=179 \mathrm{MPa}$

$S 3=164 M P a$

$S 4=145 \mathrm{MPa}$

$S 5=128 \mathrm{MPa}$

$S 6=118 \mathrm{MPa}$

- Perdas lentas totais

$$
\begin{aligned}
& S 1=134 \mathrm{MPa} \\
& S 2=137 \mathrm{MPa} \\
& S 3=154 \mathrm{MPa} \\
& S 4=171 \mathrm{MPa} \\
& S 5=175 \mathrm{MPa}
\end{aligned}
$$


$S 6=175 \mathrm{MPa}$

Tensões finais

- $\quad$ Fase 1

$$
\begin{aligned}
& \sigma_{i}(1)=0-\left(\frac{2,733}{0,89}+\frac{2,733 *-0,09 * 0,81}{0,1552}\right)=-1,5 \mathrm{MPa} \\
& \sigma_{s}(1)=0+\left(-\frac{2,733}{0,89}+\frac{2,733 *-0,09 * 0,59}{0,1552}\right)=-4,3 \mathrm{MPa} \\
& \sigma_{i}(2)=2,4-\left(\frac{2,761}{0,68}+\frac{2,761 * 0,27 * 0,83}{0,1458}\right)=-5,9 \mathrm{MPa} \\
& \sigma_{s}(2)=-1,6+\left(-\frac{2,761}{0,68}+\frac{2,761 * 0,27 * 0,57}{0,1458}\right)=-2,8 \mathrm{MPa} \\
& \sigma_{i}(3)=4,2-\left(\frac{2,804}{0,68}+\frac{2,804 * 0,55 * 0,83}{0,1458}\right)=-8,7 \mathrm{MPa} \\
& \sigma_{s}(3)=-2,9+\left(-\frac{2,804}{0,68}+\frac{2,804 * 0,55 * 0,57}{0,1458}\right)=-1,0 \mathrm{MPa}
\end{aligned}
$$

$$
\begin{aligned}
& \sigma_{i}(4)=5,5-\left(\frac{2,854}{0,68}+\frac{2,854 * 0,72 * 0,83}{0,1458}\right)=0,0 \mathrm{MPa} \\
& \sigma_{S}(4)=-3,8+\left(-\frac{2,854}{0,68}+\frac{2,854 * 0,72 * 0,57}{0,1458}\right)=-10,3 \mathrm{MPa}
\end{aligned}
$$

$$
\sigma_{i}(5)=6,3-\left(\frac{2,900}{0,68}+\frac{2,900 * 0,77 * 0,83}{0,1458}\right)=0,1 \mathrm{MPa}
$$$$
\sigma_{s}(5)=-4,3+\left(-\frac{2,900}{0,68}+\frac{2,900 * 0,77 * 0,57}{0,1458}\right)=-10,6 \mathrm{MPa}
$$

$$
\begin{aligned}
& \sigma_{i}(6)=6,6-\left(\frac{2,927}{0,68}+\frac{2,927 * 0,77 * 0,83}{0,1458}\right)=0,0 M P a \\
& \sigma_{S}(6)=-4,5+\left(-\frac{2,927}{0,68}+\frac{2,927 * 0,77 * 0,57}{0,1458}\right)=-10,5 \mathrm{MPa}
\end{aligned}
$$


- $\quad$ Fase 2

$$
\begin{aligned}
& \sigma_{i}(1)=0-\left(\frac{2,372}{0,89}+\frac{2,372 *-0,09 * 0,81}{0,1552}\right)=-1,3 \mathrm{MPa} \\
& \sigma_{s}(1)=0+\left(-\frac{2,372}{0,89}+\frac{2,372 *-0,09 * 0,59}{0,1552}\right)=-3,8 \mathrm{MPa} \\
& \sigma_{i}(2)=3,7-\left(\frac{2,390}{0,68}+\frac{2,390 * 0,27 * 0,83}{0,1458}\right)=0,0 \mathrm{MPa} \\
& \sigma_{s}(2)=-2,5+\left(-\frac{2,390}{0,68}+\frac{2,390 * 0,27 * 0,57}{0,1458}\right)=-5,9 \mathrm{MPa} \\
& \sigma_{i}(3)=6,5-\left(\frac{2,387}{0,68}+\frac{2,387 * 0,55 * 0,83}{0,1458}\right)=1,8 \mathrm{MPa} \\
& \sigma_{s}(3)=-4,5+\left(-\frac{2,387}{0,68}+\frac{2,387 * 0,55 * 0,57}{0,1458}\right)=-7,2 \mathrm{MPa} \\
& \sigma_{s}(6)=-7+\left(-\frac{2,454}{0,68}+\frac{2,454 * 0,77 * 0,57}{0,1458}\right)=-9,9 \mathrm{MPa} \\
& \sigma_{i}(6)=10,1-\left(\frac{2,454}{0,68}+\frac{2,454 * 0,77 * 0,83}{0,1458}\right)=5,5 \mathrm{MPa} \\
& \sigma_{s}(4)=-5,9+\left(-\frac{2,392}{0,68}+\frac{2,392 * 0,72 * 0,57}{0,1458}\right)=-8,3 \mathrm{MPa} \\
& \sigma_{i}(4)=8,5-\left(\frac{2,392}{0,68}+\frac{2,392 * 0,72 * 0,83}{0,1458}\right)=3,4 \mathrm{MPa}
\end{aligned}
$$

